\title{
SOBRE EL GÉNERO CHRYSOPA LEACH, 1815 DE LA PENÍNSULA IBÉRICA Y BALEARES (INSECTA, NEUROPTERA: CHRYSOPIDAE)
}

\author{
V. J. Monserrat ${ }^{1, *}$ \& R. A. Pantaleoni ${ }^{2}$ \\ ${ }^{1}$ Departamento de Biodiversidad, Ecología y Evolución, Unidad Docente de Zoología, \\ Facultad de Biología, José Antonio Novais, 12, Universidad Complutense, 28040 Madrid (España). \\ Email: artmad@bio.ucm.es - ORCID iD: https://orcid.org/0000-0003-2586-0077 \\ 2 Dipartimento di Agraria, sezione di Entomologia, Università degli Studi, via Enrico De Nicola, 07100 Sassari SS (Italia). \\ Email: pantaleo@uniss.it, r.pantaleoni@uniss.it - ORCID iD: https://orcid.org/0000-0003-0118-7244 \\ * Autor para correspondencia
}

\section{RESUMEN}

Se aportan nuevos datos sobre las especies del género Chrysopa Leach, 1815 citadas en la Península lbérica y Baleares. De las especies mencionadas en su fauna sobre las que existían dudas en la veracidad de sus citas o se había cuestionado su validez taxonómica, se ha estudiado y anotado la mayoría del material correspondiente, tanto ibérico como material de comparación de otras zonas, con la intención de dilucidar estas cuestiones. Bien sea para constatar su presencia en su fauna, con la correspondiente confirmación o corrección de ciertas citas, como para verificar la identidad de algunas especies de este género y algunas de sus variedades descritas, con la confirmación o revisión de su identidad taxonómica. Se confirma la validez de Chrysopa nierembergi Navás, 1908 respecto a C. formosa Brauer, 1850 y se designa para ella Lectotipo. También se designa Lectotipo para Chrysopa nierembergi var. andreui Navás, 1910 y para Chrysopa nierembergi var. clara Navás, 1915, ambas son consideradas sinónimas de C. nierembergi. Se dan por válidas solo dos de las citas ibéricas de Chrysopa phyllochroma Wesmael, 1841, y se confirma la presencia de Chrysopa dubitans McLachlan, 1887 en la fauna ibérica. Se eleva a categoría de especie la variedad Chrysopa nierembergi var. nitens Navás,1909, considerándola como especie válida: Chrysopa nitens Navás, 1909 stat. prom., designando para ella Lectotipo. De estas cinco especies se anotan sus caracteres de morfología externa y de genitalia masculina, así como algunos elementos diagnósticos y comparativos entre ellas o con otras especies próximas. Se comentan y se discuten algunos caracteres habitualmente utilizados en la identificación de las especies de Chrysopidae (variabilidad y persistencia de la pigmentación tegumentaria de los ejemplares según poblaciones, tiempo transcurrido desde su recolección y modo de conservación; uñas dilatadas en su base o no). Por último, y hasta que no existan nuevas evidencias, se descarta definitivamente la supuesta presencia de Chrysopa abbreviata Curtis, 1834 y Chrysopa walkeri McLachlan, 1893 en el solar ibérico, ya que está basada en citas antiguas imprecisas o inconsistentes, no corroboradas por nuevo material. El género Chrysopa está representado en la fauna lbero-Balear por diez especies, de las cuales se anota y recopila la información existente, y se aporta nuevo material, también se actualizan la clave de especies de este género y los mapas de su distribución en la Península lbérica y Baleares.

Palabras clave: Neuroptera; Chrysopidae; Chrysopa; faunística; morfología; taxonomía; Península lbérica; Baleares.

\section{ABSTRACT}

On the genus Chrysopa Leach, 1815 (Insecta, Neuroptera: Chrysopidae) from the Iberian Peninsula and Balearics.

New data are provided about the species of genus Chrysopa Leach, 1815 recorded in the lberian Peninsula and the Balearic Islands. Regarding those species for which there were doubtful records or taxonomic questions, almost all the lberian specimens were studied and compared with material coming from other areas to clarify these questions. So, their presence in Iberian-Balearic fauna, with the corresponding confirmation or correction of certain records, was verified, and the identity of some taxa (species and varieties) was elucidated. The validity of Chrysopa nierembergi Navás, 1908 regard to C. formosa Brauer, 1850 is confirmed, and its Lectotype is designated. Also the Lectotypes of Chrysopa nierembergi var. andreui Navás, 1910 and for Chrysopa nierembergi var. clara Navás, 1915 are designated. Both are considered synonyms of C. nierembergi. Only two of the lberian records of Chrysopa phyllochroma Wesmael, 1841 are considered as valid, and the presence of Chrysopa dubitans Mclachlan, 1887 in the Iberian fauna is confirmed. The variety Chrysopa nierembergi var. nitens Navás, 
1909 is considered as a valid species: Chrysopa nitens Navás, 1909 stat. prom., designating for her Lectotype. The external morphology and male genitalia characters of these five species are discussed, as well some diagnostic and comparative elements between them or with other nearby species. It commented and discussed some characters usually used in the identification of the species of the Chrysopidae family (variability and persistence of integumentary pigmentation of the specimens according to populations and time elapsed since their collection and conservation mode; dilated claws at their base or not). Finally, and until there is no new evidence, the alleged presence of Chrysopa abbreviata Curtis, 1834 and Chrysopa walkeri McLachlan, 1893 in the lberian fauna is definitely ruled out, since it is based on inaccurate or inconsistent old quotations, not corroborated by new material. The genus Chrysopa is represented in the lberian-Balearic fauna by ten species, of which the existing information is recorded and compiled, new material is provided, and the key of species of this genus and the maps of its distribution in the Iberian Peninsula and the Balearic Islands are updated.

Keywords: Neuroptera; Chrysopidae; Chrysopa; faunistics; morphology; taxonomy; Iberian Peninsula; Balearics.

Recibido/Received: 25/12/2019; Aceptado/Accepted: 1/06/2020; Publicado en línea/Published online: 10/11/2020

Cómo citar este artículo/Citation: Monserrat V. J. \& Pantaleoni, R. A. 2020. Sobre el género Chrysopa Leach, 1815 de la Península lbérica y Baleares (Insecta, Neuroptera: Chrysopidae). Graellsia, 76(2): e114. https://doi.org/10.3989/graellsia.2020. v76.265

Copyright: (C) 2020 SAM \& CSIC. This is an open-access article distributed under the terms of the Creative Commons Attribution 4.0 International (CC BY 4.0) License.

\section{Introducción}

Los crisópidos constituyen una extensa familia de neurópteros que es particularmente interesante debido a su amplia distribución geográfica, al elevado número de individuos que frecuentemente constituyen sus poblaciones, y especialmente por su utilización como aliados de nuestros intereses, al tratarse de eficaces agentes de control de pequeños artrópodos fitófagos, especialmente en sus fases larvarias (Smith, 1922; Killington, 1936, 1937; New, 1975a, 1975b, 1984a, 1988, 1989, 1999, 2001, 2002; Canard et al., 1984; Principi, 1984; McEwen \& Senior, 1998; McEwen et al., 1998, 2001; Nicoli Aldini, 2002; Pappas et al., 2011). Por ello, se trata de la familia de neurópteros que mayor atención ha venido recibiendo en comparación con otras familias, incluso otras también de interés en el Control Biológico de plagas agrícolas, sea Coniopterygidae o Hemerobiidae, y por ello son ingentes los datos y publicaciones existentes sobre la distribución, biología, fenología, morfología, histología, fisiología, estadios juveniles y variabilidad de muchas de sus especies, y en particular las utilizadas en Control Biológico, sobre las que existen cientos de artículos de interés aplicado.

Esta familia es una de las más extensas dentro de los neurópteros, y está constituida por más de 1.400 especies agrupadas en 86 géneros/subgéneros (Aspöck et al., 1980; Brooks \& Barnard, 1990; Winterton \& Brooks, 2002; Jiang et al., 2017), cifras que han venido incrementándose desde entonces. Está representada en la fauna del paleártico occidental por unas 116 especies (Aspöck et al., 2001).

La Fauna Ibérico-Balear posee representantes de todos los géneros de esta familia presentes en la Fauna neuropterológica Europea, constituyendo en el caso de la familia que tratamos el 71,23\% de las especies europeas, con 52 especies en la fauna ibérica, de las 73 especies válidas hoy citadas en Europa (Aspöck et al., 1980, 2001, 2015; Aspöck, 1992; Aspöck \& Hölzel, 1996; Monserrat, 2011, 2016; Monserrat \& Triviño, 2013; Monserrat et al., 2013, 2014), algunas son endémicas y otras únicamente han sido citadas de la Península Ibérica dentro del Continente Europeo. Obviamente estos porcentajes son relativos, ya que son varias las especies citadas en nuestra fauna que aún requieren confirmación, otras especies europeas han sido últimamente revalidadas como especies válidas o han sido recientemente descritas (Leraut, 1992; Tillier et al., 2014; Henry et al., 2014; Badano \& Makris, 2020) y en algún caso cabría suponer su presencia en nuestra fauna, y otras especies están en fase de discusión y/o aceptación generalizada.

La mayoría de la información existente sobre la Fauna Ibérica corresponde a la zona española (Monserrat et al., 2013, 2014; Monserrat, 2016), pero también muchas de las especies ibéricas están citadas de Portugal: Passos de Carvalho (1997) recoge 25 especies citadas en Portugal continental, Letardi et al. (2013) listan 28 especies en esta parte ibérica de Portugal, Jones et al. (2013) aportan nuevas citas, y alguna otra novedad para la fauna portuguesa ha sido recientemente aportada (Monserrat, 2008, 2016), y ahora añadimos en su listado una nueva especie: Chrysopa nitens Navás, 1909 stat. prom.

En relación con este género y con nuestra fauna, son numerosos los artículos de naturaleza aplicada que han sido publicados, y desde el punto de vista faunístico o taxonómico, recientemente Monserrat (2016), Porcel et al. (2016), Canard \& Thierry (2017a), Alcalá Herrera et al. (2019a, 2019b) y Monserrat et al. (2019) aportan nuevos datos.

Respecto a la posición taxonómica de las especies ibéricas, y partiendo de la obra de Hölzel \& Ohm 
(1972) como punto de inicio para el estudio de los crisópidos ibero-baleares desde el punto de vista de la Entomología Contemporánea, la mayoría de ellas presentan una situación adecuada, correcta y bien definida (Aspöck et al., 1980, 2001), y mayoritariamente han sido recientemente resueltas algunas cuestiones que aún venían presentando ciertos problemas o se han ampliado, corroborado, corregido o cuestionado algunas citas dadas en el solar ibero-balear (Monserrat, 1986a, 2005, 2008, 2010, 2011, 2013, 2016; Monserrat \& Díaz-Aranda, 1989b, 2012; Monserrat \& Rodrigo, 1992; Monserrat \& Triviño, 2013; Monserrat et al., 2014, 2019).

No obstante, algunos temas generales aún quedan por resolver, y dentro de nuestro más próximo entorno citemos, por ejemplo, la posición de ciertas especies de algunos géneros (Chrysoperla Steinmann, 1964, Pseudomallada Tsukaguchi, 1995) que están siendo permanentemente motivo de estudio y discusión (Henry, 1985; Wells \& Henry, 1992a, 1992b; Thierry \& Adams, 1992; Thierry et al., 1992, 1996, 1997, 1998, 2013; Brooks, 1994; Henry et al., 1996, 2001, 2002, 2003, 2011, 2013, 2014, 2015; Lourenço et al., 2006; Canard \& Thierry, 2007, 2017a; Monserrat, 2008; Pantaleoni \& Sechi, 2014; Duelli et al., 2017; Duelli \& Obrist, 2019, etc.).

En relación con el género que tratamos también existen elementos que requieren nuevos estudios. Mencionemos como ejemplos la supuesta "uniformidad" del género Chrysopa Leach, 1815, género cuya necesaria revisión ya había sido sugerida por numerosos autores desde hace tiempo, y se ha seguido considerado conforme se ha ido perfilando el verdadero concepto e identidad actual del género (Naville \& Beaumont, 1933, 1936; Killington, 1937; Adams, 1975; Principi, 1977; Barnard, 1978; Séméria, 1984; New, 1984b; Brooks \& Barnard, 1990; Cadena et al., 2007; Monserrat et al., 2014, etc.), la problemática en las especies del grupo Chrysopa formosa-phyllochroma (Aspöck et al., 1980, 2001) con varias especies descritas, revalidadas o con posición incierta, y también dentro de este género la situación de Chrysopa viridana Schneider, 1845 en relación a las otras especies del género (ver problemática en Monserrat, 2016), o la revalidación de especies de este género recientemente descritas que fueron consideradas sinónimas de otras previamente descritas (Leraut, 1989, 1992; Tillier et al., 2014; Devetak et al., 2015; Canard \& Thierry, 2017b) sin tener demasiado en cuenta las decenas de variedades y subespecies descritas con anterioridad dentro del género Chrysopa (ver por ejemplo Navás, 1915a, 1924, 1925), algunas de las cuales tendría prioridad sobre alguna de las especies recientemente descritas o revalidadas (como ahora anotamos en el caso de Chrysopa nierembergi var. nitens Navás, 1909), pero toda esta laboriosa tarea aún no ha sido realizada, y son temas que habrá que abordar adecuadamente en algún momento.
Circunscribiéndonos a nuestra fauna y al género Chrysopa que ahora nos ocupa, faltaba aún por confirmar la validez taxonómica de algunos taxa y la veracidad, y en su caso confirmación o corrección, de algunas especies citadas en la fauna ibérica. Tal es el caso de corroborar la validez de Chrysopa nierembergi Navás, 1908 (y sus tres variedades descritas) respecto a $C$. formosa Brauer, 1850, que ha sido cuestionada en algunas ocasiones, definiendo mejor la especie y las diferencias entre ellas; de confirmar o descartar definitivamente las citas ibéricas de Chrysopa phyllochroma Wesmael, 1841, Chrysopa dubitans McLachlan, 1887, Chrysopa abbreviata Curtis, 1834 y Chrysopa walkeri McLachlan, 1893, también cuestionadas en alguna ocasión, deteniéndonos en comentar la problemática de estas citas y, en el caso de ser confirmadas en nuestra fauna, anotar nuevos elementos para su caracterización en comparación con otras especies afines; así como recopilar y actualizar la información existente sobre todas las especies de este género en nuestra fauna; poner al día la clave de especies y aportar nuevos datos faunísticos de distribución y biología. Temas que ahora abordamos en esta contribución.

\section{Material y métodos}

La mayoría de los ejemplares que se citan pertenecen a la colección del primer autor, depositada en la Facultad de Biología de la Universidad Complutense de Madrid (UCME); sin embargo, otro material estudiado pertenece a diferentes instituciones que a continuación listamos, anotando las siglas empleadas para indicar la pertenencia del material que se cita:
EEZ = Estación Experimental del Zaidín, Granada
MNCN $=$ Museo Nacional de Ciencias Naturales, Madrid
MZB = Museu de Ciències Naturals, Barcelona
UGR = Departamento de Zoología, Facultad de Ciencias, Universidad de Granada

Las especies se mencionan por orden cronológico y de ellas se anota la información general dada por Aspöck et al. $(1980,2001)$ y la de nuestra fauna dada por Monserrat (2016), aportando ahora nuevos elementos. De cada una de las especies citadas en esta contribución anotamos una breve sinopsis de su distribución geográfica, fenológica y altitudinal conocida y de sus preferencias ecológicas, tanto general como en el área que nos compete, así como las referencias a los autores que han descrito sus estadios larvarios y los datos más significativos que merezcan citarse en relación con el nuevo material ahora aportado.

La exposición del material estudiado se cita ordenado alfabética- y cronológicamente siguiendo la siguiente secuencia, siempre que se dispusiera en los datos de los ejemplares: País, provincia, localidad de 
captura, coordenadas, altitud (anotamos $10 \mathrm{~m}$ como la altitud de las localidades a nivel del mar), fecha de captura, número de $\hat{\partial} \hat{\delta}, ~ q q+$ estudiados, datos de biología, recolector (si no han sido alguno de los autores) e institución a la que dicho material pertenece, según las siglas anteriormente anotadas. Para no reiterar en esta secuencia datos del país, provincia, localidad, fecha de captura o recolector, y salvo en el caso del material tipo citado, se separan por comas o puntos según se haya citado o no parte de la información en los ejemplares mencionados inmediatamente antes de los que se exponen. En el material tipo estudiado, se separan por barras (/) los datos contenidos en cada una de las etiquetas que portan los ejemplares.

Para acceder a las estructuras y genitalia internas, el abdomen de los imagos era previamente reblandecido en agua y tratado con ácido láctico templado hasta su aclarado. Las fotografías, según sus autores, se han realizado con cámara Canon Power Shot, G7X Mark II (autores); Nikon 5300 y objetivo macro Nikkor 60 mm (F. Rodríguez); Canon EOS 700D con objetivo EF $100 \mathrm{~mm}$ f/2.8 Macro USM, en algunos casos se acopló a una lupa Motic SMZ-171 (S. Gago); Nikon D-700 con objetivo AF-S VR Micro-Nikkor $105 \mathrm{~mm}$ f/2.8G IF-ED y software usado para capturar y apilar las imágenes Helicon Remote y Helicon Focus (M. París). Los dibujos se realizaron a mano alzada con un estereo-microscopio ZEISS ${ }^{\circledR}$ STEMI-SV8 con cámara clara de dibujo incorporada, tras lo cual se pasaban a tinta china sobre papel vegetal. El programa de diseño Corel Paint Shop Pro Photo XI, y el software Adobe Photoshop ${ }^{\circledR}$ CS5 Extended ver. 12.0 fue utilizado para el procesamiento y mejora de alguna de las imágenes.

\section{Resultados}

Subfamilia CHRYSOPINAE Schneider, 1851

Tribu Chrysopini Schneider, 1851

Género Chrysopa Leach, 1815

\section{Chrysopa perla (Linnaeus, 1758)}

Fig. 12d

Nuevo material estudiado. ESPAÑA: Cantabria: Puerto de los Tornos, 430 $7^{\prime} 44.40^{\prime \prime} \mathrm{N}, 3^{\circ} 27^{\prime} 19.45^{\prime \prime} \mathrm{O}, 858 \mathrm{~m}$, 13.VII.2017, 1 oิ sobre hierba (UCME). Vizcaya: Presa, $34^{\circ} 12^{\prime} 02.86^{\prime \prime} \mathrm{N}$, $3^{\circ} 23^{\prime} 48.30^{\prime \prime} \mathrm{O}, 473 \mathrm{~m}, 13$.VII.2017, 1 के sobre hierba (UCME).

Especie de distribución eurosiberiana, desde Europa, Anatolia y Cáucaso a Mongolia y Siberia. Está citada en medios húmedos sobre una gran variedad de plantas, sean olmos, abetos, nogales, avellanos, caducifolios bajos, vegetación de galería, ortigas, jardines, matorrales, setos, etc., y con frecuencia sobre otras herbáceas, de voltinismo variable según latitudes y altitudes, ha sido recolectada entre los meses de IV-IX (X?), en altitudes de 10 hasta $1.600 \mathrm{~m}$. Parece demostrado que hiberna en fase de prepupa (Aspöck et al., 1980).
En nuestra fauna tiene una clara tendencia eurosiberiana y se circunscribe a su tercio septentrional (Fig. 12d), y ha sido citada en medios húmedos sobre robles, avellanos, hayas, rosales, sauces, claros de bosque y vegetación herbácea, ocasionalmente sobre pinos. Es una especie bastante local, pero a veces extremadamente abundante, recolectada entre los meses de V-VIII, con varias generaciones anuales, en altitudes generalmente montanas que oscilan entre 650-1.890 m.

El huevo, la larva y la pupación de esta especie fueron descritos por Brauer (1850), Schneider (1851), Pariser (1919), Lacroix (1921a), Withycombe (1923), Killington (1937), Philippe (1970), Canard (1971, 1973a, 1973b, 1976), Gepp (1983, 1984, 1986, 1989, 1999) y Monserrat \& Díaz-Aranda (2012).

\section{Chrysopa pallens (Rambur, 1838)} Fig. 12i

Nuevo material estudiado. ESPAÑA: Almería: Adra, $36^{\circ} 45^{\prime} 00^{\prime \prime} \mathrm{N}$,

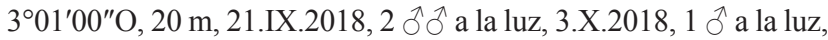
3.IV.2019, 1 ○ a la luz, 27.IV.2019, 1 a la luz, 8.V.2019, $4 \hat{\delta} \widehat{\delta}$, 3 우 a la luz, 8.VI.2019, 1 , 1 ㅇ a la luz, F. Rodríguez (UCME). Laujar de Andarax, 36 $56^{\prime} 38^{\prime \prime} \mathrm{N}, 2^{\circ} 53^{\prime} 49^{\prime \prime} \mathrm{O}, 918$ m, 13.VIII.1958, 1 స. J. Suárez (MNCN-Ent. 223662). Granada: La Herradura, Punta de la Mona, 30SVF36, 200 m, 17.VIII.2014, 1 q a la luz (UGR). Málaga: Coín, Sierra Alpujata, Arroyo del Corcho, 30S 339 4052,

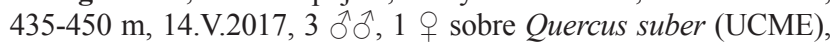
2.VII.2017, 1 §े, 1 q sobre Salix pedicellata (UCME).

Especie paleártica introducida por acción humana a otras zonas (Mauricio, Taiwán y Camboya) y probablemente en Canarias (Monserrat, 2008). Es una especie francamente eurioica, y está recolectada sobre una gran variedad de medios, jardines urbanos, frutales, caducifolios, etc., citada como multivoltina, aunque mayoritariamente recolectada entre los meses de V-XI, en altitudes de 10 hasta $2.000 \mathrm{~m}$. Parece demostrado que hiberna en fase de prepupa (Aspöck et al., 1980).

Es una especie ampliamente distribuida en nuestra fauna, incluyendo Baleares (Mallorca, Menorca) (Fig. 12i), donde también presenta un carácter marcadamente eurioico, generalmente está asociada a medios arbóreos abiertos y soleados, donde ha sido citada sobre una enorme variedad de sustratos vegetales, bien planifolios o, en menor medida, coníferas [citas que quizás alguna correspondan a Chrysopa gibeauxi (Leraut, 1989), especie centroeuropea que ha sido recientemente revalidada y aceptada como especie válida (Leraut, 1992; Tillier et al., 2014; Devetak et al., 2015; Canard \& Thierry, 2017b)], citada entre los meses de IV-IX, en altitudes que oscilan entre 10-1.340 m. Parece demostrado que hiberna en fase de prepupa (Aspöck et al., 1980).

El huevo, la larva y la pupación de esta especie (en algunos casos bajo la denominación de Chrysopa septempunctata Wesmael, 1841) fueron descritos por Pariser (1919), Withycombe (1923), Lacroix (1929), Killington (1937), Principi (1940), Agekjan (1973), Tsukaguchi (1978, 1995), Pantaleoni (1983), Gepp 
(1983, 1989, 1999) y Monserrat \& Díaz-Aranda (2012).

\section{Chrysopa dorsalis Burmeister, 1839 \\ Fig. $12 \mathrm{~g}$}

Nuevo material estudiado. ESPAÑA: Cantabria: Liencres,

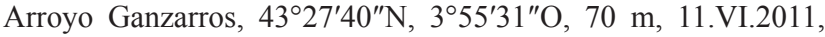
1 స, T. Farino (UCME). Jaén: $\mathrm{S}^{\mathrm{a}}$. de Cazorla, Barranco Carril, $37^{\circ} 55^{\prime} 44.16^{\prime \prime} \mathrm{N}, 2^{\circ} 48^{\prime} 23.13^{\prime \prime} \mathrm{O}, 1.660 \mathrm{~m}, 7 . \mathrm{VII}-25 . V I I .2018,1$ ठ en trampa de vino, M. López (UCME).

Especie mediterránea septentrional expansiva, extendida hacia Israel, Anatolia, Georgia, Cáucaso y Kazakhstán. Está mayoritariamente recolectada sobre coníferas (Pinus, Juniperus), citada entre los meses de V-IX, y posee tendencia orófila, citada en altitudes de 10 hasta $1.640 \mathrm{~m}$. Parece demostrado que hiberna en fase de prepupa (Aspöck et al., 1980).

En nuestra fauna está citada del norte y centro peninsular, con citas puntuales más meridionales (Granada, Jaén, Albacete) (Fig. 12g), en ella también muestra una cierta tendencia orófila y una marcada preferencia por las coníferas, y ha sido citada sobre pinos, especialmente Pinus sylvestris y P. pinaster, también sobre enebros, sabinas, y puntualmente sobre hayas, robles, quejigos y encinas, entre los meses de V-IX, en altitudes que oscilan entre 70-1.610 m.

El huevo, la larva y la pupación de esta especie fueron descritas por Brauer (1850), Alderson (1911), Pariser (1919), Withycombe (1923, 1924), Killington (1937), Fraser (1945), Gepp (1983, 1986, 1989), DíazAranda \& Monserrat (1995), Díaz-Aranda et al. (2001), Monserrat (2008) y Monserrat \& Díaz-Aranda (2012).

\section{Chrysopa phyllochroma Wesmael, 1841}

Figs. 1a-e, 5d, 12a

Nuevo material estudiado. ESPAÑA: Lérida, Valle de Arán, Lés, 4248'37"N, 042'36"E, 640 m, (29-6-14) 29.VI.1914, 1 q, H. León Hilario leg., L. Navás (71-9465 MZB).

RUMANÍA: Cluj, Băişoara, 14.VII.1968, 1 $\widehat{\partial}$, B. Kis (UCME 44204); Caraorman, 24.VII.1967, 1 ㅇ, B. Kis (UCME 44205).

UKRANIA: Sumi, 8.VI.1981, 1 ô, A. V. Zakharenko (UCME 44206).

Material DE COMPARACIÓN ESTUdiado.

Chrysopa commata Kis \& Újhelyi, 1965. RUMANÍA: Transilvania, Aiud, 22.VIII.1968, 1 $\widehat{\partial}$, B. Kis (UCME 45379).

RUSIA: Astrakhan, 26.VII.1978, 1 §ิ, 1 +, A. V. Zakharenko (UCME 44213, 44214).

Especie sibérica extra-mediterránea, mayoritariamente conocida de Europa central, septentrional y oriental, que está citada desde el Cáucaso al este de Siberia, Islas Kuriles, Japón, Corea, Mongolia y N.E. China (Manchuria, Jehol), si bien su relación con algunas especies orientales (especialmente algunas descritas o citadas de Corea y Japón) está por confirmar (Aspöck et al., 1980, 2001). Está mayoritariamente recolectada en prados y cultivos sobre vegetación baja, herbácea y flores, principalmente de crucíferas, leguminosas o solanáceas (Achillea, Vicia, Medicago, Solanum, Beta, Artemisia, Sinapis, Pisum, Hordeum, Trifolium, etc.), también gramíneas (trigo, centeno), sobre Ulmus, Nerium, Quercus, Crataegus, etc. Habitualmente local, sus poblaciones presentan cortas fenologías (a veces citada como monovoltina), con imagos recolectados entre los meses de V-IX, de tendencia montana-alpina se ha recolectado en altitudes de 150 hasta $2.150 \mathrm{~m}$. Parece demostrado que hiberna en fase de prepupa (Zelený, 1965; Aspöck et al., 1980).

Se trata de una especie aparentemente abundante, muy frecuentemente registrada en la bibliografía (conocemos más de 261 referencias bibliográficas sobre esta especie o sus sinonimias), si bien de confusa diagnosis inicial (Kis \& Újhelyi, 1965), con varias especies próximas descritas del Paleártico oriental cuya vinculación con ella no ha sido aún resuelta (Aspöck et al., 1980, 2001) y con varias identificaciones erróneas confirmadas (Kuwayama, 1962; Kis \& Újhelyi, 1965; Barnard, 1978). Por ello, y por su similitud con otras especies, es muy probable que muchas de las citas de esta especie en la bibliografía hayan sido confundidas, en particular con Chrysopa commata Kis \& Újhelyi, 1965, especialmente antes de la descripción de esta especie, incluso consideradas sinónimas (Killington, 1937; Fraser, 1959; Kis \& Újhelyi, 1965; Zelený, 1965, 1969, 1971; Kis et al., 1970; Barnard, 1978; Aspöck et al., 1980; Popov, 2002; Bozdoğan \& Bahadıroğlu, 2015), por lo que han podido ser mezclados los datos existentes de una y otra especie. De hecho, los estadíos preimaginales de esta especie fueron descritos por Withycombe (1924), Killington (1937), Tsukaguchi (1978) y Gepp $(1983,1984,1986,1989)$, pero en algún caso pueden corresponder a $C$. commata.

A diferencia de otras especies del género, su genitalia masculina ha sido descrita con relativa frecuencia, bien como Chrysopa phyllochroma, bien como alguna de sus sinonimias propuestas (Chrysopa magnicauda Tjeder, 1937; Chrysopa electra Hölzel, 1965) o bien descrita, pero confundida con Chrysopa commata Kis \& Újhelyi, 1965, si bien con algunas lógicas diferencias en su interpretación por parte de algunos autores (Killington, 1937: 216; Tjeder, 1937: 24-26, pl. XIII; Hwang \& Bickley, 1961: 426; Kis \& Újhelyi, 1965: 351; Hölzel, 1965: 458, 1967a: 259, 1973b: 85; Kis et al., 1970: 267; Zelený, 1971: 179, pl. IV; Dorokhova, 1973: 634, 1987: 70; Barnard, 1978: 173; Makarkin, 1985: 56; Canard \& Jacquemin, 2006: 484). Es cierto que la morfología y pigmentación externa de ambas especies es muy similar, pero la pigmentación del escapo y la morfología genital masculina las diferencia incuestionablemente (Figs. 1a-e, 5d-e).

Por la problemática existente en las citas de esta especie en nuestra fauna anotamos y comentamos 


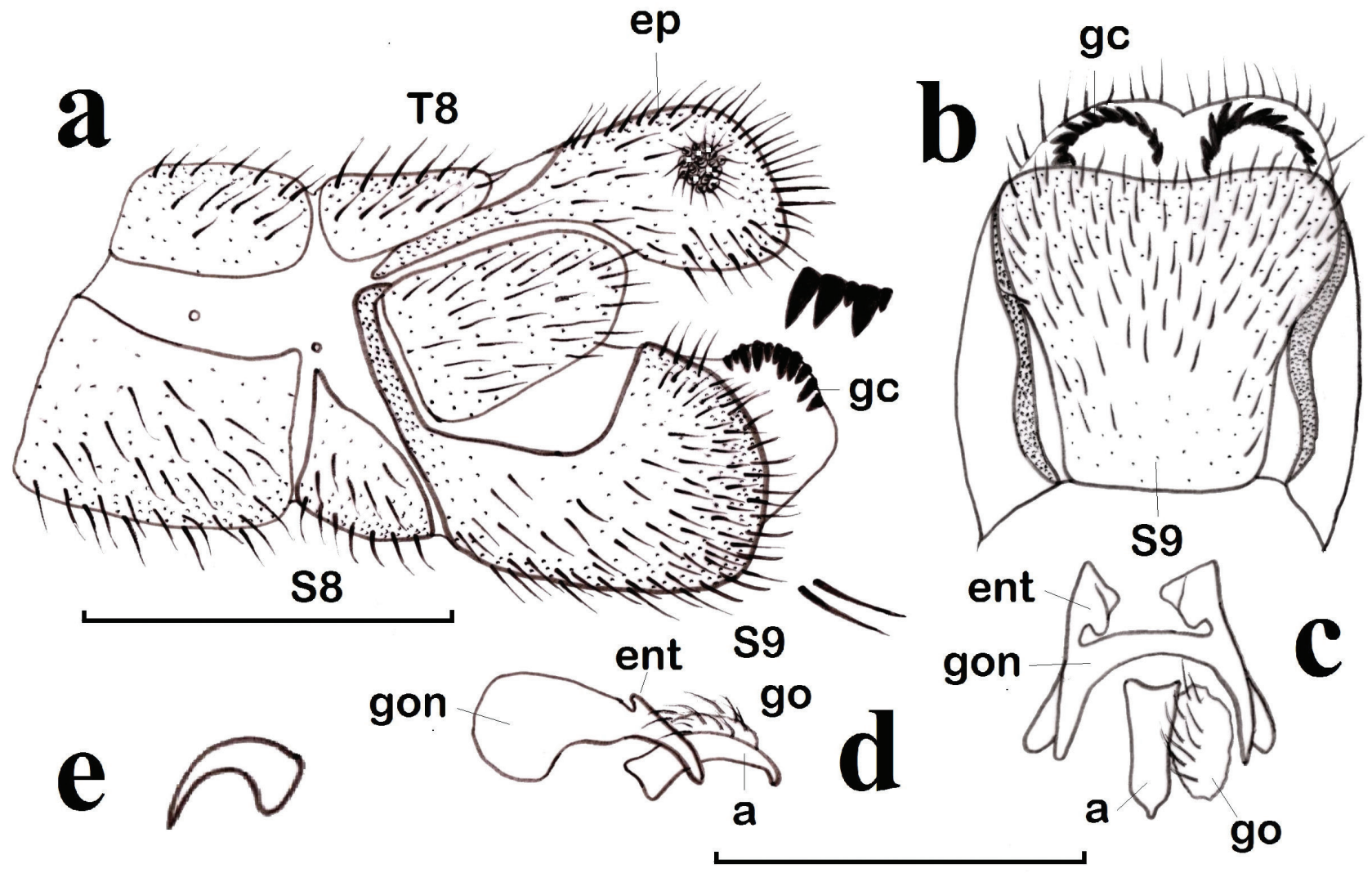

Fig. 1.- Chrysopa phyllochroma, đ. a: extremo abdominal, vista lateral (aumentadas dos setas y gonocristas), b: noveno esternito, vista ventral, c: complejo gonarco-mediuncos-entoprocesos-arceso-gonosetas, vista dorso-caudal, d: ídem, vista lateral, e: uña (a: arceso, ep: ectoprocto, ent: entoproceso, gc: gonocrista, go: gonosetas, gon: gonarco, S: esternito, T: terguito). Escala para a-d: $1 \mathrm{~mm}$.

Fig. 1.- Chrysopa phyllochroma, ô. a: abdominal apex, lateral view (two setae and gonocristae magnified), b: ninth sternite, ventral view, c: complex gonarcus-mediuncus-entoprocessus-arcessus-gonosetae, dorso-caudal view, d: ditto, lateral view, e: claw (a: arcessus, ep: ectoproct, ent: entoprocessus, gc: gonocristae, go: gonosetae, gon: gonarcus, S: sternite, T: tergite). Scale for a-d: $1 \mathrm{~mm}$.

algunos datos aclaratorios y suplementarios. Sobre la presencia de esta especie en la fauna ibérica, Monserrat et al. (2014) y Monserrat (2016) anotaron todos los registros antiguos y las reseñas más recientes referentes a nuestra fauna, poniendo en duda la veracidad de muchas de estas citas. En realidad en nuestra fauna apenas existen datos reales (Zaragoza, Mallorca, Granada, Lérida, Alicante y Almería) y la mayoría son simples reseñas bibliográficas reiterativas derivadas de estas citas. En ella ha sido citada sobre Ulmus, Nerium y Crataegus, entre los meses de VI-VII, en altitudes que oscilan entre 10-1.500 m, existiendo identificaciones, no siempre incuestionables, de escasos ejemplares y siempre ejemplares hembras entre los recolectados por nosotros, con lo que hasta ahora no había podido corroborarse la autenticidad de estas identificaciones.

Ya comentaban Monserrat et al. (2014) y Monserrat (2016) que, siendo una especie típica de montaña, claramente alpina-subalpina, las citas de Navás (1909a: 175) a orillas del Ebro (Zaragoza) o de Navás (1915a: 74, 1924: 169, 1925: 74, 79); Vidal y López (1943: 21) en Orihuela (Alicante) parecían muy dudosas. Muy imprecisa encontramos la referencia de Klapálek, 1909: 30 (Montseny?, Montserrat?, Monistrol?, Algeciras?, VI, 1907), pareciendo ser más probable la cita de Navás (1915b: 80) en Lés, en el Valle de Arán (Lérida) (29.VI), hecho que parecen confirmar Hölzel \& Ohm (1972: 130, 144), quienes la citan de esta provincia en Sudanell (sobre Ulmus, Crataegus, VI, c. $160 \mathrm{~m}$, la altitud fue estimada por nosotros). Por otra parte, los datos de Baleares (Mallorca) siempre nos habían parecido muy dudosos, y fueron corregidos por Monserrat (2005), y Monserrat et al. (2014) ponen en duda la veracidad de otras citas, incluso recientes, dadas en nuestra fauna en medios mediterráneos meridionales y térmicos, como es el caso de las citas dadas por Monserrat (1987: 137), Monserrat \& Díaz-Aranda (1989b: 254) y Monserrat et al. (2014: 6) de Almería en base a ejemplares hembras, ejemplares que ahora hemos reestudiado, corrigiendo su identificación y asignando estos ejemplares de Almería a Chrysopa dubitans (ver su material estudiado), especie a la que también podrían presumirse, al menos, las citas de 
Alicante y quizás Zaragoza anteriormente mencionadas. También Hölzel \& Ohm $(1972: 130,144)$ la citaban en Granada, Sierra Nevada (meses de VI-VII), cita que siempre nos ha parecido bastante sospechosa, ya que, como decimos, se trata de una especie típica de montaña, claramente alpina-subalpina, con tendencia marcadamente sibérica y septentrional extra-mediterránea. Este último material sobre el que se basó esta cita ibérica no permaneció en el Naturhistorisches Museum de Viena (donde quedó depositada parte de la colección de Chrysopidae de H. Hölzel), según nos informan del citado museo, por lo que no ha podido ser estudiado, pero tenemos fundadas dudas de que este material de Granada perteneciera a Chrysopa phyllochroma, sino en realidad también a $C$. dubitans, especie próxima que ahora citamos en esta zona peninsular (Fig. 12b) y cuyos requerimientos ambientales son mucho más acordes que los de la especie que tratamos, y de hecho adjudicaremos esta cita al tratar esta especie. Similar error de identificación había ocurrido con un ejemplar de Nineta flava (Scopoli, 1763) citado por estos autores (Hölzel \& Ohm, 1972: 140) en esta misma zona (Granada: Sierra Nevada-Las Alpujarras), cita que, por las mismas causas, siempre nos había parecido muy dudosa (Monserrat, 2010, 2011), y que tras años de muestreos en la zona esta cita fue adjudicada a Nineta guadarramensis (Pictet, 1865) en base a ejemplares recolectados en esta zona, siendo la presencia de esta especie en esta zona (y no la citada) un hecho mucho más acorde con los requerimientos ambientales y distribución de ambas especies (Monserrat, 2013: 294).

Es cierto que Sierra Nevada es una formación montañosa, pero mucho más árida y térmica que Pirineos y otras cordilleras del centro y norte de Europa. También es cierto que esta especie sibérica extra-mediterránea está ocasionalmente citada en Europa de zonas más meridionales o de influencia más mediterránea, como es el caso de Croacia, norte de Italia, de Grecia, de Francia y de España (Aspöck et al., 1980, 2001; Canard et al., 2007), aunque en estas zonas se limita a zonas montanas y más septentrionales, y por ejemplo en Italia, esta especie posee una distribución marcadamente alpina, y está ausente en áreas más meridionales (Letardi, 2005), hechos que nos avalan ante nuestras dudas sobre las citas ibéricas meridionales anteriormente mencionadas, no digamos en áreas marcadamente xero-térmicas del S.E. peninsular donde fue citada. Por todo ello sospechábamos que solo las citas de Lérida serían válidas (Navás, 1915b; Hölzel \& Ohm, 1972; ver todas las referencias compiladas por Monserrat, 2016) (Fig. 12a).

Ante la falta de nuevo material ibérico reciente, hemos estudiado el ejemplar a partir del cual Navás (1915b) dio la primera cita de esta especie en nuestra fauna y hemos comprobado que es acertada, con lo que se confirma su presencia en ella, dando por válida esta cita y, con ciertas dudas (por la escasa altitud de la localidad), suponemos también como válida la de Hölzel \& Ohm (1972) de esta provincia (Fig. 12a). Por lo cual, y con el fin de facilitar la identificación de posibles nuevos ejemplares, la mantenemos en la clave de especies ibéricas de este género (ver más adelante) y aportamos datos sobre su pigmentación tegumentaria y su genitalia masculina en base a éste y otro material de comparación ahora estudiado de Chrysopa phyllochroma (Figs. 1a-e, 5d).

Con estos elementos podemos anotar que en nuestra fauna ha sido recolectada en zonas pirenaicas-prepirenaicas (Lérida), sobre Ulmus, Crataegus, en el mes de VI, y en altitudes estimadas por nosotros comprendidas entre $160-640 \mathrm{~m}$.

\section{Chrysopa viridana Schneider, 1845}

Fig. $12 \mathrm{~h}$

Nuevo material estudiado. ESPAÑA: Almería: Adra, $36^{\circ} 45^{\prime} 00^{\prime \prime} \mathrm{N}$, $3^{\circ} 01^{\prime} 00^{\prime \prime} \mathrm{O}, 20 \mathrm{~m}, 19 . \mathrm{VII} .2018,1$ 우 a la luz, 4.VIII.201, 2 우우

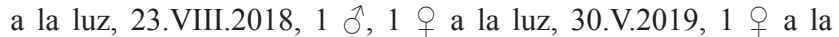
luz, 8.VI.2019, 1 §, 3 우 a la luz, 21.VI.2019, 1 ㅇ a la luz, 9.VII.2019, 1 § a la luz, 4.VIII.2019, 2 우 a la luz, 23.VIII.2019, 1 तิ a la luz, F. Rodríguez (UCME). Granada: Deifontes, VII. 2000, 1 ㅇ sobre Olea europaea F. Ruano (EEZ); Pinos Puente, $37^{\circ} 15^{\prime} 5^{\prime \prime} \mathrm{N}, 3^{\circ} 45^{\prime} 4^{\prime \prime} \mathrm{O}, 577 \mathrm{~m}, 28$.VII.2009, 1 ô, 1 ㅇ, M. Porcel (EEZ), 11.VIII.2009, 1 ô, 1 o, M. Porcel (EEZ), 10.VIII.2010, 1 ${ }^{\lambda}$, M. Porcel (EEZ). Madrid: San Fernando de Henares, $40^{\circ} 28^{\prime}$ N, 327'O, 580 m, 11.IX.2015, 1 ㅇ, J. I. López-Colón (UCME). Toledo: Cuerva, 39³9'49"N, 4¹2'42"O, 714 m, 5.VII.2014, 1 \& sobre Quercus rotundifolia, (UCME 44321); Fuensalida, $40^{\circ} 03^{\prime} 23^{\prime \prime} \mathrm{N}, 4^{\circ} 11^{\prime} 56^{\prime \prime} \mathrm{O}, 593 \mathrm{~m}, 6 . \mathrm{VI} .2014,2$ 우 sobre Quercus ilex (UCME 44319, 44320). Málaga: Coín, Sierra Alpujata, Arroyo del Corcho, 30S 339 4052, 435-450 m, 14.V.2017, 1 § sobre Quercus suber (UCME), 18.VI.2017, 3 के ठै sobre Quercus

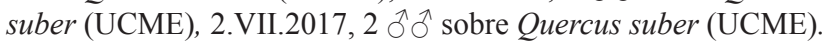

Especie holomediterránea expandida hacia Armenia, el Cáucaso, Irán, Afganistán y Turkmenistán. Está asociada a medios mediterráneos, mayoritariamente hallada sobre Quercus en estos medios, y también recolectada sobre una amplia gama de sustratos vegetales (oleáceas, salicáceas, sapindáceas, coníferas, lináceas, geraneáceas, cultivos, jardines, etc.), entre los meses de IV-IX, en altitudes de 100 hasta $2.000 \mathrm{~m}$. Parece demostrado que hiberna en fase de prepupa (Aspöck et al., 1980).

En nuestra fauna esta especie tiene una clara tendencia continental mediterránea, incluyendo Baleares (Mallorca), con citas puntuales en zonas más septentrionales (Asturias, Pontevedra, León, Zamora, Salamanca, Lérida, Huesca) (Fig. 12h), y ha sido citada en medios mediterráneos sobre Quercus, especialmente encinas, alcornoques, robles y quejigos, puntualmente sobre olivos, pinos, enebros, sabinas, alisos, castaños, olmos, pistáceas, almeces, frutales, etc., entre los meses de V-X, en altitudes mayoritariamente medias que oscilan entre $10-2.250 \mathrm{~m}$.

Estadios preimaginales descritos por Lacroix (1921b), Principi (1954) y Monserrat \& Díaz-Aranda 
(2012). Otros datos sobre su morfología larvaria, basadas en la coloración tegumentaria, son aportados por Gepp (1983) y Pantaleoni (1983).

\section{Chrysopa nigricostata Brauer, 1850}

Fig. $12 \mathrm{j}$

Especie holomediterránea expansiva hacia el centro de Europa, Anatolia, el Cáucaso, Armenia, Irak, Irán, Afganistán, Turkmenistán, Azerbaiyán, Tadschikistán, Kirguistán, Tayikistán y Kazakstán. Se trata de una especie frecuentemente citada, también en nuestra fauna, pero mayoritariamente confundida con Cunctochrysa cosmia (Navás, 1918), siendo aclaradas alguna de estas citas y la mayoría de las ibéricas por Monserrat et al. (2014), por lo que los datos bibliográficos correspondientes a ambas especies están parcialmente mezclados. Citada como marcadamente estenotópica y frecuentemente referida en la bibliografía asociada a choperas y bosques de galería y también a pinares, robles, encinas, etc. en medios mediterráneos, aunque los datos más fidedignos sobre esta especie la asocian a chopos y álamos, incluso dentro de sus agallas (ej.: Homoptera: Aphididae, Pemphigus spyrothecae Passerini, 1860), bosques de galería/riveras, parques y zonas urbanas, riveras o zonas arenosas y de vegetación baja, vinculada a medios térmicos y esteparios surcados por cauces rivereños más húmedos con chopos y álamos (Populus nigra, P. tremula, P. alba, etc.) y los restantes datos (especialmente sobre coníferas) deben asociarse a Cunctochrysa cosmia. Está mayoritariamente citada entre los meses de V-XI, y aunque ha sido citada como orófila, incluso marcadamente alpina (c. 500-1000 m en Centroeuropa, hasta 1.800 $\mathrm{m}$ en el sur de Europa y hasta 3.000-4.600 m en Próximo Oriente y Asia Central), también en su distribución altitudinal los datos de ambas especies puedan estar mezclados, y probablemente correspondiendo las citas de cotas medias y altas entre 670$2.100 / 3.000 \mathrm{~m}$ a Cunctochrysa cosmia, y limitando la especie que tratamos hasta los $930 \mathrm{~m}$. Por nuestros propios datos en estudios sobre su desarrollo, confirmamos que hiberna en fase de prepupa.

También en nuestra fauna los datos existentes estaban mezclados, y descartadas las citas anteriores erróneas (Monserrat et al., 2014), en realidad hay muy pocos datos (Burgos, Zaragoza, Madrid, Navarra) (Fig. 12j), siempre asociada a medios xéricos, térmicos, esteparios y/o gipsícolas. Todos los ejemplares conocidos se han mayoritariamente recolectados a la luz en estos medios esteparios y secos con vegetación xerófila, donde no descartamos la existencia de chopos y/o álamos en vaguadas próximas con mayor humedad endorreica, recolectada entre los meses de V-VIII, en altitudes que oscilan entre 225-930 m (los datos bibliográficos en la Península Ibérica a mayores cotas de 670-2.100 m corresponden a Cunctochrysa cosmia).

Sus estadios preimaginales son fragmentariamente conocidos (Brauer, 1850; anotado por Gepp, 1983, 1989 y Hölzel, 1998).

\section{Chrysopa formosa Brauer, 1850}

Figs. 2a-e, 5b, 8a, 12e

Nuevo material estudiado. ESPAÑA: Alicante: Jávea, 31SBC5397, 120 m, VIII.1984, 1 q, S.V. Peris (UCME 37658), citada como Chrysopa nierembergi por Monserrat \& Rodrigo (1992: 127), Orihuela, 385'5.39’N, 056’38.44’'O, 30 m, 1933, 1 ô, J. Andreu (MNCN-Ent 199594), VI.1935, 1 ô, J. Andreu

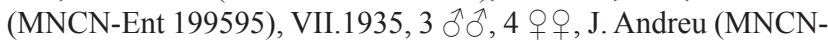
Ent 199569, 199577, 199580, 199585, 199588, 199598, 199762), Pilar de la Horadada, 37 $52^{\prime} 03^{\prime \prime} \mathrm{N}, 0^{\circ} 47^{\prime} 33^{\prime \prime} \mathrm{O}, 35 \mathrm{~m}, 16 . \mathrm{VI} .1982$, 1 ô (UCME 38254). Almería: Adra, $36^{\circ} 45^{\prime} 00^{\prime \prime} \mathrm{N}, 3^{\circ} 01^{\prime} 00^{\prime \prime} \mathrm{O}, 20$

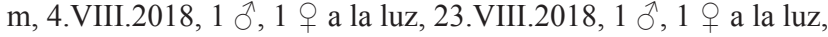
21.IX.2018, 1 q a la luz, 16.IV.2019, 1 ô a la luz, 27.IV.2019,

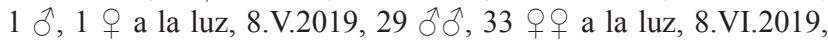
3 웅 a la luz, 21.VI.2019, 1 ㅇ a la luz, 9.VII.2019, $5 \hat{\jmath} \hat{\sigma}^{2}, 2$ 우우 a la luz, 22.VII.2019, 2 रे $\hat{\delta}$ a la luz, 2.VIII.2019, 1 रे a la luz, 23.VIII.2019, 1 §, 1 ㅇ a la luz, F. Rodríguez (UCME), Adra, San Isidro Trebolar, $36^{\circ} 45^{\prime} 00^{\prime \prime} \mathrm{N}, 3^{\circ} 01^{\prime} 00^{\prime \prime} \mathrm{O}, 20 \mathrm{~m}$, 12.IX.2018, 1 q a la luz, F. Rodríguez (UCME), El Ejido, Punta Entinas, $36^{\circ} 42^{\prime} \mathrm{N}, 2^{\circ} 42^{\prime} \mathrm{O}, 10 \mathrm{~m}, 1 . \mathrm{VII} .2019,1$ ते a la luz, F. Rodríguez, Fondón, $36^{\circ} 58^{\prime} 45^{\prime \prime} \mathrm{N}, 2^{\circ} 51^{\prime} 30^{\prime \prime} \mathrm{O}, 846 \mathrm{~m}, 1 . \mathrm{VIII} .2018,1$ ㅇ a la luz, F. Rodríguez (UCME), Los Albaricoques, 30SWF77, $120 \mathrm{~m}$, 20.VII.2005, 2 우 ex larva sobre Genista sphaerocarpa (UCME 37664, UCME 37665), citadas como 1 o, 1 ㅇ de Chrysopa nierembergi por Monserrat (2008: 181), Níjar, 30SWF78, $460 \mathrm{~m}$, 8.VII.1996, 1 § sobre Ceratonia siliqua (UCME 37663), citado como Chrysopa nierembergi por Monserrat (2008: 181), Rambla del Retamar, 36 $49^{\prime} 58^{\prime \prime} \mathrm{N}, 2^{\circ} 18^{\prime} 53^{\prime \prime} \mathrm{O}, 10 \mathrm{~m}, 14$. VI.1992, 1 q (UCME 44292), Rambla de Morales, 30SWF6774, 55 m, 23.VII.1991, 1 §ै (UCME 37670) citado como Chrysopa nierembergi por Monserrat \& Rodrigo (1992: 127), Rambla del Retamar, $36^{\circ} 49^{\prime} 58^{\prime \prime} \mathrm{N}, 2^{\circ} 18^{\prime} 53^{\prime \prime} \mathrm{O}, 10 \mathrm{~m}, 11 . \mathrm{VII} .2014,1 q$ a la luz, F. Acevedo (UGR), San José, Playa de Mónsul, 3643'49.36”N, $2^{\circ}$ 9'23.27'O, 30SWF76, 12 m, 28.VI.2011, 1 ㅇ a la luz (UCME 37662), citada como Chrysopa nierembergi por Monserrat et al. (2014: 19), Sierra de Adra, $36^{\circ} 45^{\prime} 00^{\prime \prime} \mathrm{N}, 3^{\circ} 01^{\prime} 00^{\prime \prime} \mathrm{O}, 200$ m, 10.VII.2014, 1 ô a la luz (UCME), F. Acevedo. Madrid: Torrejón de Ardoz, 15.IX.1984, 1 §, leg.? (UCME 37659), citado como Chrysopa nierembergi por Monserrat \& Díaz-Aranda

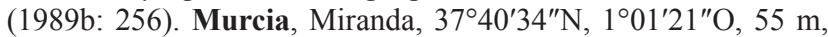
24.VI.1982, 1 ऊै, 1 ㅇ sobre Ceratonia siliqua (UCME-38263 / UCME 38264), San Pedro del Pinatar, 37 50'11" N, 047'19"O, 15 m, 16.VI.1982, 1 § , 1 ㅇ sobre Pinus halepensis (UCME-38248 / UCME 38249). Zaragoza: Pina de Ebro, Retuerta de Pina, 30TYL29, 400 m, 1.IX.1990, 1 ô, 25.VI.1993, 2 웅, 10.IX.1993, 1 ㅇ, a la luz, J. Blasco (UCME), citados como Chrysopa nierembergi por Monserrat (2008: 182).

Parte del material previamente citado por nosotros como Chrysopa nierembergi pertenece, en realidad, a la especie que ahora nos ocupa, este tema se tratará y discutirá seguidamente al hablar de esta especie y ahora corregimos las citas erróneas que han podido ser revisadas.

Especie paleártica, marcadamente eurioica. Está mayoritariamente citada entre los meses de V-IX, por 


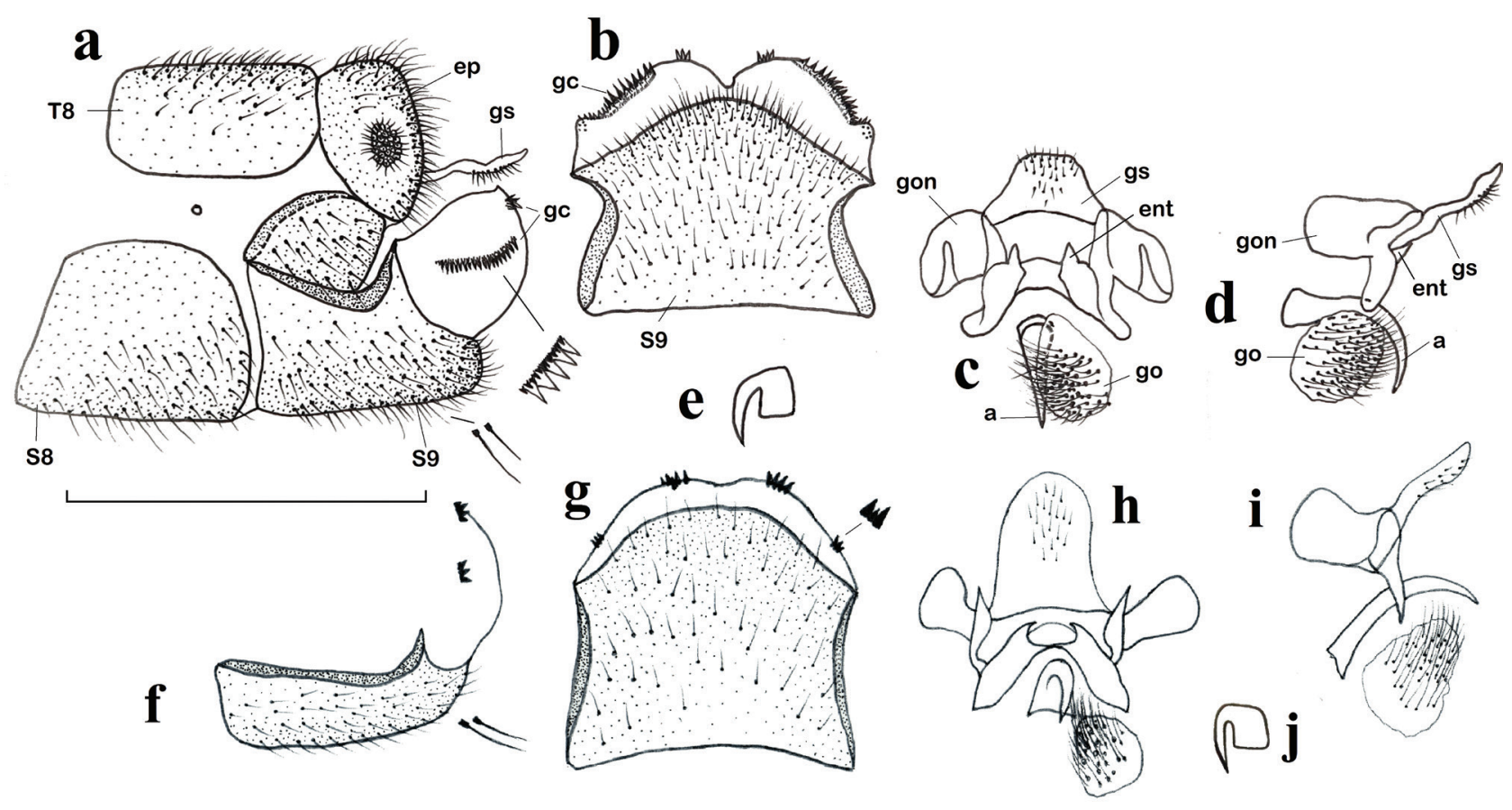

Fig. 2.- a-e: Chrysopa formosa, $\widehat{\partial}$. a: extremo abdominal, vista lateral (aumentadas dos setas y gonocristas), b: noveno esternito, vista ventral, c: complejo gonarco-entoprocesos-arceso-gonosaco-gonosetas, vista dorso-caudal, d: ídem, vista lateral, e: uña. - f-j: Chrysopa nitens Navás, 1909 stat. prom., ô: f: noveno esternito y gonocristas, vista lateral (aumentadas dos setas), g: noveno esternito, vista ventral (aumentadas gonocristas), h: complejo gonarco-entoprocesos-arceso-gonosaco-gonosetas, vista dorso-caudal, i: ídem, vista lateral, j: uña (a: arceso, ep: ectoprocto, ent: entoproceso, gc: gonocrista, go: gonosetas, gon: gonarco, gs: gonosaco, S: esternito, T: terguito). Escala $1 \mathrm{~mm}$ para a-d, $\mathrm{f}-\mathrm{i}$.

Fig. 2.- Chrysopa formosa, $\delta$. a: abdominal apex, lateral view (two setae and gonocristae magnified), b: ninth sternite, ventral view, c: complex gonarcus-entoprocessus-arcessus-gonosetae, dorso-caudal view, d: ditto, lateral view, e: claw. f-j: Chrysopa nitens Navás, 1909 stat. prom., ô: f: ninth sternite and gonocristae, lateral view (two setae magnified), g: ninth sternite, ventral view (gonocristae magnified), h: complex gonarcus-entoprocessus-arcessus-gonosetae, dorso-caudal view, i: ditto, lateral view, j: claw (a: arcessus, ep: ectoproct, ent: entoprocessus, gc: gonocristae, go: gonosetae, gon: gonarcus, gs: gonosaccus, S: sternite, T: tergite). Scale for a-d, f-i: $1 \mathrm{~mm}$.

lo que varias generaciones se suceden, en altitudes de 10 hasta $2.000 \mathrm{~m}$. Parece demostrado que hiberna en fase de prepupa (Aspöck et al., 1980).

Ampliamente citada en la fauna ibérica, incluyendo Baleares (Mallorca, Ibiza, Formentera, Menorca), donde presenta una clara tendencia a zonas extra-eurosiberianas (Fig. 12e), ha sido citada en medios muy diversos, frecuentemente mediterráneos sobre encinas, sauces, algarrobos, almendros, cítricos, acacias, también castaños, coníferas, arbustos (Genista, Nerium, Tamarix, Atriplex, Chenopodium, Arenaria, Minuartia, etc.), hierbas, hiedras, juncos, helechos, etc., mayoritariamente entre los meses de IV-X, aunque existen capturas que sugieren su actividad todo el año, al menos en zonas peninsulares más meridionales (meses de I, III, XII), en altitudes que oscilan entre 10-1.750 m.

Estadios preimaginales descritos por Schneider (1851), Pariser (1919), Principi (1947), Tsukaguchi (1978) y Monserrat \& Díaz-Aranda (2012). Descripciones más someras, basadas en la coloración tegumentaria, han sido realizadas por Gepp (1983) y Pantaleoni (1983).
Chrysopa dubitans Mclachlan, 1887

Figs. 3a-f, 5c, 12b)

Nuevo material estudiado. ESPAÑA: Alicante, Orihuela, 38 5'5.39'N 0 $^{\circ} 56^{\prime} 38.44^{\prime \prime} \mathrm{O}, 30 \mathrm{~m}, 1933$, 1 ej. sin abdomen, J. Andreu (MNCN-Ent 199599), 1933, 1 ㅇ, J. Andreu (MNCNEnt 199597). Almería, Adra, $36^{\circ} 45^{\prime} 00^{\prime \prime} \mathrm{N}, 3^{\circ} 01^{\prime} 00^{\prime \prime} \mathrm{O}, 20$ m, 19.VII.1988, 1 , a la luz (UCME 38435) (citada como Chrysopa phyllochroma por Monserrat \& Díaz-Aranda, 1989b: 254), 2.VIII.2019, 2 đิ ô a la luz, F. Rodríguez (UCME), Carboneras, Playa del Algarrobico, $37^{\circ} 00^{\prime} 02^{\prime \prime} \mathrm{N}, 1^{\circ} 53^{\prime} 31^{\prime \prime} \mathrm{O}$, 10 m, 25.VII.1983, 1 ㅇ a la luz (UCME 38436) (citada como Chrysopa phyllochroma por Monserrat, 1987: 137), El Ejido, Punta Entinas, $36^{\circ} 42^{\prime} \mathrm{N}, 2^{\circ} 42^{\prime} \mathrm{O}, 10 \mathrm{~m}, 22$.VII.2018, 2 ๙े $\mathrm{o}^{\prime}$, 2 우우 a la luz, 11.IV.2019, 1 $\widehat{\delta}, 3$ 우우 a la luz, 3.V.2019, 1 추 a la luz, 6.V.2019, 1 $\hat{\mathrm{d}}$ a la luz, 3.VI.2019, $14 \hat{\delta} \hat{\delta}, 7$ 우 a la

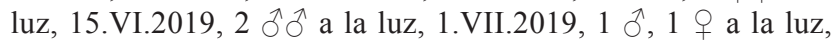
25.VII.2019, 1 ते, 1 ㅇ a la luz, F. Rodríguez (UCME 44208, 44209, 44210, 44211), San José, Playa de Mónsul, 36 45'28"N, $2^{\circ} 06^{\prime} 34^{\prime \prime} \mathrm{O}, 10 \mathrm{~m}, 14 . \mathrm{VI} .2012,1$ क sobre Nerium holeander (UCME 45375) (citada como Chrysopa phyllochroma por Monserrat et al., 2014: 6), Tabernas, $\mathrm{S}^{\mathrm{a}}$. Alhamilla, $36^{\circ} 59^{\prime} 20^{\prime \prime} \mathrm{N}$, $2^{\circ} 21^{\prime} 05^{\prime \prime} \mathrm{O}, 470 \mathrm{~m}, 28 . V .2019,1$ ते, 1 ㅇ a la luz, F. Rodríguez (UCME). 

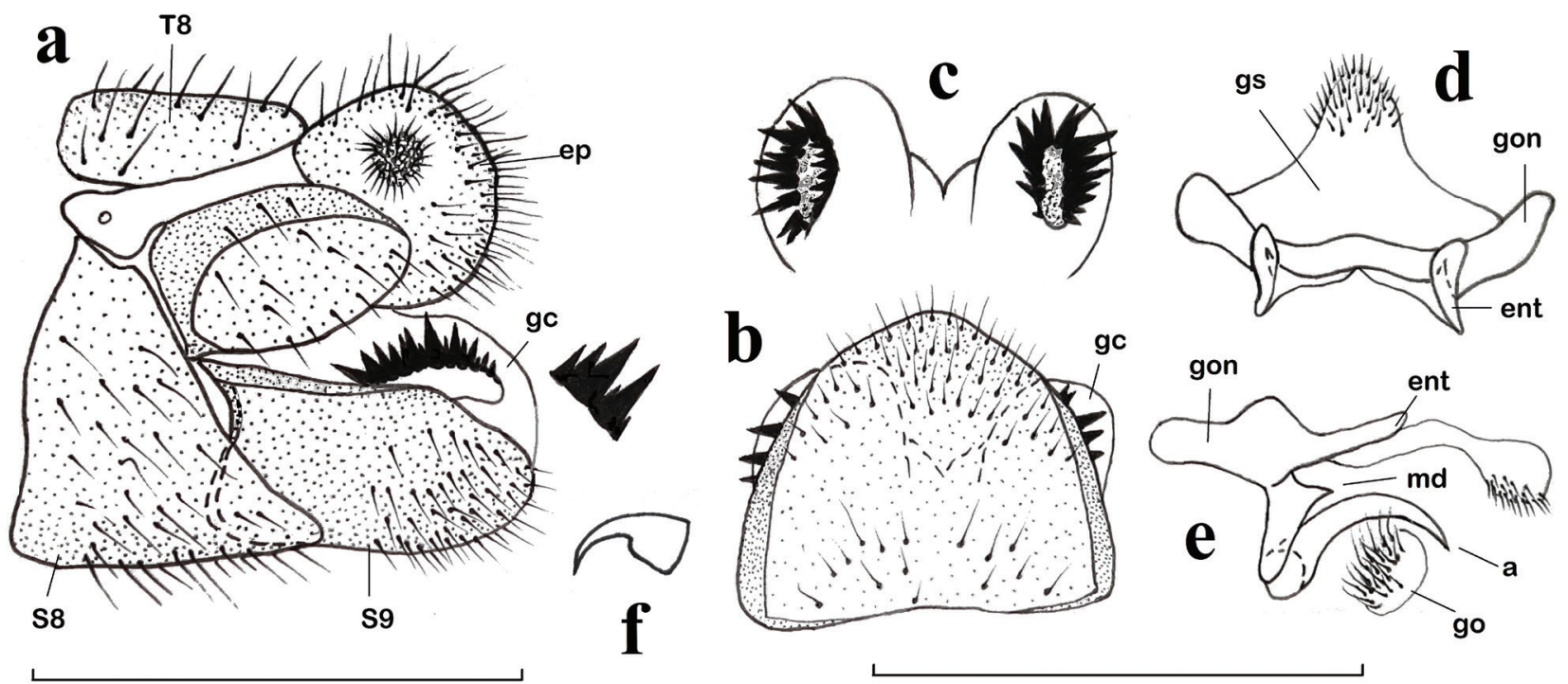

Fig. 3.- Chrysopa dubitans, $\widehat{\partial}$. a: extremo abdominal, vista lateral (gonocrista aumentada), b: noveno esternito y gonocristas, vista ventral, c: gonocristas, vista dorsal, d: complejo gonarco-mediuncos-entoprocesos-arceso-gonosaco, vista dorso-caudal, e: ídem, vista lateral, f: uña (a: arceso, ep: ectoprocto, ent: entoproceso, gc: gonocrista, go: gonosetas, gon: gonarco, gs: gonosaco, $\mathrm{md}$ : mediunco, S: esternito, T: terguito). Escala para a-e: $1 \mathrm{~mm}$.

Fig. 3.- Chrysopa dubitans, $\widehat{o}$ : a: abdominal apex, lateral view (gonocristae magnified), b: ninth sternite and gonocristae, ventral view, c: gonocristae, dorsal view, d: complex gonarcus-mediuncus-entoprocessus-arcessus-gonosaccus, dorso-caudal view, e: ditto, lateral view, f: claw (a: arcessus, ep: ectoproct, ent: entoprocessus, gc: gonocristae, go: gonosetae, gon: gonarcus, gs: gonosaccus, md: mediuncus, S: sternite, T: tergite). Scale for a-e: $1 \mathrm{~mm}$.

TAYIKISTÁN: Badajshán: Pamir, 25.VI.1979, 1 ô, A. V. Zakharenko (UCME 38434, 44207).

Especie eremial, esencialmente asiática (Anatolia, Cáucaso, Irán, Afganistán, Pakistán, Turkmekistán, Usbekistán, Kasachstán, Tadschijistán, Kirgisistán, Mongolia y China) y aparentemente rara en Europa, citada de Rusia, también sureste de España, este y sur de Francia (Lorraine y con ciertas dudas Bouches-duRhone) y Rumanía, y especialmente del Mediterráneo oriental (Grecia, Chipre, Creta, Israel, Palestina, Anatolia y Líbano), también del norte de África (Argelia) (Hölzel \& Ohm, 1972; Aspöck et al., 1980, 2001; Neuenschwander et al., 1981; Canard, 2001; Canard \& Jacquemin, 2006; Canard et al., 2007).

De biología esencialmente desconocida, esta especie probablemente esté asociada a medios esteparios con vegetación escasa y baja, posiblemente sobre vegetación herbácea, a veces frutales (Canard com. per.), y está citada entre los meses de IV-IX, en altitudes de hasta $2.000 \mathrm{~m}$. Parece demostrado que hiberna en fase de prepupa (Aspöck et al., 1980). No conocemos que la larva haya sido descrita.

Por la problemática existente en las citas de nuestra fauna, anotamos, discutimos y corregimos ahora nuevos elementos, antes de definir y anotar sus datos reales en nuestra fauna.

La única cita concreta de esta especie en nuestra fauna fue dada por Hölzel \& Ohm (1972: 130, 142, 144) en Murcia, N.E. Totana (estimamos c. 270 m),
13.VI.1963 (3 ejemplares en campos de alfalfa irrigados en un paisaje estepario), cita que ha generado varias referencias posteriores en la fauna ibérica (ver Monserrat et al., 2014 y Monserrat, 2016).

Aunque es cierto que varias especies presentan similar distribución en zonas eremiales del Paleártico occidental que alcanzan el S.E. peninsular, esta cita había sido puesta en duda en varias ocasiones, y recientemente Monserrat \& Díaz-Aranda (2012), Monserrat \& Triviño (2013), Monserrat et al. (2014) y Monserrat (2016) mantenían ciertas reservas sobre esta cita, ya que ha sido precisamente esta zona una de las más intensamente muestreada por nosotros durante décadas (Monserrat, 1984, 1985a, 1987; Díaz-Aranda \& Monserrat, 1988a, 1988b; Monserrat \& Díaz-Aranda, 1989a, 1989b; Marín \& Monserrat, 1991; Monserrat \& Rodrigo, 1992; Monserrat \& Marín, 1994, etc.), y nunca más se ha hallado, y estos autores se reservaban la autenticidad de la identificación, a la espera de que nuevos datos nos la confirmaran.

Tras el nuevo estudio de estos ejemplares, anteriormente citados por nosotros como Chrysopa phyllochroma (Monserrat, 1987: 137; Monserrat \& Díaz-Aranda, 1989b: 254 y Monserrat et al., 2014: 6) de Almería, en base a ejemplares hembras, comprobamos y corregimos las identificaciones y asignamos estos ejemplares de Almería a Chrysopa dubitans. También, damos por válida la cita de Chrysopa dubitans de Totana (Murcia) dada por Hölzel \& Ohm (1972), si bien, aunque solicitados para su estudio, 
no han sido localizados los ejemplares citados en el Naturhistorisches Museum de Viena, según nos comunican de esta institución, donde podrían permanecer, ya que en este museo se custodia gran parte de la colección de H. Hölzel. También, con cierto margen de duda, asignamos a esta especie las citas de los ejemplares de Granada (Carretera del Veleta, 2.VI-8. VII.1962) citados como Chrysopa phyllochroma por Hölzel \& Ohm (1972), hecho que es más acorde con la biología y la distribución de ambas especies (Figs. $12 \mathrm{a}-\mathrm{b})$. Ante esta situación, y por similitud entre algunas especies de este género, es probable que algunas de las citas antiguas de Chrysopa en esta zona del sudeste ibérico pudieran pertenecer, en realidad, a la especie que estamos tratando.

Sobre este tipo de errores de identificación (o de interpretación), es el momento de comentar nuestro punto de vista alguno de los caracteres morfológicos más utilizado en la identificación de las especies de esta familia, y sin duda en el género Chrysopa. En cuanto a la pigmentación externa, es conocido que puede variar en función de la variabilidad en las poblaciones o la edad del individuo, así como con el tiempo trascurrido desde su captura, especialmente en los ejemplares conservados en seco, y ejemplo tenemos en el color amarillo-anaranjado en la cabeza de los ejemplares vivos, que se diluye y torna a más verdoso en ejemplares en seco hace décadas recolectados (Figs. 6-7). Pero, al margen de esto, nos referimos a la morfología de un carácter permanentemente utilizado: "uñas dilatadas o no en su base". A parte de la dificultad de que, en ocasiones, puede ofrecer su visualización sin aclarar el tarso, el margen de error a la hora de definirse ante este carácter no presenta dudas entre especies con base "abruptamente dilatadas" (Figs. 2e, $\mathrm{j}$, 4f) (habitualmente citadas como "uñas dilatadas en su base") y "progresivamente dilatadas" (Fig. 1e) (habitualmente citadas como "uñas no dilatadas en su base"), pero es más difícil de interpretar (y más subjetivo) en especies con una morfología más o menos intermedia (Fig. 3f). Consideramos que el término "uñas dilatadas / no dilatadas en su base" se presta a interpretación y a errores en la identificación de las especies, pues en realidad todas las uñas en las especies de esta familia de neurópteros (y de las demás) están "dilatadas en su base" y mejor debería utilizarse "uñas abruptamente dilatadas en su base" (parecido a Figs. 2e, j, 3f, 4f), y posteriormente indicar qué tipo de dilatación presenta (o qué tipo de ángulo forman sus márgenes internos o la longitud relativa de ambos márgenes) y "uñas progresivamente dilatadas hacia su base" (parecido a Fig. 1e).

Sobre esta especie, de morfología externa muy característica, y al margen de su escueta descripción original (McLachlan, 1887), conocemos 26 referencias bibliográficas, bien como Chrysopa dubitans, como Chrysopa (Chrysopa) dubitans o como Cintameva venulosa Navás, 1914, que aportan datos sobre su morfología, biología o distribución, pero solo hemos hallado tres referencias en las que se describe su morfología genital, bien masculina, femenina o ambas (Tjeder, 1937: 27, pl. XIV; Şengonca, 1980: 62 y Canard \& Jacquemin, 2006: 484). Los ejemplares ibéricos ahora estudiados, se ajustan a lo conocido en la morfología externa de esta especie, y tanto los machos en su genitalia como las hembras en su genitalia externa y espermateca se ajustan a lo anotado por Tjeder (1937) para esta especie, así como a otro material centroasiático de comparación estudiado (Fig. 3).

Ahora aportamos datos sobre su morfología y pigmentación cefálica y sus uñas en base a material ibérico (obsérvese la ausencia de manchas oscuras sobre el clípeo y las proporcionalmente grandes y brillantes manchas presentes sobre las genas) y sobre su genitalia masculina, que pueda servir de comparación para futuros ejemplares recolectados en nuestra fauna (Figs. 3a-f, 5c), y confirmada su presencia en ella, se mantiene en la clave de Monserrat (2016) para las especies ibéricas del género Chrysopa que anotamos actualizada más adelante.

En base a los ejemplares ahora estudiados, sobre la biología de esta especie en nuestra fauna, parece asociada a zonas xéricas de carácter mediterráneo, saladares, estepas y sabinares térmicos, frecuentemente de baja o media cota (mayoritariamente recolectada entre 10-30 m), entre los meses de VI-VII, lo que sugiere un ciclo monovoltino en nuestra fauna.

\section{Chrysopa nierembergi Navás, 1908}

Figs. 4, 5f, 6, 7a-b, 8c, 9-10, $12 \mathrm{f}$

Nuevo material estudiado. ESPAÑa: Alicante: Orihuela, $38^{\circ} 05^{\prime} 08^{\prime \prime} \mathrm{N}, 0^{\circ} 56^{\prime} 49^{\prime \prime} \mathrm{O}, 25 \mathrm{~m}, 1925,1$ ㅇ, leg.?, (UCME), Rojales, $38^{\circ} 05^{\prime} 19^{\prime \prime} \mathrm{N}, 0^{\circ} 43^{\prime} 25^{\prime \prime} \mathrm{O}, 10 \mathrm{~m}, 11 . \mathrm{VI} .1909,1$ ej. $\sin$ abdomen (MZB): / Ch. Nierembergi v. Andreui Nav. Rojales (A.) 11.Jun.1909 / Typus / Chrysopa nierembergi var. andreui Navás, 1910 Lectotipo V. J. Monserrat \& R. A. Pantaleoni des. / 71-2547 MZB/ (Fig. 6c), 11.VI.1909, 1 o (MZB): / Ch. Nierembergi v. clara Nav. Navás S. J. det. / Rojales (A1.) 11.Jun.1909 / Typus / Chrysopa nierembergi var. clara Navás, 1915 Lectotipo V. J. Monserrat \& R. A. Pantaleoni des. / 71-2548 MZB/ (Fig. 6 b), 22.VI.1908, $1 \curvearrowright$, Andreu, 71-9470 MZB (Figs. 9 d-f). Almería: Adra, $36^{\circ} 45^{\prime} 00^{\prime \prime} \mathrm{N}, 3^{\circ} 01^{\prime} 00^{\prime \prime} \mathrm{O}, 20 \mathrm{~m}, 8$.VI.2019, 1 오 a la luz, F. Rodríguez (UCME), El Ejido, Punta Entinas, $36^{\circ} 42^{\prime} \mathrm{N}$, $2^{\circ} 42^{\prime} \mathrm{O}, 10 \mathrm{~m}, 23 . I I I .2019,1$ q a la luz, 6.V.2019, 1 क a la luz, 3.VI.2019, 1 a la luz, F. Rodríguez (UCME). Málaga: Málaga, 12.VII.1902, 1 đ (MZB): / Chrysopa Nierembergi N. (Málaga) 12 Jul.1902 / Typus/ Abdomen boiled in $\mathrm{KOH}$ preserved in glycerine rev. H. Hölzel 1973 Chr. nierembergi Navas / Chrysopa nierembergi Navás, 1908 Lectotipo V. J. Monserrat \& R. A. Pantaleoni des. / 71-2546 MZB/ (Figs. 6a, 10), 27.VI.1902, 1 ㅇ (MZB) / Chrysopa / Nierembergi Nv / (Málaga) / 27 Jun. 1902 / Chrysopa nierembergi Navás, 1908 Paralectotipo V. J. Monserrat \& R.A. Pantaleoni des. / 71-9469 MZB /. Murcia: Sierra Espuña,

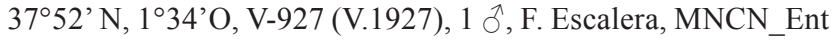
199600 (MNCN) (Figs. 7a-b, g), 1 ô, F. Escalera, MNCN Ent 223660 (MNCN) (Fig. 7h), 1 ㅇ, F. Escalera, MNCN_Ent 223659 (MNCN). 


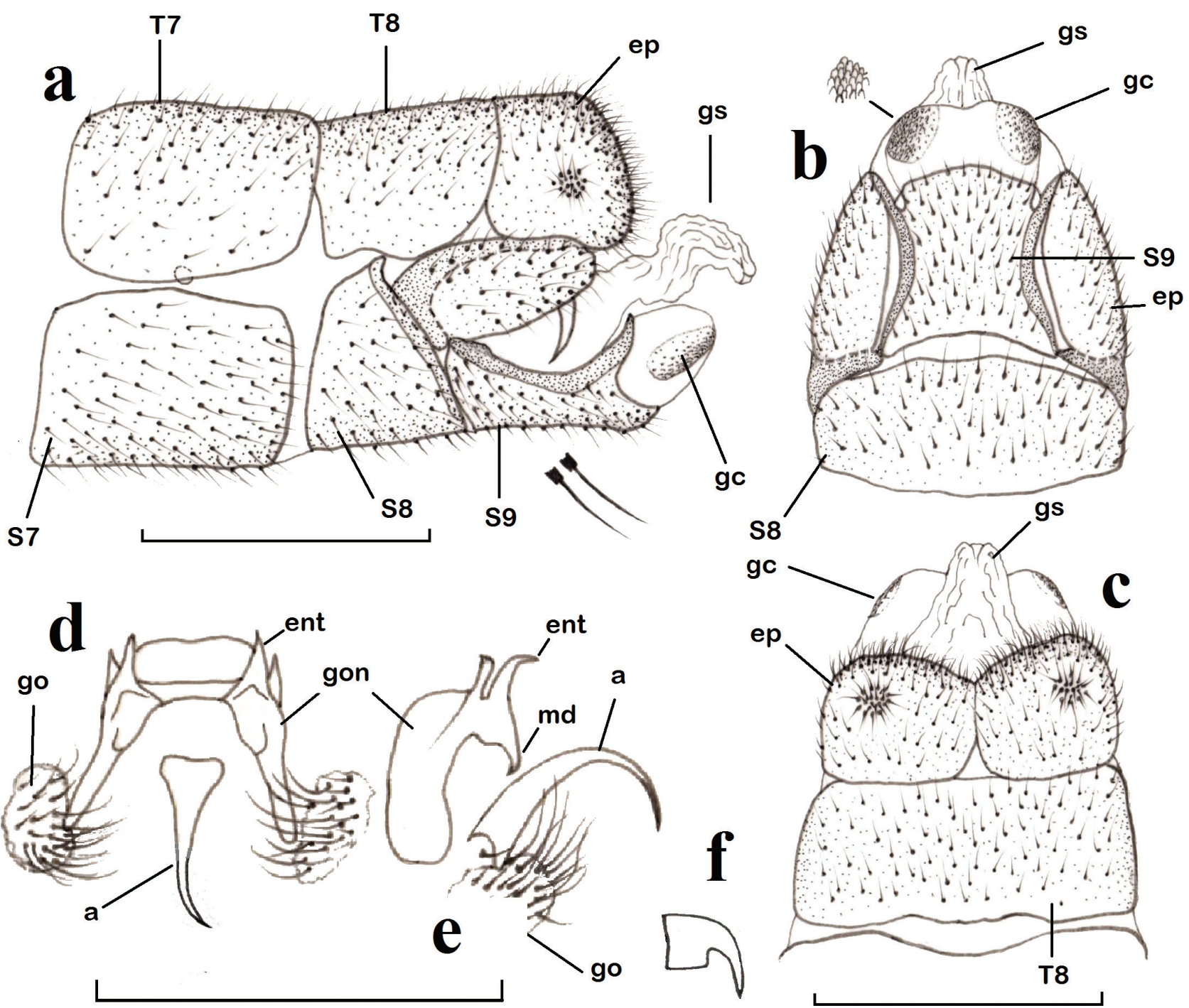

Fig. 4.- Chrysopa nierembergi, ô. a: extremo abdominal, vista lateral (aumentadas dos setas), b: ídem, vista ventral (aumentadas gonocristas), c: ídem, vista dorsal, d: complejo gonarco-mediuncos-entoprocesos-arceso, vista dorso-caudal, e: ídem, vista lateral, f: uña. (a: arceso, ep: ectoprocto, ent: entoproceso, gc: gonocrista, go: gonosetas, gon: gonarco, gs: gonosaco, md: mediunco, S: esternito, T: terguito). Escala para a-e: $1 \mathrm{~mm}$.

Fig. 4.- Chrysopa nierembergi, ô: a: abdominal apex, lateral view (two setae magnified), b: ditto, ventral view (gonocristae magnified), c: ditto, dorsal view, d: complex gonarcus-mediuncus-entoprocessus-arcessus, dorso-caudal view, e: ditto, lateral view, f: claw. (a: arcessus, ep: ectoproct, ent: entoprocessus, gc: gonocristae, go: gonosetae, gon: gonarcus, gs: gonosaccus, md: mediuncus, S: sternite, T: tergite). Scale for a-e: $1 \mathrm{~mm}$.

Especie ibérica de biología prácticamente desconocida, muy poco citada y en ocasiones cuestionada. De esta especie se conocen solo 21 referencias bibliográficas antiguas, en su mayoría reiterativas:

Chrysopa nierembergi Navás, 1908a: 401; 1908b: 108, 114; 1915a: 76. - Andréu, 1909: 161.

Cintameva nierembergi (Navás, 1908): Navás, 1924: 162; 1925: 76; 1927: 97.

Chrysopa nierembergi var. nitens Navás, 1909b: 150; 1915a: 77; 1919: 199.

Chrysopa nierembergi var. andreui Navás, 1910: 38; 1915a: 76. Chrysopa nierembergi var. clara Navás, 1915a: 77.

Cintameva nierembergi var. nitens (Navás, 1909): Navás, 1924: 163; 1925: 77.

Cintameva nierembergi var. andreui (Navás, 1910): Navás, 1924: 163; 1925: 77. - Vidal y López, 1943: 21.
Cintameva nierembergi var. clara (Navás, 1915): Navás, 1924: 163; 1925: 77. - Vidal y López, 1943: 21.

Hemos anotado ahora las citas anteriores a Hölzel \& Ohm (1972), las posteriores fueron recopiladas por Monserrat (2016), aunque tampoco recientemente ha sido una especie muy citada y menos aún con nuevos ejemplares (Hölzel \& Ohm, 1972; Hölzel, 1973a; Aspöck et al., 1980, 2001; Díaz-Aranda et al., 1986; Monserrat \& Rodrigo, 1992; Monserrat \& DíazAranda, 1989b, 2012; Marín \& Monserrat, 1995; Monserrat, 2008, 2016; Monserrat et al., 2014).

En base a los datos existentes en la bibliografía, esta especie y sus variedades han sido mayoritariamente circunscrita a la zona litoral y continental de la región mediterránea peninsular, con alguna cita aislada en la 

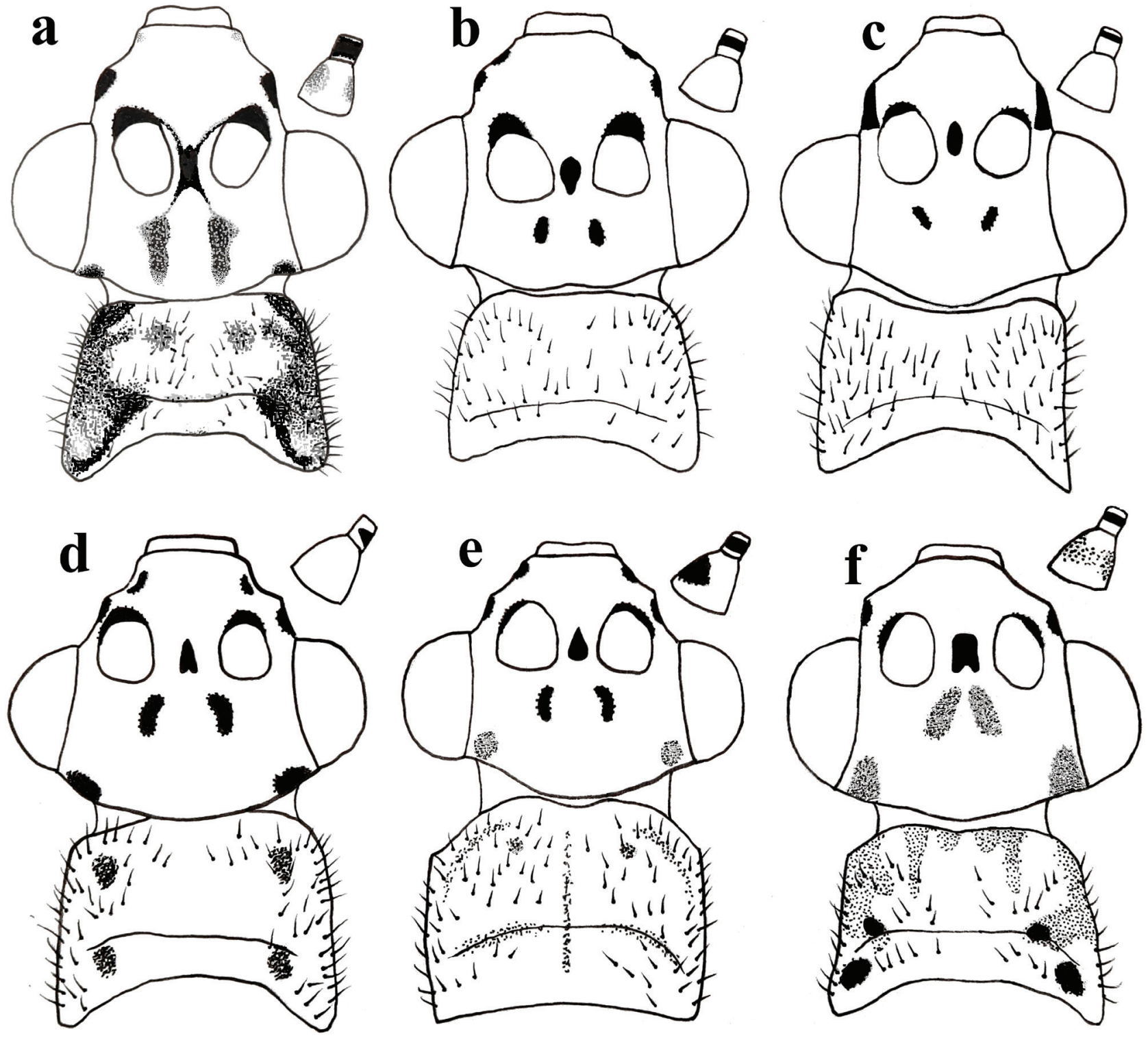

Fig. 5.- Cabeza, pronoto, escapo y pedicelo, vista dorsal de Chrysopa spp.: a: C. nitens Navás, 1909 stat. prom.; b: C. formosa, c: C. dubitans, d: C. phyllochroma, e: C. commata, f: C. nierembergi.

Fig. 5.- Head, pronotum, scape and pedicel, in dorsal view of Chrysopa spp. a: C. nitens Navás, 1909 stat. prom.; b: C. formosa, c: C. dubitans, d: C. phyllochroma, e: C. commata, f: C. nierembergi.

zona atlántica (Albacete, Alicante, Almería, Castellón, Granada, Guadalajara, Málaga, Madrid, Tarragona, Teruel, Zaragoza en España y San Fiel en Portugal), con imagos mayoritariamente recolectados a la luz entre los meses de V-IX, desde 10 a $1.410 \mathrm{~m}$, sus larvas no han sido descritas, pero han sido citadas sobre pinos, Genista sphaerocarpa y sus imagos sobre Ceratonia siliqua (Monserrat, 2016). Ahora hemos corregido parte de esta información y la actualizamos más adelante.

Sobre su relación con Chrysopa formosa es evidente que, aparentemente, los ejemplares típicos de Chrysopa nierembergi y de Chrysopa formosa se diferenciaban inicialmente sin problema en base a caracteres de pigmentación tegumentaria (especialmente cabeza y escapo amarillos-naranja y no verde, tergo torácico con manchas oscuras laterales extensas y no, y cuando existen, solo sombras o pequeños pares de puntos oscuros, etc.), sin embargo a veces estos caracteres no están suficientemente definidos en otros muchos ejemplares y quizás puedan depender de la edad/ madurez de los ejemplares y sin duda están sometidos a la variabilidad de las poblaciones, y en numerosos casos las identificaciones pueden ser dudosas y subjetivas. De hecho en más de una ocasión nos ha hecho dudar sobre su identidad y sobre la validez de Chrysopa nierembergi respecto a C. formosa (Monserrat \& Díaz-Aranda, 2012, Monserrat \& Triviño, 2013, Monserrat et al., 2014), así como de nuestras propias identificaciones y citas, algunas de las cuales ahora se han rectificado (ver material estudiado de $C$. formosa y $C$. nitens). Ya Aspöck et al. (1980) citaban que el margen de variabilidad de esta especie era desconocido, y que la gran similitud 
y la estrecha relación entre ambas especies (Chrysopa nierembergi y C. formosa) requería una verificación genital en especímenes atípicos. También Monserrat (2016) citaba sus reservas sobre la validez de esta especie respecto a Chrysopa formosa, manteniéndose a la espera de nuevos datos. Problemática que ahora resolvemos.

La única referencia sobre la genitalia masculina de esta especie fue dada por Hölzel (1973a), en base al ejemplar tipo. Si bien aporta interesantes datos descriptivos de su morfología externa, coloración tegumentaria, no nos parecen suficientes los aportados sobre su genitalia, sea externa o interna. Por ello, en base al material tipo existente, bien de la forma tipo: Chrysopa nierembergi y de dos de sus variedades descritas: Chrysopa nierembergi andreui, Chrysopa nierembergi clara (Fig. 6), así como todo el material disponible ya citado o no, hemos tratado de dilucidar los caracteres más definitorios (morfología y pigmentación externa y genitalia masculina) entre ambas especies y su variabilidad, así como la de estas dos variedades ahora citadas.

En relación a ambas especies (Chrysopa nierembergi + estas dos variedades y C. formosa) (Figs. 6, 7a-b, 8a, c, 9-10), y dejando para más adelante la identidad de la tercera variedad de $C$. nierembergi: Chrysopa nierembergi var. nitens, ahora hemos encontrado nuevos elementos de setación, coloración y pigmentación tegumentaria y alar (Figs. 5b, f, 6, 7a-b, $8 \mathrm{a}, \mathrm{c}, 9)$ que, al margen de cierta variabilidad entre los ejemplares, se mantienen constantes en ambos sexos $\mathrm{y}$ en todos los ejemplares estudiados, así como algunas diferencias significativas en la genitalia masculina de ambas especies (Figs. 2a-e, 4, 10) que también se mantienen constantes y permiten diferenciar a los ejemplares sin dudas ni subjetivismos, por lo que la duda sobre la identidad de Chrysopa nierembergi respecto a $C$. formosa queda despejada.

Para una mejor diferenciación entre ejemplares de ambas especies ("típicos" o no), anotamos (según este quebrado: Chrysopa nierembergi / C. formosa) los caracteres que mejor permiten diferenciarlas: Respecto a su pigmentación: siempre cabeza amarillenta o anaranjada / normalmente verde, muy ocasionalmente más amarillenta en algunos ejemplares (Figs. 6, 7a-b) (puede disminuir la intensidad en ejemplares en seco hace tiempo recolectados); presencia de mancha oscura tras los ojos cerca del margen ocular / mayoritaria ausencia de esta mancha (Figs. 5b, f); manchas del vértex grandes, pardas y difusas / pequeñas, negras y bien delimitadas (Figs. 5b, f); sin mancha oscura sobre el lateral del clípeo / con ella (Figs. $5 \mathrm{~b}, \mathrm{f}$ ); escapo amarillo o anaranjado con manchas pardas en las zonas lateral externa e interna / verde, sin ellas (Figs. 5b, f); pronoto con dos marcadas manchas oscuras a cada lado y zonas pardas sobre sus márgenes laterales / sin ellas o, a veces, con pequeñas manchas circulares más oscuras de extensión variable en ocasiones formando tenues sombras laterales (Figs. $5 \mathrm{~b}, \mathrm{f}, 6,7 \mathrm{a}-\mathrm{b}, 9)$; región externa de los escleritos ventrales del meso y metatórax y zonas membranosa entre ellas oscuras / verdes, de similar color; meso y metaescutum con una amplia mancha semilunar pardo violácea oscura sobre sus márgenes posteriores que alcanzan la base alar / sin ellas (Figs. 6, 7a-b, 9); patas anteriores verdes con los extremos del fémur pardos / verdes; uñas abruptamente dilatadas en ambos casos, pero con el margen interno basal de menor longitud que la mitad del distal / similar a mitad del distal (Figs. 2e, 4f); longitud alas anteriores 12,0-13,5 mm / $14,0-15,0 \mathrm{~mm}$; setas costales largas e irregularmente orientadas / cortas, paralelas y curvadas hacia la costal (Figs. 8a, c); alas anteriores con venillas del campo costal verdes en su mitad anterior y negras en su mitad posterior / negras, solo puntualmente verdes en su contacto con la costal (Figs. 6, 7a-b, 8a, c, 9); vena Sc siempre ampliamente oscurecida en su margen anterior en el contacto con las venillas trasversales del campo costal / completamente verde, ocasionalmente oscurecida en este contacto (Figs. 8a, c); base de vena radial con una línea oscura en el arranque de $\mathrm{Mp} / \sin$ ella (Figs. 6, 7a-b); tras las bifurcaciones de las venas anales son verdes por un tramo antes de contactar con la costal / completamente oscuras (Figs. 6, 7a-b); alas posteriores con la primera venilla costal verde / negra (Figs. 6, 7a-b); zonas laterales de los tergos abdominales con dos tenues bandas longitudinales oscuras y pleuras oscuras / verdes (Figs. 6a, 9a, d-e). Un cuadro comparativo de estos caracteres externos se anota en la Tabla 1.

Respecto a su genitalia masculina destaca: la forma del octavo esternito en vista lateral triangular / semicircular (Figs. 2a, 4a); porción ventral del ectoprocto elíptica / triangular (Figs. 2a, 4a); noveno esternito estrecho y bifurcado caudalmente con proceso dorsal formando un ángulo agudo en el margen caudal / ancho y en ángulo obtuso (Figs. 2a, 4a); gonocristas muy pequeñas agrupadas en dos masas compactas / grandes agrupadas en dos hileras, mayor la más externa y menor la mediana (Figs. 2a-b, $4 \mathrm{a}-\mathrm{c}, 10$ ); gonosaco $\sin /$ con setas (Figs. 2a, c-d, 4a-c); aspecto de la genitalia interna (Figs. 2c-d, 4d-e), etc.

Definidas mejor ambas especies, parte de estos caracteres, los más reseñables y fáciles de observar, se utilizarán en la clave de especies ibéricas de este género que más adelante actualizamos.

A pesar de su decoloración debido al paso de más de cien años, estas características citadas se mantienen tanto en el ejemplar rotulado como tipo de Chrysopa nierembergi, como en los ejemplares tipo de Chrysopa nierembergi var. andreui y Chrysopa nierembergi var. clara que hemos estudiado (Fig. 6), así como los de genitalia masculina del ejemplar tipo (Figs. 6a, 10). También coinciden con el nuevo material que ahora hemos revisado y/o reestudiado, en algunos casos corrigiendo o descartando las anteriores 
a

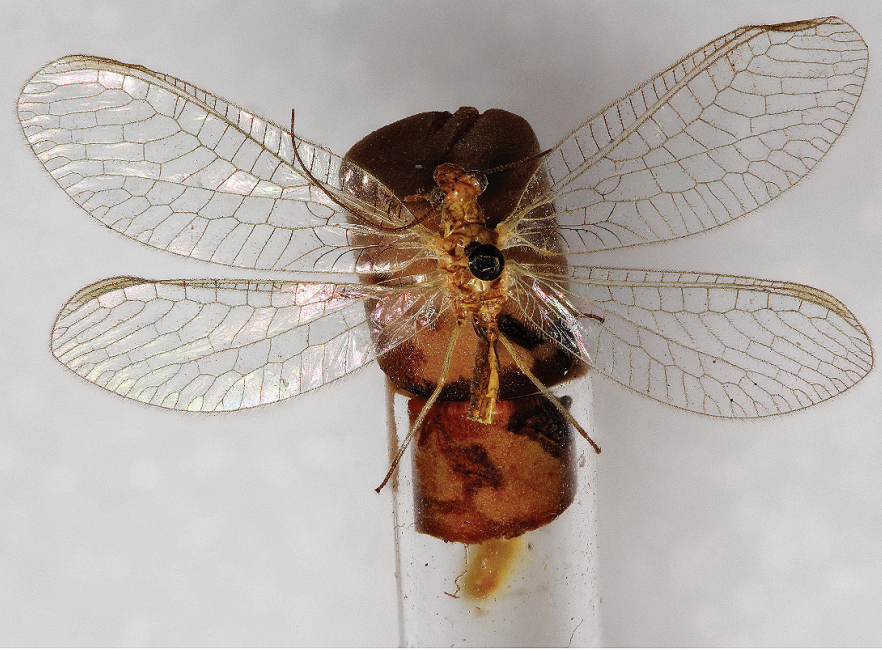

b

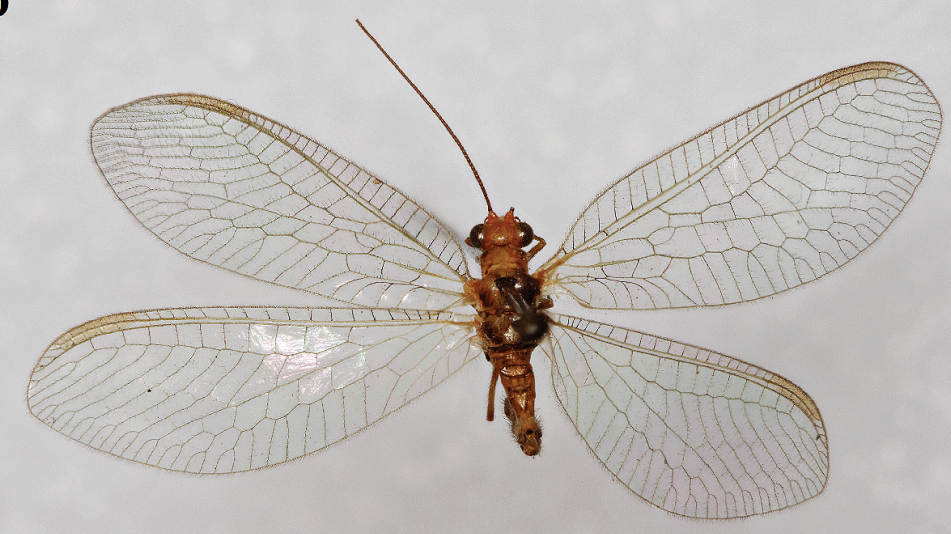

c

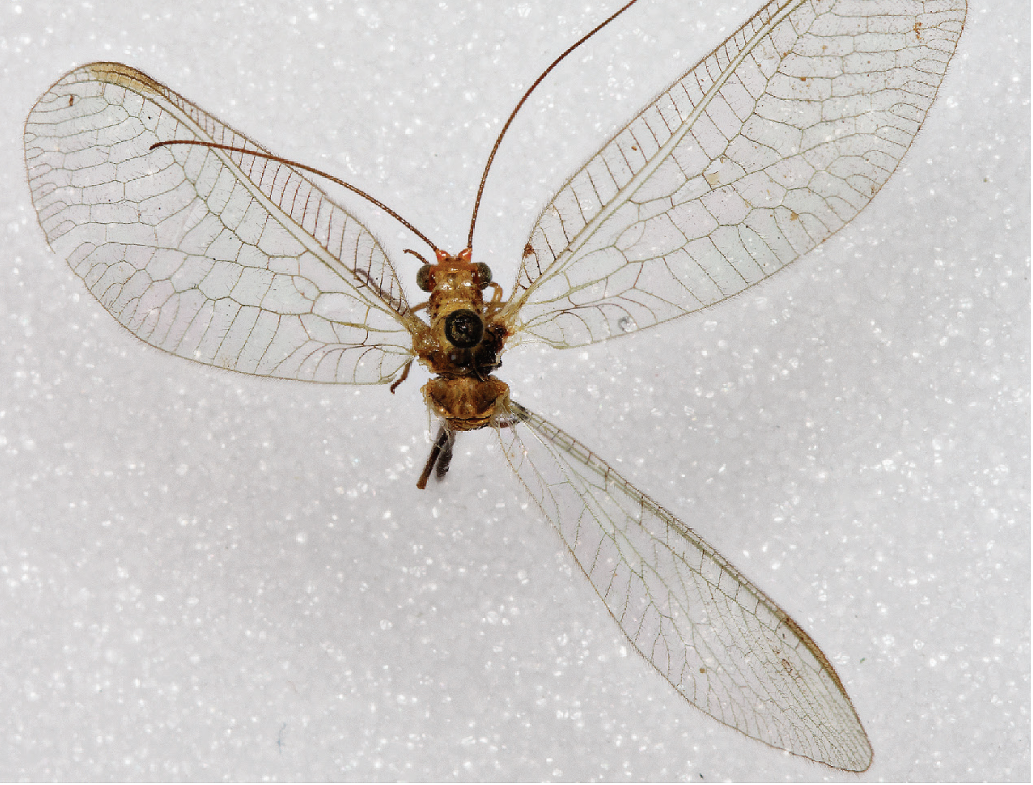

Chrysopa

Nicienulargi $N$.

$M$ alaga

i1. Jul. 1902

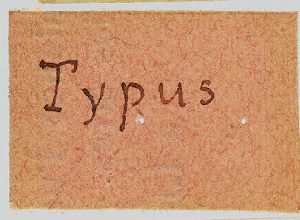

Abdomen bolled inkot

preserved in olycorine rev.H.holzed 1943. Navas

chr.hieremberg

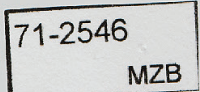

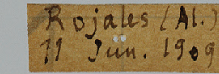

Ch. Nierembergi v. claráa Nar. Navás S.J. det.

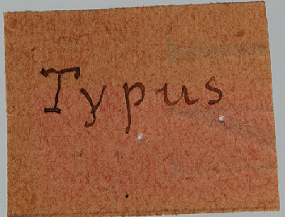

$71-2548$ MZB
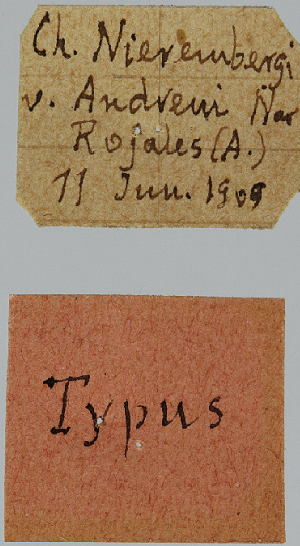

$71-2547$

Fig. 6.- Ejemplares tipo (ahora designados como Lectotipos) y etiquetas de: a: Chrysopa nierembergi Navás, 1908, b: Chrysopa nierembergi var. clara Navás, 1915, c: Chrysopa nierembergi var. andreui Navás, 1910 (fotos de S. Gago).

Fig. 6.- Type specimens (now designated as Lectopypes) and labels of: a: Chrysopa nierembergi Navás, 1908, b: Chrysopa nierembergi var. clara Navás, 1915, c: Chrysopa nierembergi var. andreui Navás, 1910 (photos by S. Gago). 


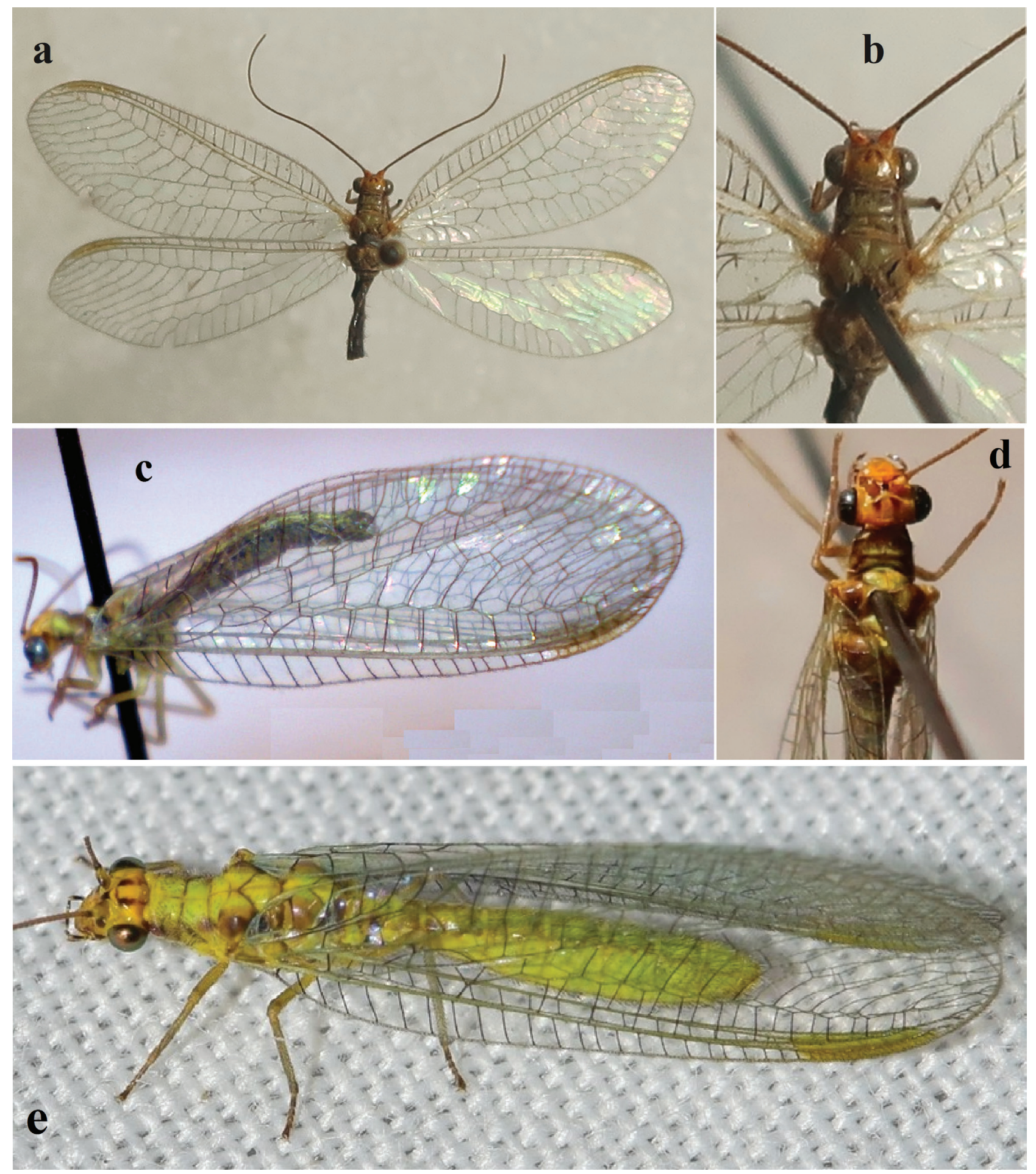

Fig. 7.- a-b: Chrysopa nierembergi, a: aspecto de un ejemplar ibérico, b: detalle de cabeza y tórax. - c-e: Chrysopa nitens Navás, 1909 stat. prom., c, e: aspecto de un ejemplar ibérico, d: detalle de cabeza y tórax (fotos a-d: de autores; e: de F. Rodríguez).

Fig. 7.- a-b: Chrysopa nierembergi, a: appearance of an Iberian specimen, b: detail of head and thorax, c-e: Chrysopa nitens Navás, 1909 stat. prom., c, e: appearance of an Iberian specimen, d: detail of head and thorax (photos a-d by authors; e: by F. Rodríguez).

identificaciones (ver material estudiado de C. formosa y de C. nierembergi var. nitens).

Definidas ambas especies, pasemos a comentar algunos elementos taxonómicos sobre estos ejemplares tipo, tanto de Chrysopa nierembergi como de Chrysopa nierembergi var. andreui y Chrysopa nierembergi var. clara (Fig. 6), ya que sobre ellos conviene realizar más de un comentario, dejando para más adelante el material de $C$. nierembergi var. nitens. 

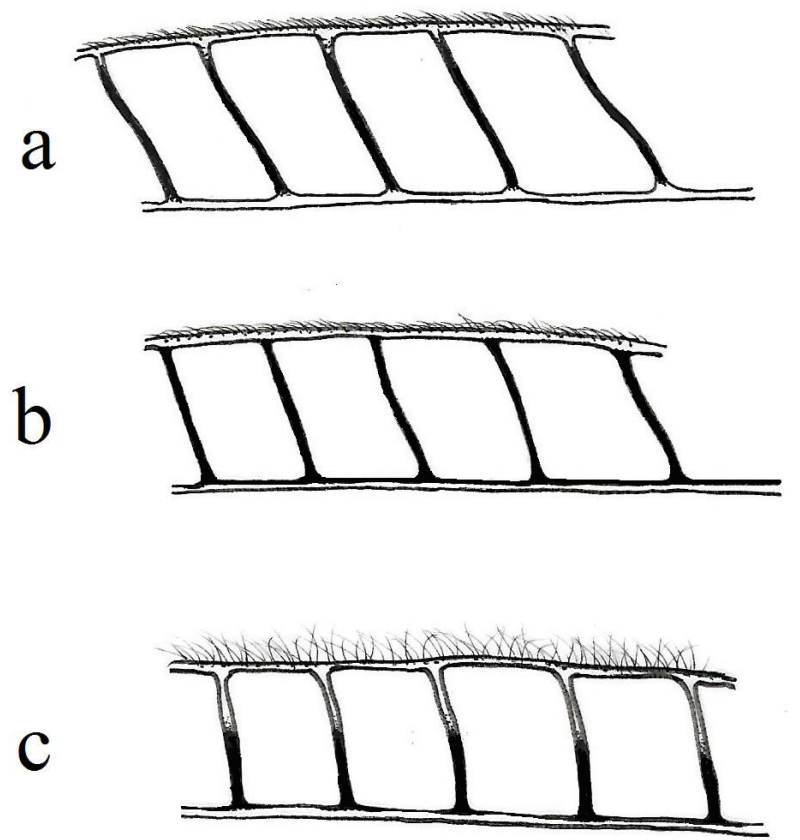

Fig. 8.- Esquema del campo costal del ala anterior en: a: Chrysopa formosa, b: Chrysopa nitens Navás, 1909 stat. prom., c: Chrysopa nierembergi.

Fig. 8.- Scheme of the costal field of the anterior wing in: a: Chrysopa formosa, b: Chrysopa nitens Navás, 1909 stat. prom., c: Chrysopa nierembergi.

Respecto al ejemplar rotulado como tipo de Chrysopa nierembergi (Fig. 6a) existente en el museo de Barcelona, citemos que porta las correspondientes etiquetas cuyos datos son, en parte, coincidentes con los anotados en la descripción original (ver material estudiado), según Navás (1908a: 402): "Patria. Cogida en Málaga, en junio, por el R. P. Alberto Risco S.J." (no se indica número de ejemplares, día o año de captura, ni depósito del ejemplar/es, pero se sugiere según lo anotado en la introducción: "Al revisar mi colección de Neurópteros...”), datos que, sin indicar la fecha, reitera en Navás (1908b: 114), apostillando (Col. m.) en Navás, 1915a: 76). Sin embargo añade un elemento confuso en Navás (1924: 162): "Málaga, 12 i 22 de juliol de 1900 (P. Alberto Risco, S.J.)", pues no coincide el mes con lo anotado en su descripción y teórica tipificación de la especie, abriendo la posibilidad que existiera más de un ejemplar (como así hemos comprobado), al margen de sugerir que habite en Cataluña: "Falta trobar-s'hi el tipus, que hi viu sens dubte". Por último Navás (1925: 76) solo indica: "Málaga", y también bastante confusa resulta la referencia a Cintameva nierembergi en Navás (1927: 97): "Orihuela. 2 ejemplares. Hasta ahora esta especie sólo se ha encontrado en la provincia de Alicante" ( $i$ !), cuando Orihuela está en la provincia de Alicante y él la describió y citó de la provincia de Málaga (quizás estuviera confundiéndose y se refiriera a las variedades de esta especie descritas de esta provincia de Rojales que citamos más adelante).
No deja de ser cansino e irritante la discordancia de datos en la desordenada obra de este autor, no solo respecto al número de ejemplares de la supuesta Serie Tipo y la correcta tipificación de la nueva especie, sino de las fechas de captura de los ejemplares. Sobre estas fechas en la bibliografía de Navás se menciona: en la descripción de la especie (Navás, 1908a: 402): "junio", y más adelante (Navás, 1924: 162): "12 i 22 de juliol de 1900", datos que no coinciden, y en el material conservado encontramos estos datos: en las etiquetas del ejemplar rotulado como tipo (71-2546 MZB) se indica "12 Jul. 1902" (Fig. 6a) (como 12.7.02 citaban Hölzel \& Ohm, 1972: 130), pero que no coincide con el mes que se anotaba en la descripción (Navás, 1908a: 402), y en el otro ejemplar (71-9469 MZB) (Figs. 9a-c) se indica "27 Jun. 1902" que coincide con el mes que se anotaba en la descripción (Navás, 1908a: 402), pero no coincide ni en el día, ni el mes, ni en el año de captura, que anota Navás (1924: 162).

Tras estudiar el material de su colección disponible comprobamos que, efectivamente, existen al menos dos ejemplares con estos datos de localidad de captura manuscritos por Navás ("Málaga") (71-2546 MZB y 71-9469 MZB) que, a pesar de su desorden, se corresponden con la Serie Tipo (Figs. 6a, 9a-c) y que citamos en el material estudiado de esta especie.

Ante esta situación consideramos a ambos ejemplares como Sintipos de Chrysopa nierembergi Navás, 1908, designando como Lectotipo al ejemplar: Málaga: Málaga, 12.VII.1902, 1 đ (MZB): / Chrysopa Nierembergi N. (Málaga) 12 Jul.1902 / Typus / Abdomen boiled in $\mathrm{KOH}$ preserved in glycerine rev. H. Hölzel 1973 Chr. nierembergi Navas / Chrysopa nierembergi Navás, 1908 Lectotipo V. J. Monserrat \& R. A. Pantaleoni des. / 71-2546 MZB/ (Figs. 6a, 10), quedando tras esta designación, automáticamente asignados como Paralectotipos los restantes ejemplares relacionados con la Serie Tipo, en este caso el ejemplar: Málaga: Málaga, 27.VI.1902, 1 ( (MZB): /Chrysopa / Nierembergi Nv / (Málaga) / 27 Jun. 1902/ Chrysopa nierembergi Navás, 1908 Paralectotipo V. J. Monserrat \& R.A. Pantaleoni des. / 71-9469 MZB/. (Figs. 9a-c).

Al margen de la Serie Tipo de Chrysopa nierembergi, ahora mejor definida, hemos localizado y estudiado en su colección los ejemplares etiquetados como Tipo de otras dos, de las tres, variedades descritas por Navás para esta especie (Figs. 6b-c), de las que también conviene anotar alguna consideración taxonómica. Nos referimos a Chrysopa nierembergi var. andreui y Chrysopa nierembergi var. clara, dejando para más adelante el estudio de la tercera variedad Chrysopa nierembergi var. nitens.

Chrysopa nierembergi var. andreui, fue descrita de Alicante: Rojales por Navás (1910: 38): "Patria. Rojales 


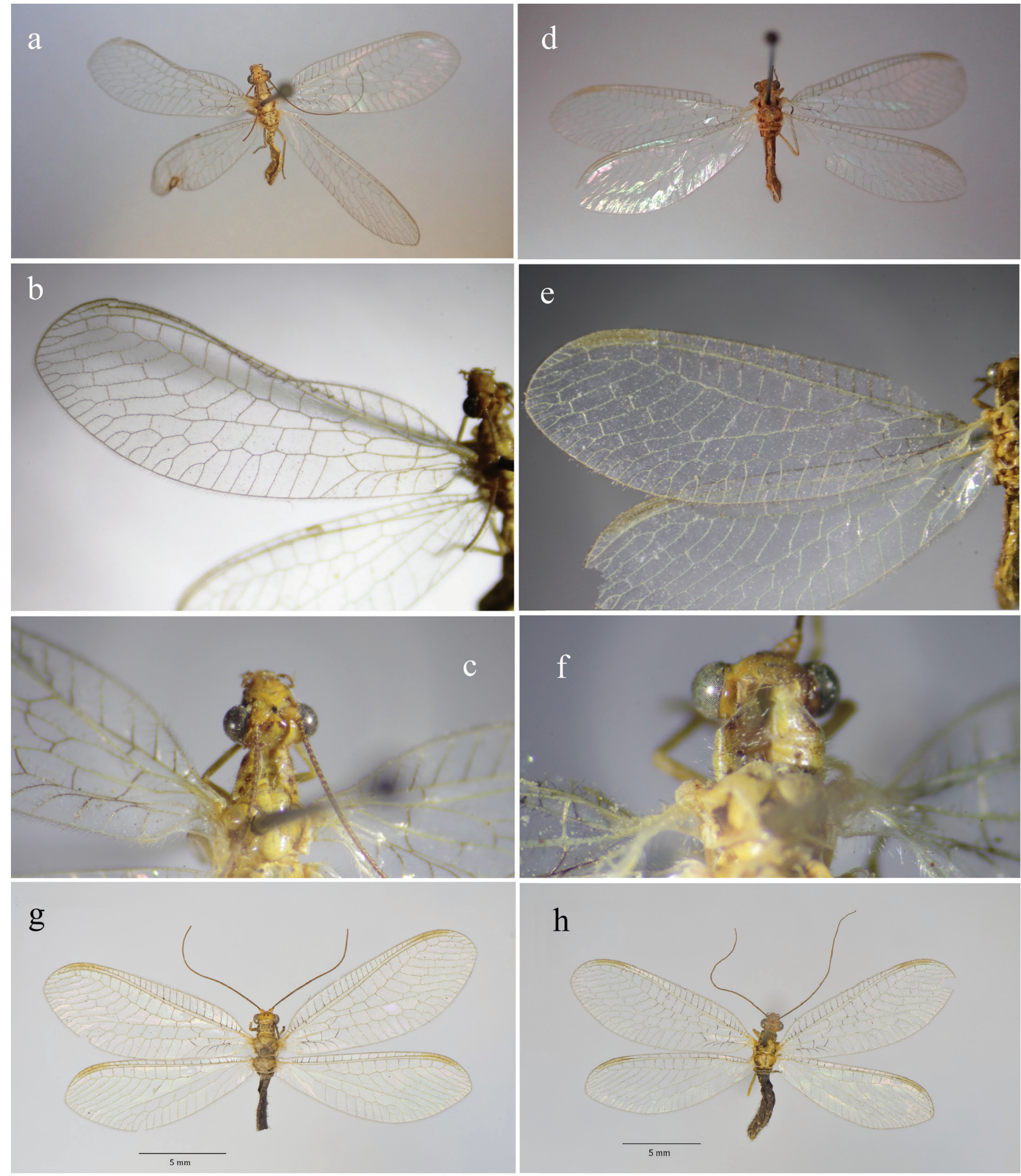

Fig. 9.-Ejemplares de Chrysopa nierembergi pertenecientes a la colección de Navás (Museu de Ciències Naturals de Barcelona) y del Museo Nacional de Ciencias Naturales de Madrid: a-c: ejemplar ahora designado como Paralectotipo (71-9469 MZB), d-f: (71-9470 MZB), g: (MNCN_Ent 199600), h: (MNCN_Ent 223660). (a-f, fotos de S. Gago, g, h: de M. París).

Fig. 9.- Specimens of Chrysopa nierembergi belonging to the Navás collection (Museu de Ciències Naturals of Barcelona) and to the Museo Nacional de Ciencias Naturales of Madrid : a-c: copie now designated as Paralectotype (71-9469 MZB), d-f: (71-9470 MZB), g: (MNCN_Ent 199600), h: (MNCN_Ent 223660). (a-f, photos by S. Gago, g, h: by M. París).

(Alicante), 11 de Junio de 1909 (Colección mía). Varios ejemplares cogidos por el Rdo. Andréu, á (sic) quien la dedico", cita reiterada, sin anotar nuevo material, bien dentro de este género o del género Cintameva por Navás (1915a: 77, 1924: 163, 1925: 77 solo indica "Rojales (Alicante)") y por Vidal y López (1943: 21).

Chrysopa nierembergi var. clara, fue descrita por Navás (1915a: 77) también de Alicante: Rojales, 


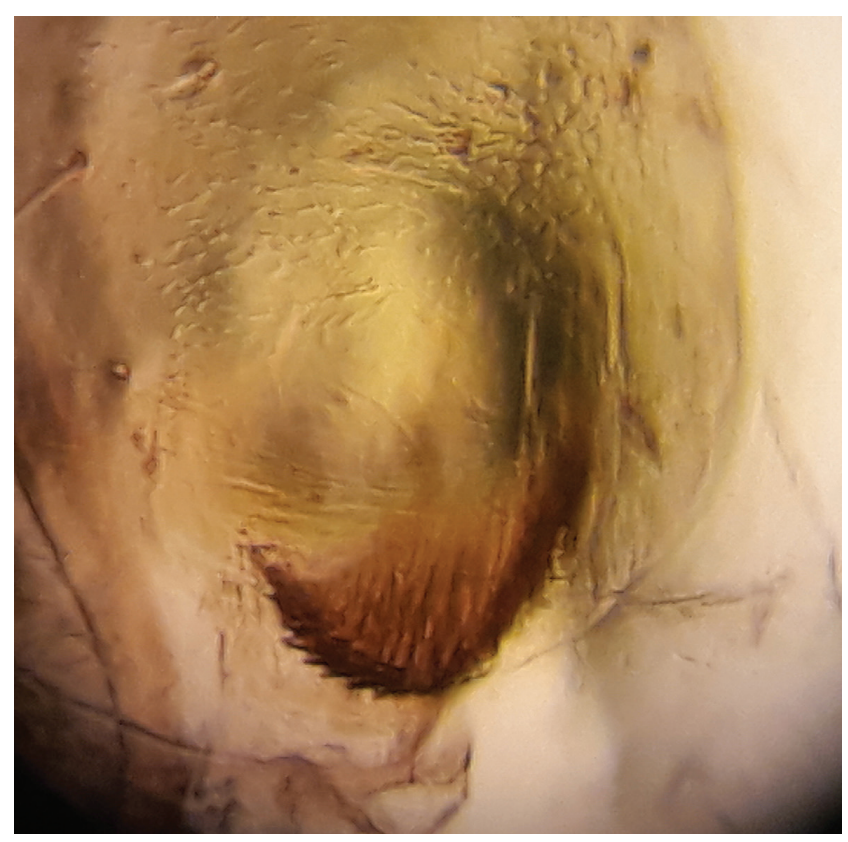

Fig. 10.- Gonocristae del ejemplar tipo (ahora designado como Lectotipo) de Chrysopa nierembergi (foto de S. Gago).

Fig. 10.- Gonocristae of the type specimen (now designated as Lectotype) of Chrysopa nierembergi (photo by S. Gago).

("Hab. Espanya: Rojales (Alacant), 15 Juny 1909, Rnd. Andreu (Col. m.)", cita reiterada, con diferente fecha de recolección, por Navás (1924: 163): "Rojales (Alacant), 19 de juny de 1909 (Andreu)", de lo que también podría deducirse la existencia de más de un ejemplar, y también es citada dentro del género Cintameva por Navás (1925: 77 solo indica "Rojales (Alicante)") y por Vidal y López (1943: 21).

En ambos casos, bien porque expresamente se indica en la descripción original o porque posteriormente parece deducirse, las Series Tipo de ambos taxa constaba de varios ejemplares y así lo sugerimos (ver material ahora estudiado de Alicante: Rojales).

Designamos como Lectotipo de Chrysopa nierembergi var. andreui Navás, 1910 al ejemplar rotulado como: / Ch. Nierembergi v. Andreui Nav. Rojales (A.) 11.Jun.1909 / Typus / Chrysopa nierembergi var. andreui Navás, 1910 Lectotipo V. J. Monserrat \& R. A. Pantaleoni des. / 71-2547 MZB/ (Fig. 6c) y de Chrysopa nierembergi var. clara Navás, 1915 al ejemplar rotulado como: / Ch. Nierembergi v. clara Nav. Navás S. J. det. / Rojales (Al.) 11.Jun.1909 / Typus / Chrysopa nierembergi var. clara Navás, 1915 Lectotipo V. J. Monserrat \& R. A. Pantaleoni des. / 71-2548 MZB/ (Fig. 6b), quedando tras esta designación, automáticamente asignados como Paralectotipos los posibles restantes ejemplares relacionados con sus Series Tipo que, según lo anteriormente indicado, pudieran existir, bien en ésta o en otras colecciones de instituciones o museos donde Navás solía enviar algunos ejemplares (de esta localidad y recolector, y con diferentes fechas de captura). En relación a esta cuestión, mencionemos que, a pesar de que como hemos indicado Navás (1910: 38) cita expresamente "Varios ejemplares" en la descripción de Chrysopa nierembergi var. andreui y de deducirse la existencia de varios ejemplares en la de Chrysopa nierembergi var. clara, sólo hemos podido localizar con seguridad un ejemplar de cada taxa (ahora asignados como Lectotipos), y en relación a otro posible material de esta localidad (supuestos Paralectotipos), dado que ambos taxa tienen la misma Localidad Tipo, de que no se especificaron otras fechas de recolección en su descripción y de que entre el material estudiado no están rotulados/ identificados por Navás como tales, no tenemos la seguridad de que otro material estudiado de esta localidad pudiera formar parte de la Serie Tipo de una u otra variedad. En cualquier caso, estos ejemplares ahora designados como Lectotipos pertenecen sin ningún margen de duda a Chrysopa nierembergi.

Conviene comentar un último apunte sobre la sorprendente y marcada similitud de Chrysopa nierembergi, tanto en pigmentación tegumentaria como en genitalia masculina, con Chrysopa curdica Hölzel, 1967, de la que solo encontramos diferencias en el tipo de dilatación basal de las uñas (según cita Hölzel, 1967b, y de nuevo insistimos sobre la problemática en la interpretación de este carácter anteriormente anotada), quedando por ello sin dilucidar definitivamente la relación entre ambas especies. Se trata de una especie descrita por Hölzel (1967b) de Turquía (Anatolia, Van Gölü), de la que durante mucho tiempo no se conocía más que el ejemplar tipo y de la que han aparecido algunas nuevas referencias bibliográficas, bien como Chrysopa curdica Hölzel 1967 o como Chrysopa (Chrysopa) curdica Hölzel 1967: Hölzel (1970: 51), Şengonca (1980: 59, 1981: 128), Brooks \& Barnard (1990: 270), Aspöck \& Hölzel (1996: 60), Canbulat (2007: 37), Aspöck (2009: 308) y Ari (2014: 62), autores la incluyen listados generales o en la lista o en la clave de especies de Anatolia o que en base al ejemplar tipo aportan sus datos de morfología, de su en gran medida desconocida biología o de su distribución conocida, también Aspöck et al. (2001: 87) la citan como una especie del grupo de Chrysopa formosa, bien diferenciada y posiblemente sibérica. Solo Ari et al. (2007: 203) citan nuevos ejemplares, también de Turquía (Kars, KaÛ̃oman-Akçay, $1.185 \mathrm{~m}, 10 . \mathrm{VIII} .2002)$, considerándolo un elemento Irano-Turaniano.

Al margen de esto, volviendo a Chrysopa nierembergi y definida esta especie, corregidas las anteriores identificaciones erróneas y anotado el nuevo material ahora estudiado, es el momento de actualizar sus datos reales de distribución geográfica y altitudinal, fenología y biología de esta especie.

Pocos datos podemos aportar sobre la biología de esta especie, pues los datos anteriores existentes han de descartarse pues pertenecen a material erróneamente identificado (ver material estudiado de C. formosa y de Chrysopa nitens) y los restantes se corresponden 
con material antiguo, que apenas aportan elementos o fueron recolectados a la luz. Por el ejemplar ahora estudiado citado por Andreu (1909: 161 "Hallada en una pinada de Rojales, ... (22 de junio de 1908)", se sugiere su asociación con coníferas (son típicos de algunas localidades de los ejemplares ahora citados las formaciones de pinos y sabinas: Pinus halepensis y Juniperus phoenicea), y por su distribución conocida (S.E peninsular) (Fig. 12f), es obvio que esta especie está asociada a medios mediterráneos y térmicos, en ocasiones xéricos. Los datos que poseemos anotan ejemplares recolectados entre los meses de III, V-VII, a bajas cotas 10-25 m (desconocemos las de los ejemplares de Murcia: Sierra Espuña y no podemos asignar con seguridad a esta especie o a la siguiente que citamos los dos ejemplares que citan Hölzel \& Ohm (1972: 130) de Granada: Carretera del Veleta y de Órgiva, 300 m, 13.7.62 y 2.6.72. Como en nuestras latitudes es lo habitual en las especies de este género, debe hibernar en fase de prepupa. Sus estadios larvarios son desconocidos.

Con mayor repercusión en la taxonomía del género, pero similar grado de confusión y falta de precisión en los datos aportados por este autor encontramos en la tercera variedad descrita por Navás de esta especie. Nos referimos a Chrysopa nierembergi var. nitens, taxón que ahora citamos y que por este motivo también merece nuestros comentarios.

Chrysopa nierembergi var. nitens Navás, 1909 Figs. $2 \mathrm{f}-\mathrm{j}, 5 \mathrm{a}, 7 \mathrm{c}-\mathrm{e}, 8 \mathrm{~b}, 11,12 \mathrm{c}$

Nuevo material estudiado. ESPAÑa: Almería: Adra, $36^{\circ} 45^{\prime} 00^{\prime \prime} \mathrm{N}, 3^{\circ} 01^{\prime} 00^{\prime \prime} \mathrm{O}, 20 \mathrm{~m}, 8 . \mathrm{VI} .2019,1$ ㅇ a la luz, F. Rodríguez (UCME), Tabernas, $\mathrm{S}^{\mathrm{a}}$. Alhamilla, $36^{\circ} 59^{\prime} 20^{\prime \prime} \mathrm{N}, 2^{\circ} 21^{\prime} 05^{\prime \prime} \mathrm{O}, 470 \mathrm{~m}$, 28.V.2019, 3 우 a la luz, F. Rodríguez (UCME). Guadalajara: Taravilla, 30TWL8705, $1.317 \mathrm{~m}, 6$.VII.1984, 1 ते sobre Quercus faginea, L. M. Díaz-Aranda (UCME 37666), citado como Chrysopa nierembergi por Díaz-Aranda et al. (1986: 1139). Tarragona: Cabacés, $41^{\circ} 14^{\prime} 51^{\prime \prime} \mathrm{N}, 0^{\circ} 44^{\prime} 01^{\prime \prime} \mathrm{E}, 360 \mathrm{~m}, 1$.VII.1918, 1 §., L. Navás (71-9466 MZB), 2.VII.1918, ala anterior derecha de un ejemplar (71-9467 MZB). Teruel: Jabaloyas, 30TXK35, $1.410 \mathrm{~m}, 15 . \mathrm{VIII} .1988,1$ त a la luz en bosquete de Juniperus thurifera (37657 UCME), citado como Chrysopa nierembergi por Monserrat \& Díaz-Aranda (1989: 256).

PORTUGAL: Castelo Branco, Louriçal do Campo, Colégio de São Fiel, 4002'42"N, 7³0'43"O, 490 m, V.1908, 1 क (MZB): / Ch. Nierembergi N. v. nitens Nav. (San Fiel) Mayo 1908 / Leg. Tavares / Chrysopa nierembergi var. nitens Navás,1909 Lectotipo V. J. Monserrat \& R.A. Pantaleoni des. / 71-9468 MZB /. A esta especie podrían pertenecer los dos ejemplares de Chrysopa nierembergi citados de Granada: Órgiva, carretera del Veleta en Sierra Nevada, 1.VII.1962 y 2.VI.1972 (Hölzel \& Ohm, 1972: 130; Aspöck et al., 1980: 10, 11, 193).

No ha podido ser localizado y estudiado el ejemplar rotulado, como tal, como tipo de la variedad Chrysopa nierembergi nitens descrita por Navás (1909b: 150) de "Portugal: San Fiel": (Castelo Branco, Louriçal do Campo, Colégio de São Fiel, $40^{\circ} 02^{\prime} 42^{\prime \prime} \mathrm{N}$ $7^{\circ} 30^{\prime} 43^{\prime \prime} \mathrm{O}, 490 \mathrm{~m}$ ), y que bien dentro de este género o de Cintameva Navás, 1914 fue citada en- o listada de esta localidad por Navás (1915a: 77; 1924: 163) o sin aportar nuevos ejemplares, esta variedad aparece con simple referencia a "Portugal: San Fiel" en Navás (1925: 77), que bien como San Fiel o como Portugal "Mainland" refieren Passos de Carvalho (1997: 5, 6) o Letardi et al. (2013: 35). Al margen de esta localidad, posteriormente Navás la citará de Tarragona: Cabacés en Navás (1919: 199 "Cabacés. Especie nueva para Cataluña", por las fechas de visita a esta localidad que anota al inicio: 27 de junio - 3 de julio), material que refieren Hölzel \& Ohm (1972: 130, anotando: 1.7.18) (ver datos más precisos más adelante).

Si bien en la descripción original de este taxón no se cita el depósito de este ejemplar tipo, es de suponer y ahora lo deducimos, que el ejemplar permaneció en la colección del autor, hoy custodiada en el Museu de Ciències Naturals de Barcelona, donde hoy día rotulado como tal no se encuentra, según información del citado museo, por lo que podría darse por perdido y así había sido supuesto (Monserrat, 1985b).

Desconocíamos la identidad real de este taxón, pero siempre hemos dudado de que esta variedad se tratara realmente de Chrysopa nierembergi, especialmente por la referencia de San Fiel, que daría a esta especie una supuesta distribución también atlántica y no solo mediterránea, como parecía presentar. Sin embargo sí existen tres ejemplares de su colección en esta institución cuyos datos coinciden con los mencionados ejemplares citados por Navás de Portugal: San Fiel (supuesto material tipo): un ejemplar determinado como Chrysopa nierembergi var. nitens de San Fiel, de mayo de 1908, Tavares leg.(71-9468 MZB) (Fig. 11a) y dos de Tarragona: Cabacés (posterior material asignado a este taxón): un ejemplar del 1 de julio de 1918 (71-9466 MZB) y el ala anterior derecha de un ejemplar del 2 de julio de 1918 (71-9467 MZB) (Figs. 11b-c), fechas que coinciden con lo anotado en Navás (1919: 199).

Respecto a los datos del primer ejemplar son coincidentes con lo anotado en la descripción original por Navás (1909b: 151): "Patria. San Fiel (Portugal). Cogida en Mayo de 1908 por el Reverendo P. Joaquín da Silva Tavares, S.J.", datos que repite en Navás (1915a: 77): "Hab. Portugal: San Fiel, Maig 1908, R. P. Joaquím da Silva Tavares, S.J. (Col. m.)” y en Navás (1924: 163): "Portugal: San Fiel, maig de 1908 (P. Tavares, S.J.)". De ello se deduce que probablemente se trataba de un único ejemplar, que supuestamente podría tratarse de una hembra ("Cogida en..."), a no ser que se estuviera refiriendo a la variedad descrita, y que permaneció en su colección (“Col. m."), hoy en Barcelona.

Todo parece indicar pues que solo existe un ejemplar de San Fiel, y aunque hoy día este ejemplar no porte las etiquetas identificativas como tipo (Fig. 11a), no cabe duda que se trata de él, máxime conociendo las vicisitudes que sufrió esta colección (Monserrat, 1985b, 1986b) en las que muchos ejemplares se destruyeron o dañaron y otros perdieron o intercambiaron sus etiquetas, $\mathrm{y}$ por otra parte coincide tanto 


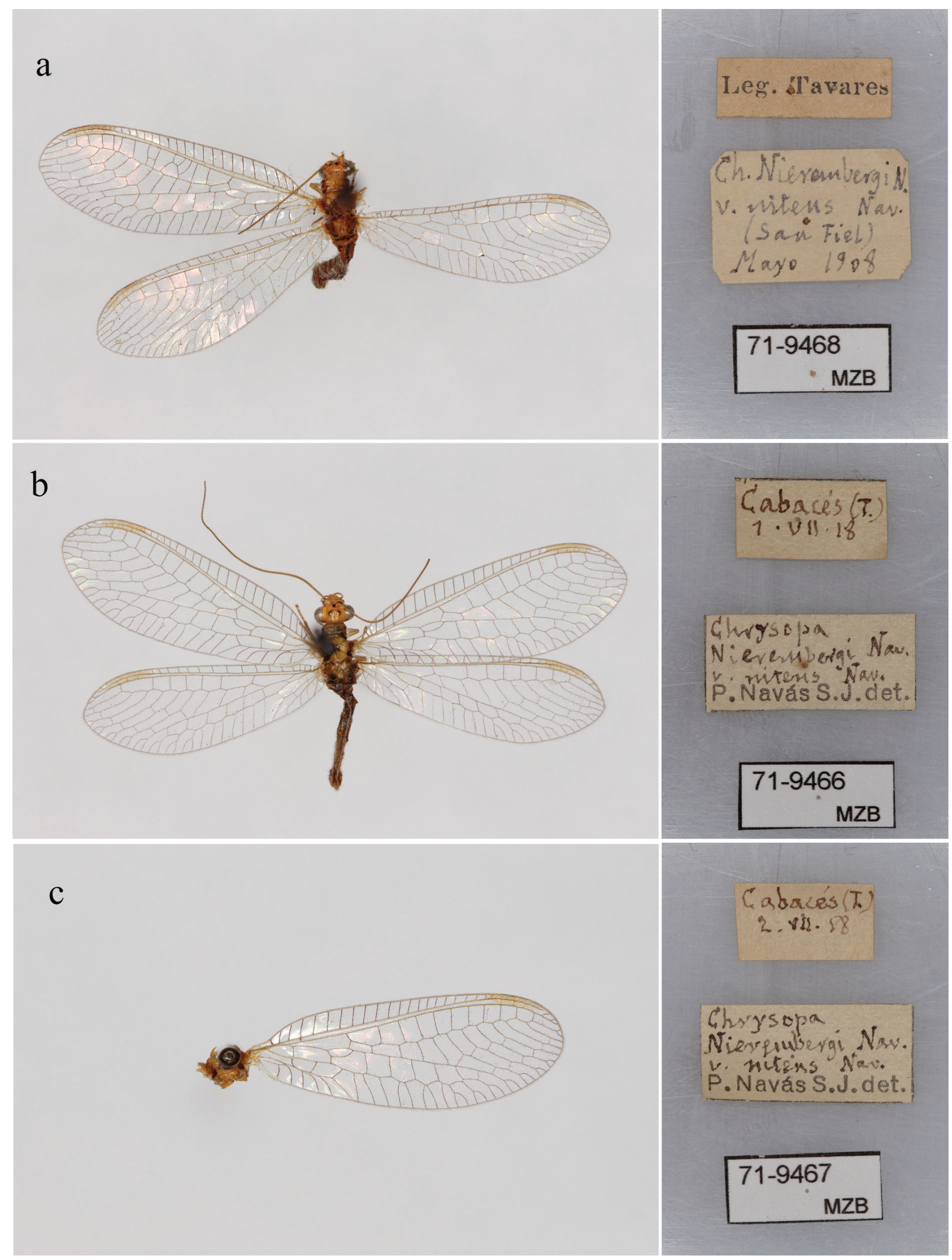

Fig. 11. - Ejemplares de Chrysopa nitens Navás, 1909 stat. prom. pertenecientes a la colección de Navás (Museo de Barcelona): a: Lectotipo ahora designado, b, c: otros ejemplares (fotos de S. Gago).

Fig. 11.- Specimens of Chrysopa nitens Navás, 1909 stat. prom. belonging to the Navás collection (Museum of Barcelona): a: designated Lectotype, b, c: other copies (photos by S. Gago). 
morfológicamente como en los datos de captura originales dados en la descripción original, por lo que, sin ningún margen de dudas, lo consideramos y lo designamos como Lectotipo de Chrysopa nierembergi var. nitens Navás, 1909 (Fig. 11a).

Ahora bien, debido a que se trata de una especie distinta a Chrysopa nierembergi y a cualquier otra anteriormente reconocida, en base a este ejemplar, elevamos a categoría de especie su categoría original de variedad: Chrysopa nitens Navás, 1909: 150 stat. prom. (Figs. 2f-j, 5a, 7c-e, 8b, 11, 12c)

Pasemos ahora a los ejemplares de Chrysopa nierembergi var. nitens citados de Cabacés (Tarragona) (Figs. 11b-c). La cita de esta localidad dada por Navás (1919: 199) no es muy precisa, sin indicar fechas ni número de ejemplares recolectados: "Cabacés. Especie nueva para Cataluña", y por lo anotado previamente (Navás, 1919: 182) se deduce que visitó esta localidad entre el 27 de junio y el 3 de julio de 1918, realizando varios muestreos por la zona, y en particular el día 1 de julio de 1918 comenta que estuvo muestreando en los santuarios de La Foya y de San Salvador (Cabacés, Ermita de la Mare de Déu de la Foia o Ermita de les Neus, $41^{\circ} 15^{\prime} 28^{\prime \prime} \mathrm{N}, 0^{\circ} 45^{\prime} 16^{\prime \prime}$ E, $588 \mathrm{~m}$ y Margalef, Ermita de San Salvador, $41^{\circ} 17^{\prime} 05^{\prime \prime} \mathrm{N} 0^{\circ} 45^{\prime} 13^{\prime \prime} \mathrm{E}$, 379 m). Esta cita se reitera en Navás (1924: 163): "Tarragona, Cabacés, 1 i 2 de juliol de 1918", de donde se deduce que pudiera haber más de un ejemplar, hecho que hemos constatado: un ejemplar del 1 de julio de 1918 (71-9466 MZB) (Fig. 11b), ejemplar estudiado por Hölzel \& Ohm (1972: 130) y el ala anterior derecha de un ejemplar del 2 de julio de 1918 (71-9467 MZB) (Fig. 11c), fechas que coinciden con lo anotado en Navás (1919: 182, 199) y ambos portan una etiqueta que reza: Chrysopa Nierembergi var. nitens Nav. P. Navás S. J. det., y de ello se deduce que ahora tratamos el material entonces citado. Ambos ejemplares pertenecen sin ninguna duda a Chrysopa nitens Navás, 1909 stat. prom. (Figs. 11a-c), y que ahora mencionamos en el material estudiado de esta especie.

Comprobado que ambas especies (Chrysopa nierembergi y Chrysopa nitens) son muy similares externamente, pero especies diferentes [caso similar a lo que Monserrat et al. (2014) citan entre Chrysopa nigricostata Brauer, 1850 y Cunctochrysa cosmia], y siguiendo el método anteriormente (quebrado: Chrysopa nierembergi / C. nitens) anotamos los caracteres que mejor permiten diferenciarlas: Respecto a algún elemento de su pigmentación: cabeza amarillenta anaranjada / amarilla (Figs. 7b, d), torna a más verdosa en ejemplares secos hace décadas recolectados, pero en ambos casos siempre es más amarillenta y menos verde que el resto del tegumento; sin mancha oscura sobre el lateral del clípeo / con muy leves sombras pardas (Figs. 5a, f); manchas ante los tóruli laterales y aisladas / anteriores y contactan entre sí y frecuentemente con la mancha internantenal (Figs. 5a, f); manchas del vértex cortas y divergentes / largas y subparalelas (Figs. 5a, f, 7b, d-e); flagelo pardo oscuro / pardo pálido; tergo protorácico con dos marcadas manchas oscuras a cada lado y zonas pardas sobre sus márgenes laterales / con dos anchas bandas violáceas oscuras a cada lado (Figs. 5a, f, 7b, d-e, 11a-b); meso y metaescutum con una amplia mancha semilunar oscura sobre sus márgenes posteriores que alcanzan la base alar / con dos amplias bandas pardas violáceas oscuras continuas sobre los laterales del meso y metanoto (Figs. 6-7, 9, 11); patas anteriores verdes con extremo del fémur pardo / verdes en su totalidad, salvo tarsos que son más pardos; uñas con el margen interno basal menor que la mitad del distal / similar a mitad del distal (Figs. 2j, 4f); longitud alas anteriores $12,0-13,5 \mathrm{~mm} / 11,0-13,0 \mathrm{~mm}$; setas costales largas e irregularmente orientadas / cortas, paralelas y curvadas hacia la costal (Figs. 8b-c); alas anteriores con las venillas del campo costal verdes en su mitad anterior y negras en su mitad posterior / completamente negras (Figs. 8b-c); vena Sc oscurecida en su margen anterior en el contacto con las venillas trasversales del campo costal / completamente oscurecida a lo largo de todo su margen anterior (Figs. 8b-c); base de vena radial con una línea oscuro en el arranque de Mp / sin ella; venillas trasversales del campo radial verdes, solo oscuras en su tramo de contacto con R / oscuras en su totalidad (Figs. 7a-c, e); las venas anales poseen un corto tramo basal verde, tras las bifurcaciones son oscuras y vuelven a ser verdes por un tramo antes de contactar con la costal / salvo un corto tramo basal verde son completamente oscuras hasta contactar con la costal (Figs. 7a-b, e); primera venilla del campo costal de las alas posteriores verde / negra. Un cuadro comparativo de estos caracteres externos se anota en la Tabla 1.

Respecto a su genitalia masculina C. nitens presenta, por el contrario, más similitudes con $C$. formosa que con C. nierembergi (Figs. 2, 4), siendo también válidas para ella las diferencias anotadas anteriormente entre estas dos especies (C. formosa, C. nierembergi). Respecto a $C$. formosa y empleando el mismo quebrado C. formosa / C. nitens, destaca: noveno esternito ancho y bifurcado caudalmente con proceso dorsal formando un ángulo obtuso / estrecho con en el margen caudal formando un ángulo más recto (Figs. 2a, f); gonocristas agrupadas en dos hileras, de menor longitud la más mediana y mucho mayor la externa / cortas y de similar longitud (Figs. 2a-b, $\mathrm{f}-\mathrm{g}$ ); aspecto de la genitalia interna (Figs. $2 \mathrm{c}-\mathrm{d}, \mathrm{h}-\mathrm{i}$ ), etc. Por otra parte esta especie ofrece muchas similitudes en su pigmentación y biología con Chrysopa dorsalis Burmeister, 1839 , siendo especies muy próximas, y quizás correspondan a esta especie alguna de las citas ibéricas (o no) de Chrysopa dorsalis, pero el tipo y coloración de las manchas en la cabeza, la dilatación de las uñas y la pigmentación alar las diferencia (ver Monserrat, 2008 y clave de especies ahora actualizada). 
Tabla 1.-Cuadro comparativo de los caracteres externos de Chrysopa formosa, C. nierembergi y C. nitens.

Table 1.- Comparative table of the external characters of Chrysopa formosa, C. nierembergi and C. nitens.

\begin{tabular}{|c|c|c|c|}
\hline & Chrysopa formosa & Chrysopa nierembergi & Chrysopa nitens \\
\hline Color cabeza & $\begin{array}{l}\text { normalmente verde, a veces } \\
\text { amarillenta }\end{array}$ & $\begin{array}{l}\text { más amarilla o anaranjada } \\
\text { que verdosa }\end{array}$ & amarilla anaranjada intensa \\
\hline Mancha tras los ojos & no & sí & sí \\
\hline Mancha sobre el clípeo & sí & no & $\begin{array}{l}\text { no, a veces una leve sombra } \\
\text { parda }\end{array}$ \\
\hline Color del escapo & verde & amarillo o anaranjado & amarillo \\
\hline Manchas en el escapo & no & pardas en laterales interno y externo & $\begin{array}{l}\text { pardas en laterales interno } \\
\text { y externo }\end{array}$ \\
\hline Color pedicelo / flagelo & negro / pardo pálido & negro / pardo muy oscuro & pardo / pardo pálido \\
\hline $\begin{array}{l}\text { Manchas ante los } \\
\text { tóruli }\end{array}$ & semilunares, anteriores, no contactan & semilunares, laterales, no contactan & semilunares, contactan entre sí \\
\hline $\begin{array}{l}\text { Manchas sobre el } \\
\text { vértex }\end{array}$ & bien delimitadas, circulares y negras & $\begin{array}{l}\text { pardas, divergentes, } \\
\text { ovoides y difusas }\end{array}$ & $\begin{array}{l}\text { pardas, paralelas, alargadas } \\
\text { y difusas }\end{array}$ \\
\hline $\begin{array}{l}\text { Bandas oscuras } \\
\text { laterales en pronoto }\end{array}$ & habitualmente sin ellas & pardas, difusas sobre sus márgenes & $\begin{array}{l}\text { patentes, violáceas, oscuras } \\
\text { y muy extensas }\end{array}$ \\
\hline $\begin{array}{l}\text { Manchas oscuras } \\
\text { en pronoto }\end{array}$ & sin ellas o con pequeños puntos & dos a cada lado, muy marcadas & $\begin{array}{l}\text { en bandas laterales y dos } \\
\text { tenues anteriores }\end{array}$ \\
\hline $\begin{array}{l}\text { Escleritos ventrales } \\
\text { del tórax }\end{array}$ & verdes & $\begin{array}{l}\text { extensamente oscuros } \\
\text { en sus márgenes }\end{array}$ & $\begin{array}{l}\text { levemente oscuros en sus } \\
\text { márgenes }\end{array}$ \\
\hline $\begin{array}{l}\text { Manchas en meso } \\
\text { y metaescutum }\end{array}$ & pequeños puntos, si existen & $\begin{array}{l}\text { amplias manchas } \\
\text { semilunares aisladas }\end{array}$ & $\begin{array}{l}\text { dos bandas violáceas } \\
\text { oscuras en laterales }\end{array}$ \\
\hline Setas costales de alas & cortas, paralelas y curvadas & largas e irregularmente orientadas & cortas, paralelas y curvadas \\
\hline $\begin{array}{l}\text { Ala anterior, venillas } \\
\text { del campo costal }\end{array}$ & $\begin{array}{l}\text { negras, verdes en zona de contacto } \\
\text { con } C\end{array}$ & $\begin{array}{l}1^{\mathrm{a}} \text { negra, resto verdes en su mitad } \\
\text { anterior }\end{array}$ & completamente negras \\
\hline $\begin{array}{l}\text { Ala anterior, venillas } \\
\text { del campo radial }\end{array}$ & $\begin{array}{l}\text { verdes, negras en zona de contacto } \\
\text { con } \mathrm{R}\end{array}$ & $\begin{array}{l}\text { verdes, negras en zona de contacto } \\
\text { con } \mathrm{R}\end{array}$ & completamente negras \\
\hline $\begin{array}{l}\text { Ala anterior, base } \\
\text { de vena radial }\end{array}$ & sin una línea oscura & con una línea oscura & sin una línea oscura \\
\hline $\begin{array}{l}\text { Ala anterior, } \\
\text { bifurcaciones venas } \\
\text { anales }\end{array}$ & negras en su totalidad & $\begin{array}{l}\text { negras, pero verdes } \\
\text { en su tramo final }\end{array}$ & negras en su totalidad \\
\hline $\begin{array}{l}\text { Alas posteriores, } 1^{\text {a }} \\
\text { venilla costal }\end{array}$ & negra & verde & negra \\
\hline Patas 1 y 2 & verdes & $\begin{array}{l}\text { verdes, pardos los extremos } \\
\text { del fémur }\end{array}$ & verdes \\
\hline $\begin{array}{l}\text { Longitud margen } \\
\text { interno dilatación basal }\end{array}$ & similar a la mitad del margen externo & $\begin{array}{l}\text { menor de la mitad del margen } \\
\text { externo }\end{array}$ & $\begin{array}{l}\text { similar a la mitad del margen } \\
\text { externo }\end{array}$ \\
\hline $\begin{array}{l}\text { Zonas laterales de los } \\
\text { tergos abdominales }\end{array}$ & verdes & $\begin{array}{l}\text { oscuras, formando tenues bandas } \\
\text { longitudinales }\end{array}$ & $\begin{array}{l}\text { oscuras formando dos patentes } \\
\text { bandas longitudinales }\end{array}$ \\
\hline Pleuras abdominales & verdes & oscuras & oscuras \\
\hline
\end{tabular}

Definida mejor esta especie, parte de estos caracteres, los más reseñables y fáciles de observar, se utilizarán en la clave de especies ibéricas de este género que más adelante actualizamos. Por otra parte, delimitada esta especie, es el momento de corregir alguna de las anteriores identificaciones erróneas, de anotar el nuevo material ahora estudiado, y de actualizar sus datos reales de su distribución geográfica y altitudinal, fenología y biología.

Hasta ahora se trata de una especie endémica de la Península Ibérica que posee una distribución algo más atlanto-mediterránea que $C$. nierembergi, aunque en algunas zonas son simpátridas (Figs. 12c, f), ha sido recolectada a la luz, sobre Quercus faginea y en un bosquete de Juniperus thurifera, y por la presencia de polen de coníferas en el tracto digestivo de algunos ejemplares estudiados, probablemente esté asociada a coníferas, recolectada entre los meses de V-VIII, en un amplio margen altitudinal, a 20, 360, 470, $490 \mathrm{~m}$ hasta $1.317-1.410 \mathrm{~m}$. Como en nuestras latitudes es lo habitual en las especies de este género, debe hibernar en fase de prepupa. Sus estadios larvarios son desconocidos. 


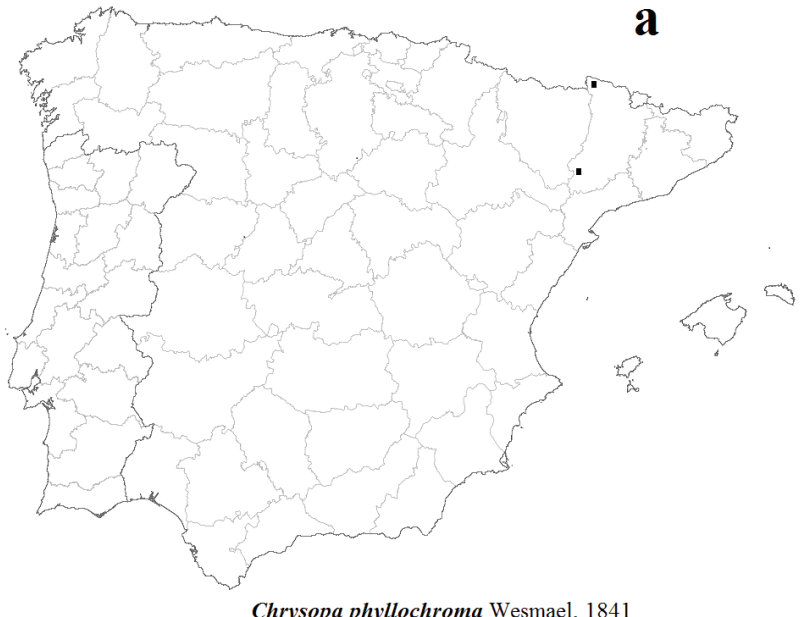

Chrysopa phyllochroma Wesmael, 1841

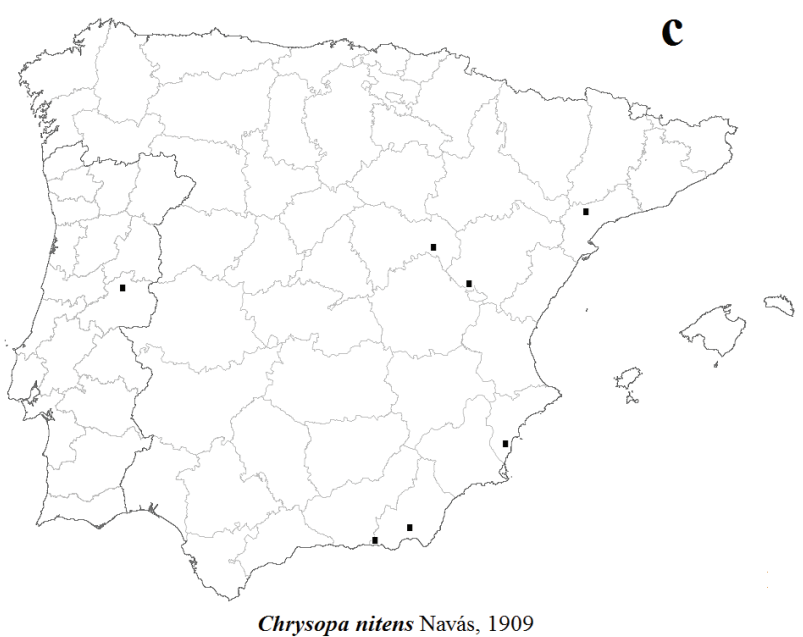

Chrysopa nitens Navás, 1909

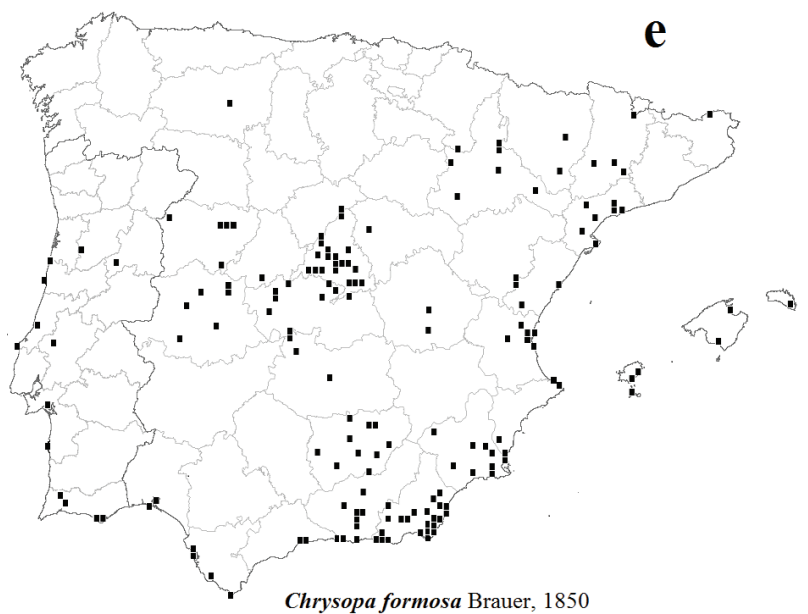

b
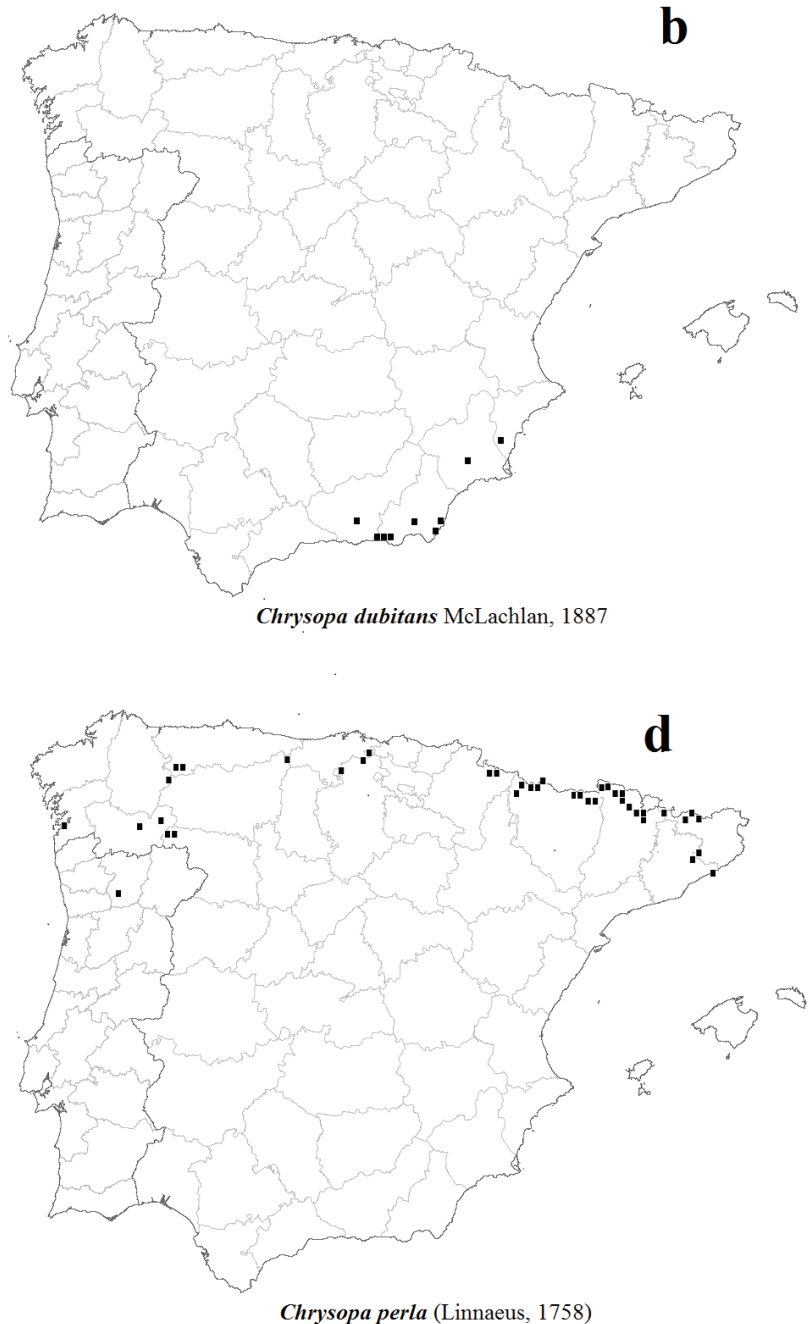

Chrysopa perla (Linnaeus, 1758)

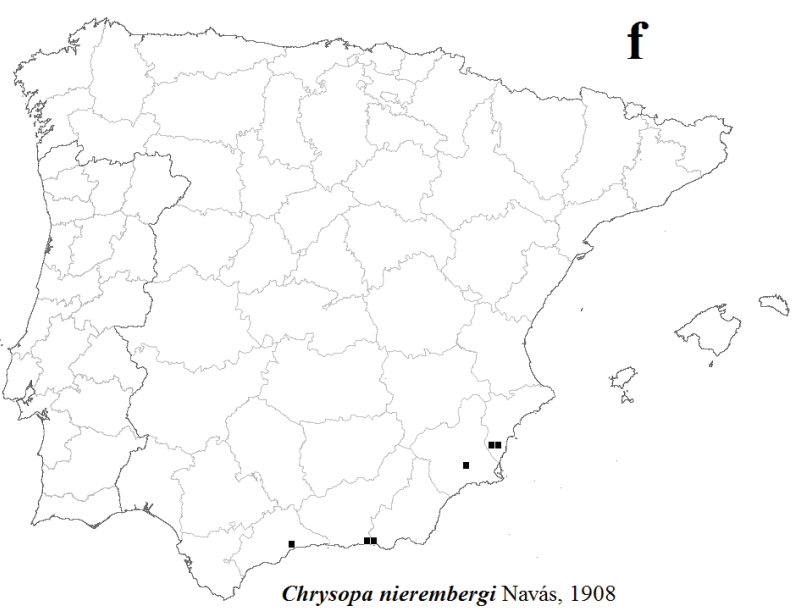

Fig. 12.- Mapas de distribución actualizada de las especies de Chrysopa de la Península lbérica y Baleares: a: C. phyllochroma, b: C. dubitans, c: C. nitens Navás, 1909 stat. prom., d: C. perla, e: C. formosa, f: C. nierembergi.

Fig. 12.- Updated distribution maps of the Iberian Peninsula and Balearic Chrysopa species: a: C. phyllochroma, b: C. dubitans, c: C. nitens Navás, 1909 stat. prom., d: C. perla, e: C. formosa, f: C. nierembergi.

\section{Actualización de la clave de especies ibero- baleares del género Chrysopa Leach, 1815}

Respecto a las especies de este género de nuestra fauna, confirmada en ella presencia de Chrysopa dubitans, asumidas como válidas las citas anteriormente comentadas de Chrysopa phyllochroma y añadida Chrysopa nitens como novedad, la clave de las especies ibéricas del género Chrysopa de Monserrat (2016) se modifica y actualiza en parte, según se 


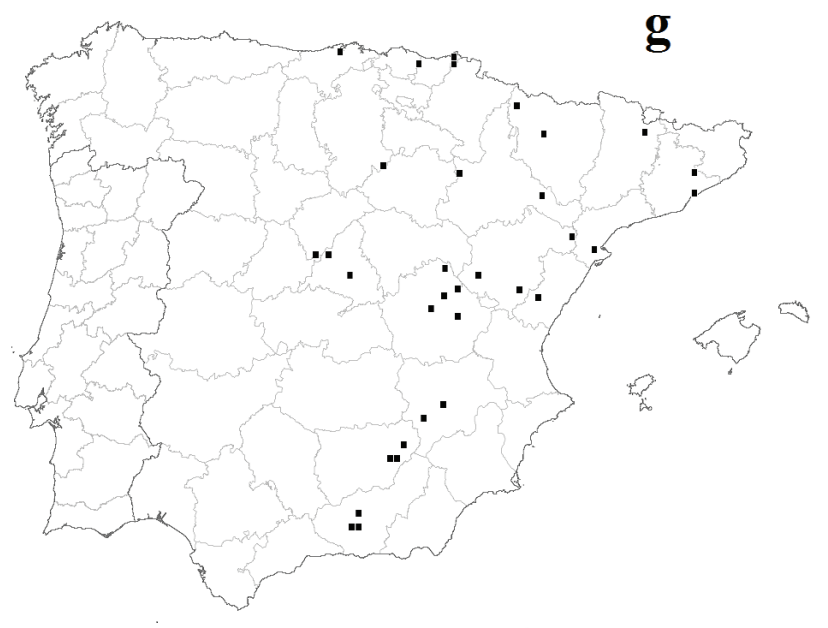

Chrysopa dorsalis Burmeister, 1839

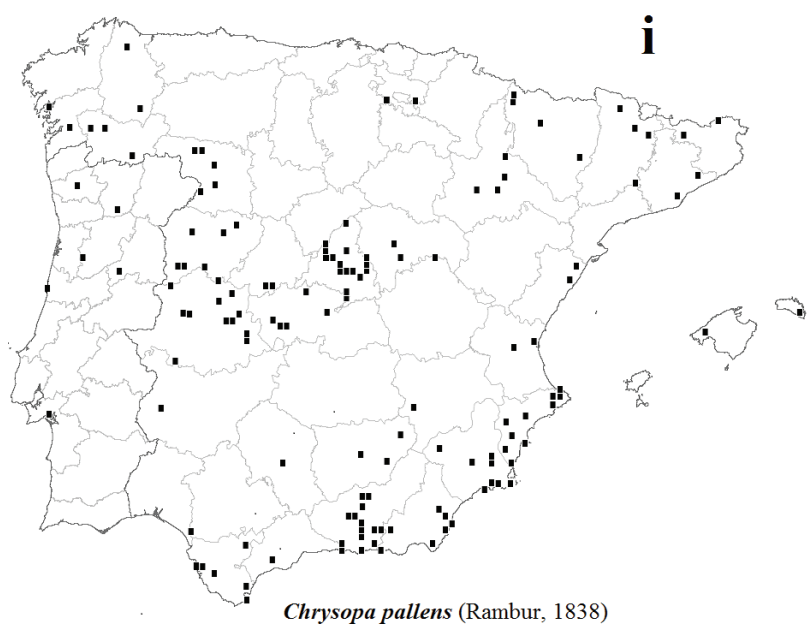

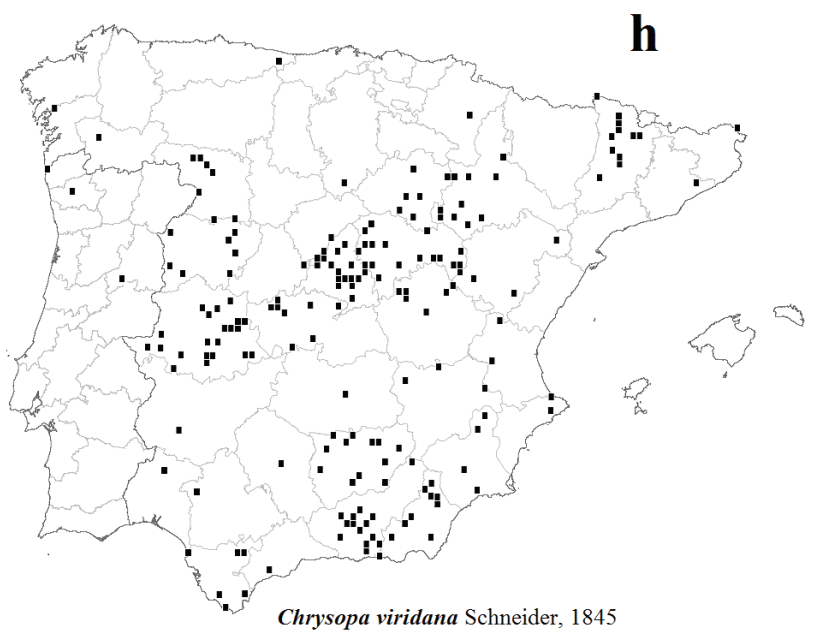

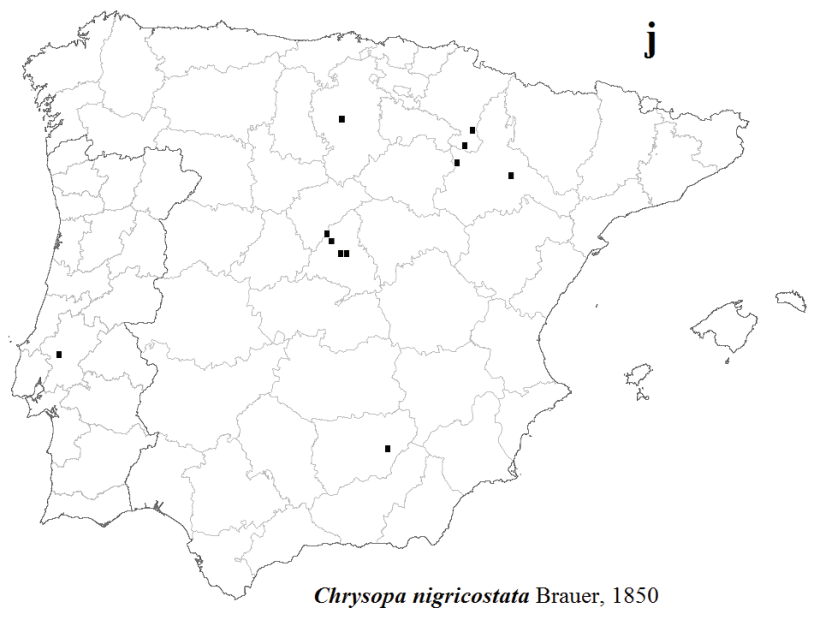

Fig. 12 (cont.).- Mapas de distribución actualizada de las especies de Chrysopa de la Península lbérica y Baleares: g: C. dorsalis, h: C. viridana, i: C. pallens, j: C. nigricostata.

Fig. 12 (cont.).- Updated distribution maps of the Iberian Peninsula and Balearic Chrysopa species: g: C. dorsalis, h: C. viridana, i: C. pallens, j: C. nigricostata.

indica, manteniendo las figuras entonces utilizadas (en negrita) y añadiendo las ahora aportadas:

2. Cabeza con un punto negro brillante entre las antenas, extendido con el mismo color y brillo sobre el vértex en forma de $X$ o $Y$ (Figs. 101, 104)

- Cabeza con un punto negro brillante entre las antenas, sin que esté extendido con el mismo color $y$ brillo sobre el vértex en forma de $\mathrm{X} \circ \mathrm{Y}$, pudiendo tener otras manchas circulares o alargadas, negras, oscuras o pardo-rojizas sobre el vértex (Figs. 5, 99, $102,103,105)$

3

3. Cabeza solo con un punto oscuro entre las antenas, sin tener otras manchas oscuras sobre el vértex (Fig. 99)

Chrysopa pallens

- Cabeza con un punto oscuro entre las antenas y con otras manchas circulares o alargadas, oscuras o pardo-rojizas sobre el vértex (Figs. $5,102,103,105) \ldots . .4$

4. Uñas abruptamente dilatadas en su base (parecido a Figs. 2e, j, 3f, 4f)
- Uñas progresivamente dilatadas hacia su base (parecido a Fig. 1e). Genitalia masculina según Figs. 1a-d..

Chrysopa phyllochroma

5. Alas anteriores con todas las venillas del campo costal verdes, incluida la primera, sólo muy levemente más oscuras en su contacto con la vena subcostal. Genitalia masculina según Figs. 3a-e..........Chrysopa dubitans

- Alas anteriores con las venillas del campo costal totalo parcialmente negras (bien con un tramo verde hacia la costal o en el contacto con la vena costal), siendo la primera siempre negra (Figs. 6-9, 11)....

6

6. Tergo torácico con una banda continua a cada lado pardo violácea oscura (Figs. 5a, 7c-e, 11). Alas anteriores con las venillas del campo costal y radial totalmente oscuras (Figs. 7c-e, 8b, 11). Genitalia masculina según Figs. 2f-i..... Chrysopa nitens

- Tergo torácico sin una banda continua a cada lado pardo violácea oscura, bien con puntos oscuros o con manchas aisladas (Figs. 5b, f, 6, 7a-b, 9). Alas anteriores con las venillas del campo costal verdes por un tramo, bien junto 
a la vena costal o en su contacto con ella (Figs. 8a, c), las del campo radial solo oscuras en la zona de contacto con R (Figs. 6, 7a-b, 9).

7. Cabeza amarilla- anaranjada, con una mancha oscura lateral sobre las genas, sin que exista otra sobre el clípeo (Fig. 5f). Escapo amarillo anaranjado con manchas rojizas oscuras (Fig. 5f), flagelo pardo oscuro. Patas anteriores verdes con extremos de fémur pardo. Margen interno de la dilatación basal de las uñas menor que la mitad del exterior (Fig. 4f). Pronoto portando dos manchas circulares muy oscuras a cada lado, otras más débiles en los márgenes anterior y laterales (Fig. 5f) y otras oscuras y aisladas sobre los meso y meta escutum (Figs. 6, 7a-b, 9). Pleuras torácicas marginadas de oscuro (Figs. 9d-e). Alas anteriores con una estría oscura en la base de $R$ y venas anales verdes en su extremo costal (Figs. 7a-b). Alas posteriores con primera venilla costal verde. Genitalia masculina según Figs. 4a-e. Chrysopa nierembergi

- Cabeza normalmente verde, con dos manchas oscuras laterales sobre las genas y el clípeo (Fig. 5b). Escapo verde, sin manchas (Fig. 5b), flagelo pardo pálido. Patas anteriores verdes. Margen interno de la dilatación basal de las uñas mayor que la mitad del exterior (Fig. 2e). Pronoto normalmente sin manchas oscuras patentes (Fig. 5b), como mucho pequeños puntos, en ocasiones más extendidos, también solo puntos pequeños oscuros sobre los meso y meta escutum. Pleuras torácicas verdes. Alas anteriores sin estría oscura en la base de $R$ y con venas anales negras en su extremo costal. Alas posteriores con primera venilla costal negra. Genitalia masculina según Figs. $2 a-d$

Chrysopa formosa

\section{Discusión}

Son pues 10 especies del género Chrysopa confirmadas en la Fauna Ibérica y Balear, y solo resta comentar que aún persiste una cierta problemática sobre la validez de algunas citas o referencias de ciertas especies de este género dadas en su fauna. Tal es el caso de Chrysopa abbreviata y de Chrysopa walkeri, citas ya comentadas recientemente por Monserrat \& Díaz-Aranda (2012), Monserrat \& Triviño (2013) y Monserrat (2016), y de las que damos nuestra última opinión.

\section{Chrysopa abbreviata Curtis, 1834}

Especie sibérica conocida de Alemania, Albania, Austria, Bélgica, Bielorrusia, Bosnia y Herzegovina, Bulgaria, Croacia, Dinamarca, Eslovaquia, Eslovenia, Finlandia, Francia, Gran Bretaña, Hungría, Irlanda, Italia, Letonia, Liechtenstein, Lituania, Moldavia, Noruega, Países Bajos, Polonia, República Checa, Rumania, Rusia, Suecia, Suiza y Ucrania en Europa, extendiéndose desde el Cáucaso, Turquía (Anatolia), Kazajstán, Kirguistán, Kasachstán, Tadschikistán y Mongolia al Fernost.

Es una especie marcadamente estenotópica y asociada a medios halófilos, dunares, rivereños y costeros, a veces en latitudes boreales (Stitz, 1928; Greve,
1984; Plant, 1994; Letardi, 1997) y generalmente asociada a vegetación de ribera, herbácea y baja en medios inalterados (ej.: Sedum, Myrrhoides, Bunium, Pimpinella, Xanthium, Ruscus, Fraxinus), citada entre los meses de V-IX, desde zonas costeras a altitudes de hasta $1.558 \mathrm{~m}$ en Turquía y $2.000 \mathrm{~m}$ en Asia central (Ohm, 1965; Zelený, 1971; Séméria, 1978; Aspöck et al., 1980, 2001; Pantaleoni, 1982; Kovrigina, 1985; Bozsik, 1994; Bozdoğan y Bahadıroğlu, 2015).

La única cita de esta especie en la fauna ibérica fue dada por Whittington (2002: 378) con referencia: "Spain" (sin más datos), cita que sigue generando posteriores referencias, incluso recientemente (Bozdoğan y Bahadıroğlu, 2015). Ya Monserrat (2011), Monserrat \& Díaz-Aranda (2012) y Monserrat \& Triviño (2013) discutían y/o descartaban varias citas cuestionables o erróneas dadas por este autor para la fauna de la Península Ibérica, que fueron desechadas, también Monserrat (2016) consideraba esta cita muy poco fiable/ creíble, ya que esta especie no ha sido nunca relacionada con nuestra fauna (Aspöck et al., 1980, 2001; Popov, 1990; Canard et al., 2007), y reiteramos que esta cita debe considerarse muy poco consistente/ creíble y la especie debe descartarse del entorno de este estudio, y por ello esta especie, de momento, no ha de considerarse.

\section{Chrysopa walkeri McLachlan, 1893}

Menos fidedigna aún debe considerarse como perteneciente a la fauna ibérica a Chrysopa walkeri. Esta especie con desarrollo en vegetación baja, posee una marcada distribución sibérica (Mongolia, Kasachstán, Ubekistán, Kirgistán) y en Europa mayoritariamente citada en países del norte y este europeo o zonas montañosas de Francia e Italia, también citada de Macedonia, Anatolia, Armenia, Cáucaso, Chipre y Líbano, en altitudes de hasta c. $2.000 \mathrm{~m}$ en Turquía, si bien es probable más de un error en algunas identificaciones (Hölzel \& Ohm, 1972; Aspöck et al., 1980, 2001; SSengonca, 1981; Badano \& Makris, 2020).

Ya Monserrat \& Díaz-Aranda (2012), Monserrat \& Triviño (2013) y Monserrat (2016) comentaban que desde que Navás (1924: 159) la cita como probable en Cataluña y la incluye en la clave de especies de esta región, y posteriormente (Navás, 1925: 73) la incluye en su clave de especies ibéricas, aún mencionando expresamente que no existe en la Península Ibérica (Navás, 1925: 75), han sido numerosas las reseñas bibliográficas que, consecuentemente, comentan o hacen referencia a la península (España) en la distribución de esta especie (Nagler, 1958: 301; Hölzel, 1964: 43; Eglin, 1968: 320; Ohm \& Remane, 1968: 224; Şengonca, 1980: 54; Ari et al., 2007: 204), pero no hay datos que lo avalen (Hölzel \& Ohm, 1972; Aspöck et al., 1980, 2001; Canard et al., 2007).

En relación a estas citas y referencias comentemos que ambas especies poseen una distribución 
marcadamente sibérica con referencias en centro y este de Europa (Aspöck et al., 1980, 2001). Por no existir ningún otro dato más fiable, y por todo lo anteriormente mencionado, quedan descartadas de nuestra fauna, de hecho, estas especies no han sido nunca relacionadas con nuestra fauna (Aspöck et al., 1980, 2001 no incluyen ni España ni Portugal, ni Andorra en su distribución conocida), por lo que, mientras no aparezcan nuevos datos, no deben considerarse en nuestro ámbito geográfico.

Tras estos datos, descartadas Chrysopa abbreviata y Chrysopa walkeri, y salvo que nuevos elementos aparezcan, en la península y archipiélago balear esta familia está representada a la fecha de hoy por 52 especies pertenecientes a 13 géneros, de las que 10 pertenecen al género Chrysopa que ahora hemos tratado.

\section{Agradecimientos}

Deseamos agradecer a Susanne Randolf del Naturhistorisches Museum de Viena por su ayuda en tratar de localizar el material ibérico citado por $\mathrm{H}$. Hölzel, a Miguel Ángel Zarazaga del Museo Nacional de Ciencias Naturales de Madrid por sus valiosos comentarios, a Mercedes París de este mismo museo y a Gloria Masó, Sergi Gago y Amador Viñolas del Museu de Ciències Naturals de Barcelona por su ayuda en el estudio de material de los citados museos y su apoyo fotográfico. También a José Ignacio LópezColón y en especial a Francisco Rodríguez por todo su material cedido y ahora anotado, a Michel Canard su ayuda bibliográfica y sus valiosos comentarios, a Francisca Ruano su ayuda en la obtención de alguna bibliografía citada, a Nuria Cantón de Celis y Calvo, Ana Santos Bernal y Pedro Monserrat por su apoyo logístico y a Eduardo Ruiz por su ayuda en la localización de algunos ejemplares citados y por la realización de alguna de las figuras anotadas.

\section{Referencias}

Adams, P. A., 1975. Status of the genera Ungla and Mallada Navás (Neuroptera: Chrysopidae). Psyche, 82: 167-173.

Agekjan, N. G., 1973. [Neuroptera feeding on bamboo aphids in Adzharia and their parasites.] Entomologicheskoe Obozrenie, 52: 549-564 (en ruso).

Alcalá Herrera, R., Campos, M., González-Salvadó, M. \& Ruano, F., 2019a. Abundance and population decline factors of chrysopid juveniles in olive groves and Adjacent trees. Insects, 10(5): 134. https://doi.org/10.3390/ insects 10050134

Alcalá Herrera, R., Campos, M. \& Ruano, F., 2019b. Late summer oviposition of green lacewings (Neuroptera: Chrysopidae) on olive groves and adjacent trees. Environmental Entomology, 48(3): 506-513. https://doi. org/10.1093/ee/nvz040
Alderson, E. M., 1911. Notes of Chrysopa dorsalis, Burm. Entomologist's Monthly Magazine, 47: 49-54.

Andréu, J. [M.], 1909. Datos para la fauna de la provincia de Alicante. Neurópteros de los alrededores de Orihuela. Memorias del Primer Congreso de Naturalistas Españoles, Zaragoza 1908: 159-162.

Ari, I., 2014. A checklist of Turkish neuropteran species (Insecta: Neuroptera) with remarks on provincial distribution in Turkey. Acta Entomologica Slovenica, 22(1): 59-86.

Ari, I., Aktas, M. \& Kiyak, S., 2007. Notes on the Chrysopidae (Neuroptera) fauna of Ardahan, Igdir and Kars provinces of Turkey. Turkish Journal of Zoology, 31: 201-208.

Aspöck, H., 1992. The Neuropteroidea of Europe: a review of present knowledge (Insecta). In: Canard, M., Aspöck, H. \& Mansell, M. W. (eds.). Current Research in Neuropterology (Proceedings of the Fourth International Symposium on Neuropterology, Bagnères-de-Luchon, 1991): 43-56.

Aspöck, H., 2009. Herbert Hölzel (1925-2008). Ein sehr persönlicher Nachruf und ein Stück Geschichte der Neuropterologie. Entomologica Austriaca, 16: 257-343.

Aspöck, H. \& Hölzel, H., 1996. The Neuropteroidea of North Africa, Mediterranean Asia and of Europe: a comparative review (Insecta). In: Canard, M., Aspöck, H. \& Mansell, M. W. (eds.). Pure and Applied Research in Neuropterology (Proceedings of the Fifth International Symposium on Neuropterology, Cairo 1994): 31-86.

Aspöck, H., Aspöck, U. \& Hölzel, H., 1980. Die Neuropteren Europas. Goecke und Evers. Krefeld. Vol. I, 495 pp., Vol. II, 355 pp.

Aspöck, U., Aspöck, H., Letardi, A. \& Jong, Y. de, 2015. Fauna Europaea: Neuropterida (Raphidioptera, Megaloptera, Neuroptera). Biodiversity Data Journal, 3: e4830. https://doi.org/10.3897/BDJ.3.e4830

Aspöck, H., Hölzel, H. \& Aspöck, U., 2001. Kommentierter Katalog der Neuropterida (Insecta: Raphidioptera, Megaloptera, Neuroptera) der Westpaläarktis. Denisia, 2: 1-606.

Badano, D. \& Makris, C., 2020. A new unexpected species of Chrysopa Leach from Cyprus with biogeographic remarks (Neuroptera: Chrysopidae). Annales de la Société entomologique de France (N.S.), 56(2): 125154. https://doi.org/10.1080/00379271.2020.1756911

Barnard, P. C., 1978. A check-list of the British Neuroptera with taxonomic notes. Entomologist's Gazette, 29: 165-176.

Bozsik, A., 1994. Impact of vegetational diversity on structure parameters of chrysopid assemblages. Redia, 77: 69-77.

Bozdoğan, H. \& Bahadıroğlu, C., 2015. Kahramanmaraş İli Chrysopidae (Neuroptera) familyası türleri üzerinde faunistik çalışmalar. Dicle üniversitesi Fen Bilimleri Enstitüsü Dergisi, 4(1): 36-51.

Brauer, F., 1850. Beschreibung und Beobachtung der österreichischen Arten der Gattung Chrysopa. Naturwissenschaftliche Abhandlungen, 4(4): 1-12.

Brooks, S. J., 1994. A taxonomic review of the common green lacewing genus Chrysoperla (Neuroptera: Chrysopidae). Bulletin of the British Museum of Natural History, Entomology, 63(2): 137-210.

Brooks, S. J. \& Barnard, P. C., 1990. The green lacewings of the world: a generic review (Neuroptera: Chrysopidae). Bulletin of the British Museum of Natural History, Entomology, 59: 117-286. 
Cadena, P., Angel, F., Gomez, L. A. \& Gonzalez, R., 2007. Diferenciación morfológica y molecular de especies de crisópidos (Neuroptera: Chrysopidae). Revista Colombiana de Entomología, 33: 171-177.

Canard, M., 1971. Les possibilités de conservation de longue durées des cocons d'un prédateur aphidiphage: Chrysopa perla (L.) (Neuroptera, Chrysopidae). Annales de Zoologie, Ecologie Animale, 3: 373-377.

Canard, M., 1973a. Influence de l'alimentation sur le développement, la fécondité et la fertilité d'un prédateur aphidiphage: Chrysopa perla (L.) (Neuroptera: Chrysopidae). Thèse Grade de Docteur. Université Paul-Sabatier. Toulouse. 175 pp.

Canard, M., 1973b. Voltinisme, diapause et sex-ratio de Chrysopa perla (L.) (Neuroptera, Chrysopidae) dans de sud-ouest. Annales de Zoologie, Écologie Animale, 5: 29-37.

Canard, M., 1976. La diapause chez Chrysopa perla (L.) (Neuroptera, Chrysopidae). Induction et élimination dans des conditions naturelles et expérimentales. Annales de Zoologie, Écologie Animale, 8: 393-404.

Canard, M., 2001. Présence en Grèce continentale de Chrysoperla carnea (Stephens, 1836) sensu stricto (Neuropt., Chrysopidae). Bulletin de la Société entomologique de France, 106: 416.

Canard, M. \& Jacquemin, G., 2006. Capture en France d'une chrysope rare ou méconnue: Chrysopa dubitans McLachlan, 1887 (Neuroptera). Bulletin de la Société entomologique de France, 111: 483-485.

Canard, M., Letardi, A. \& Thierry, D., 2007. The rare Chrysopidae (Neuroptera) of southwestern Europe. Acta Oecologica/Oecologia Applicata, 31: 290-298.

Canard, M., Séméria, Y. \& New, T. R. (Eds.), 1984. Biology of Chrysopidae. W. Junk Publishers. The Hague. $294 \mathrm{pp}$.

Canard, M. \& Thierry, D., 2007. A historical perspective on nomenclature within the genus Chrysoperla Steinman, 1964 in Europe: the carnea-complex (Neuroptera Chrysopidae). Annali del Museo Civico di Storia Naturale di Ferrara, 8: 173-179.

Canard, M. \& Thierry, D., 2017a. Une chrysope contestée et réhabilitée: Pseudomallada benedictae (Séméria, 1976) (Neuropterida, Chrysopidae). Revue de l'Association Roussillonnaise d'Entomologie, 26(2): 97-102.

Canard, M. \& Thierry, D., 2017b. The complex of the pale green lacewing Chrysopa pallens (Rambur, 1838) sensu lato (Neuropterida, Chrysopidae), Bulletin de la Société entomologique de France, 122(1): 75-82.

Canbulat, S., 2007. A checklist of Turkish Neuroptera with annotating on provincial distributions. Zootaxa, 1552: 35-52. https://doi.org/10.11646/zootaxa.1552.1.2

Devetak, D., Akšic, P., Koren, T. \& Ivajnšic, D., 2015. Two sibling green lacewing species, Chrysopa pallens and Chrysopa gibeauxi (Insecta: Neuroptera: Chrysopidae) in Slovenia and Western Balkan Countries. Annales Series Historia Naturalis, 25(1): 47-54.

Díaz-Aranda, L. M. \& Monserrat, V. J., 1988a. Contribución al conocimiento de los neurópteros de Jaén. (Insecta, Neuropteroidea). Boletín de la Asociacion Española de Entomología, 12: 111-123.
Díaz-Aranda L. M. \& Monserrat, V. J., 1988b. Contribución al conocimiento de los Neurópteros de Granada (Insecta, Neuropteroiea). Actas III Congreso Ibérico de Entomología, Granada: 211-227.

Díaz-Aranda, L. M. \& Monserrat, V. J., 1995. Aphidophagous predator diagnosis: key to genera of European chrysopid larvae (Neur.: Chrysopidae). Entomophaga, 40(2): 169-181. https://doi.org/10.1007/BF02373066

Díaz-Aranda, L.M., Monserrat, V. J. \& Marín, F., 1986. Contribución al conocimiento de los neurópteros de Guadalajara (Insecta, Neuropteroidea). Actas. VIII Jornadas de la Asociacion Española de Entomologia, Sevilla: 1131-1141.

Díaz-Aranda, L. M., Monserrat, V. J. \& Tauber, C. A., 2001. Recognition of larval Neuroptera. Recognition of early stages of Chrysopidae. In: McEwen, P. K., New, T. R. \& Whittington, A. E. (eds.). Lacewings in the Crop Environment. Cambridge University Press, Cambridge: $60-81$.

Dorokhova, G. I., 1973. [Lacewings of the genus Chrysopa Leach of the group phyllochroma from the Leningrad region (Neuroptera, Chrysopidae)]. Entomologicheskoe Obozrenie, 52: 633-636. (en ruso).

Dorokhova, G. I., 1987. [Order Neuroptera-lacewings]. In: Medvedev, G. S. (ed.). [Keys to the insects of the European part of the USSR]. Vol. 4, Part 6: Pp. 36-96. (en ruso).

Duelli, P., Henry, C. S., Hayashi, M., Nomura, M. \& Mochizuk, A., 2017. Molecular phylogeny and morphology of Pseudomallada (Neuroptera: Chrysopidae), one of the largest genera within Chrysopidae. Zoological Journal of the Linnean Society, 180: 556-569. https://doi.org/10.1093/zoolinnean/zlw008

Duelli, P. \& Obrist, M. K., 2019. In search of the real Pseudomallada prasinus (Neuroptera, Chrysopidae). Zootaxa, 4571(4): 510-530. https://doi.org/10.11646/ zootaxa.4571.4.4

Eglin, W., 1968. Chrysopa walkeri, M'L. als Lichtfang in der Schweiz und doch keine Schweizer Neuroptere. Mitteilungen der schweizerischen entomologischen Gesellschaft, 41(1-4): 320-321.

Fraser, F. C., 1945. Biological notes on Chrysopa dorsalis Burm. (Neuroptera). Proceedings of the Royal Entomological Society of London, Series A, General Entomology, 20: 116-121. http://dx.doi. org/10.1111/j.1365-3032.1945.tb01055.x

Fraser, F. C., 1959. Mecoptera, Megaloptera and Neuroptera. Handbooks for the identification of British Insects, 1(12-13): 1-40.

Gepp, J., 1983. Schlüssel zur Freilanddiagnose mitteleuropäischer Chrysopidenlarven (Neuroptera, Chrysopidae). Mitteilungen des Naturwissenschaftlichen Vereins für Steiermark, 113: 101-132.

Gepp, J., 1984. Morphology and anatomy of the preimaginal stages of Chrysopidae: a short survey. In: Canard, M., Séméria, Y. \& New, T. R. (eds.). Biology of Chrysopidae. Dr. W. Junk Publishers, The Hague: 9-19.

Gepp, J., 1986. Biology and larval diagnosis of central European Neuroptera (a review of present knowledge). In: Gepp, J., Aspöck, H. \& Hölzel, H. (eds.). Recent Research in Neuropterology (Proceedings of 
the $2^{\text {nd }}$ International Symposium on Neuropterology, Hamburg, 1984): 137-144.

Gepp, J., 1989. Zur Ökologischen Differenzierung der präemaginalen Stadien baumbewohnender Chrysopiden im Alpenraum (Planipennia: Chrysopidae). Sitzungsberichte der Österreicheschen Akademie der Wissenschaften, Mathematische-Naturwissenschaftliche Klasse, 197: 1-73.

Gepp, J., 1999. Neuropteren als Indikatoren der Naturraumbewertung. Eignung als Modellgruppe, Methodenwahl, Fallbeispiele sowie Diskussion möglicher Fragestellungen (Neuropterida). Stapfia, 60: 167-208.

Greve, L., 1984. Chrysopid distribution in northern latitudes. In: Canard, M., Séméria, Y. \& New, T. R. (eds.). Biology of Chrysopidae. Dr. W. Junk Publishers, The Hague: 180-186.

Henry, C. S., 1985. The proliferation of cryptic species in Chrysoperla green lacewings through song divergence. Florida Entomologist, 68: 18-38.

Henry, C. S., Brooks, S. J., Duelli, P. \& Johnson, J. B., 2002. Discovering the true Chrysoperla carnea (Stephens) (Insecta: Neuroptera: Chrysopidae) using song analysis, morphology, and ecology. Annals of the Entomological Society of America, 95: 172-191. https://doi. org/10.1603/0013-8746(2002)095[0172:DTTCCI]2.0 . $\mathrm{CO} ; 2$

Henry, C. S., Brooks, S. J., Duelli, P. \& Johnson, J. B., 2003. A lacewing with the wanderlust: the European song species "Maltese", Chrysoperla agilis sp. n. of the carnea group of Chrysoperla (Neuroptera: Chrysopidae). Systematic Entomology, 28: 131-148. https://doi. org/10.1046/j.1365-3113.2003.00208.x

Henry, C. S., Brooks, S. J., Duelli, P., Johnson, J. B., Wells, M.L.M. \& Mochizuki, A., 2013. Obligatory duetting behavior in the Chrysoperla carnea-group of cryptic species (Neuroptera: Chrysopidae): its role in shaping evolutionary history. Biological Reviews, 88: 787-808. https://doi.org/10.1111/brv.12027

Henry, C. S., Brooks, S. J., Johnson, J. B. \& Duelli, P., 1996. Chrysoperla lucasina (Lacroix): a distinct species of green lacewing, confirmed by acoustical analysis (Neuroptera: Chrysopidae). Systematic Entomology, 21: 205-218. https://doi.org/10.1046/j.1365-3113.1996. d01-11.x

Henry, C. S., Brooks, S. J., Johnson, J. B., Haruyama, N., Duelli, P. \& Mochizuki, A., 2015. A new East-Asian species in the Chrysoperla carnea-group of cryptic lacewing species (Neuroptera: Chrysopidae) based on distinct larval morphology and a unique courtship song. Zootaxa, 3918(2): 194-208. https://doi.org/10.11646/ zootaxa.3918.2.2

Henry, C. S., Brooks, S. J., Johnson, Mochizuki, A. \& Duelli, P., 2014. A new cryptic species of the Chrysoperla carnea group (Neuroptera: Chrysopidae) from western Asia: parallel speciation without ecological adaptation. Systematic Entomology, 39(2): 380-393. https://doi.org/10.1111/syen.12061

Henry, C. S., Brooks, S. J., Johnson, J. B., Wells, M. M. \& Duelli, P., 2011. Song analysis reveals a permanent population of the Mediterranean lacewing Chrysoperla agilis (Neuroptera: Chrysopidae) living in Central
Alaska. Annals of the Entomological Society of America, 104: 649-657. https://doi.org/10.1603/AN11045

Henry, C. S., Brooks, S. J., Thierry, D., Duelli, P. \& Johnson, J. B., 2001. The common green lacewing (Chrysoperla carnea s. lat.) and the sibling species problem. In: McEwen, P. K., New, T. R. \& Whittington, A. E. (eds.). Lacewings in the Crop Environment. Cambridge University Press, Cambridge: 29-42.

Hölzel, H., 1964. Bemerkungen zu Chrysopiden I. Chrysopa walkeri ML. (Neuropt., Planipennia). Nachrichtenblatt der Bayerischen Entomologen, 13: 41-43.

Hölzel, H., 1965. Neue oder wenig bekannte Chrysopiden aus der Sammlung des Naturhistorischen Museums (Chrysopidae, Planipennia). Annalen des Naturhistorischen Museums in Wien, 68: 453-463.

Hölzel, H., 1967a. Chrysopiden aus der Mongolei. Ergebnisse der Mongolisch-Deutschen Biologischen Expeditionen seit 1962, Nr. 31. Mitteilungen aus dem Zoologischen Museum in Berlin, 43(2): 251-260.

Hölzel, H., 1967b. Zwei neue Chrysopa-Arten aus Anatolien (Neuroptera, Chrysopidae). Nachrichtenblatt der Bayerischen Entomologen, 16: 92-95.

Hölzel, H., 1970. Zur generischen Klassifikation der Paläarktischen Chrysopinae. Eine neue Gattung und zwei neue Untergattungen der Chrysopidae (Planipennia). Zeitschrift der Arbeitsgemeinschaft Österreichischer Entomologen, 22: 44-52.

Hölzel, H., 1973a. Zur Revision von Typen europäischer Chrysopa-Arten. Revue suisse de Zoologie, 80(1): 65-82.

Hölzel, H., 1973b. Neuropteren aus Korea (Hemerobiidae und Chrysopidae). Folia Entomologica Hungarica (N.S.), 26(Suppl.): 83-90.

Hölzel, H., 1998. Kommentare zu den von Friedrich Brauer in den Jahren 1850 und 1856 aus Österreich beschriebenen "Chrysopa"-spezies (Neuroptera: Chrysopidae). Stapfia, 55: 409-420.

Hölzel, H. \& Ohm, P., 1972. Die Chrysopiden der Iberischen Halbinsel (Planipennia, Chrysopidae). FaunistischÖkologische Mitteilungen, 4: 127-145.

Hwang, J. C. \& Bickley, W. E., 1961. The reproductive system of Chrysopa oculata (Neuroptera, Chrysopidae). Annals of the Entomological Society of America, 54: 422-429. https://doi.org/10.1093/aesa/54.3.422

Jiang, Y., Garzón-Orduña, I.J., Winterton, S.L., Yang, F. \& Liu, X., 2017. Phylogenetic relationships among tribes of the green lacewing subfamily Chrysopinae recovered based on mitochondrial phylogenomics. Scientific Reports, 7: 7218. https://doi.org/10.1038/ s41598-017-07431-1

Jones, J. R., Magalhães, B. I., Saraiva, J., Gruppe, A., 2013. Post-symposium excursion to natural areas of mainland Portugal. Açoreana, Suplemento 9: 143-155.

Killington, F. J., 1936. A monograph of the British Neuroptera. Vol. 1. Ray Society. London. xix +269 pp.

Killington, F. J., 1937. A monograph of the British Neuroptera. Vol. 2. Ray Society. London. xii +306 pp.

Kis, B., Nagler, C. \& Mândru, C., 1970. Insecta: Neuroptera (Planipennia). Fauna Republicii Socialiste România, 8(6): 1-343. 
Kis, B. \& Újhelyi, S., 1965. Chrysopa commata sp. n., and some remarks on the species Chrysopa phyllochroma Wesm. (Neuroptera). Acta Zoologica Hungarica, 11: 347-352.

Klapálek, F., 1909. Některé zajímavější Neuropteroidy španělské. Acta Societatis Entomologicae Bohemiae, 6: 130-131.

Kovrigina, A. M., 1985. Introduction to the ecology of Chrysopidae (Neuroptera) from Middle Volga region. Neuroptera International, 3: 143-144.

Kuwayama, S., 1962. A revisional synopsis of the Neuroptera in Japan. Pacific Insects, 4: 325-412.

Lacroix, J. L., 1921a. Études sur les Chrysopides. Premier [I] Mémoire. Annales de la Société Linnéene de Lyon, 68: $51-104$.

Lacroix, J. L., 1921b. Description sommaire de la larve de Chrysopa viridana Schneid. [Neur. Chrysopidae]. Bulletin de la Société entomologique de France, 1921: 182-184.

Lacroix, J. L., 1929. Quelques mots sur les Chrysopides. Revue de Zoologie Agricole et Appliquée, 28: 129-141.

Leraut, P., 1989. Étude de la variation subspécifique de Metachrysopa pallens (Rambur, 1838) n. comb. [Neuroptera, Chrysopidae]. Revue Française d'entomologie (N.S.), 11:105-108.

Leraut, P., 1992. Chrysopa gibeauxi (Leraut) stat. rev., une espèce distincte (Neuroptera: Chrysopidae). Entomologica Gallica, 3(1): 24-26.

Letardi, A., 1997. Myrmeleon bore (Tjeder, 1941) new to Spain (Neuroptera Myrmeleontidae). Frustula Entomologica (N.S.), 20: 150-151.

Letardi, A., 2005. Insecta Neuroptera, Megaloptera e Raphidioptera. In: Ruffo, S. \& Stoch, F. (eds.). Checklist e distribuzione della fauna italiana. Memorie del Museo Civico di Storia Naturale di Verona, 2 Serie, Sezione Scienze della Vita, 16: 235-236.

Letardi, A., Almeida, J. M., Badano, D., Silva, R. R. \& Machado, E., 2013. Contributing to a checklist of Neuropterida in Portugal: the Naturdata project. In: Martins, A.M.F. \& M.A.M. Ventura (eds.). Proceedings of the Eleventh International Symposium of Neuropterology, Ponta Delgada, 2011. Açoreana, Suplemento, 9: 29-38.

Lourenço, P., Brito, C., Backeljau, T., Thierry, D. \& Ventura, M. A., 2006. Molecular systematics of the Chrysoperla carnea group (Neuroptera: Chrysopidae) in Europe. Journal of Zoological Systematics and Evolutionary Research, 44: 180-184. https://doi. org/10.1111/j.1439-0469.2006.00352.x

Makarkin, V. N., 1985. Ekologo-faunisticheskiy obzor zlatoglazok (Neuroptera, Chrysopidae) Dalnego Vostoka. In: Arefin, V. S., Kuznetsov, V. N. and Pashchenko, N. F. (eds.). Fauna i ekologia nasekomykh Primor'ya i Kamchatki (vrediteli i entomofagi). Sbornik nauchnykh trudov. Akademiia nauk SSSR, Far East Scientific Centre. Vladivostok: 55-64.

Marín, F. \& Monserrat, V. J., 1991. Contribución al conocimiento de los neurópteros de Albacete (Insecta, Planipennia). Jornadas Sobre el Medio Natural Albacetense, Albacete, 1990: 179-184.
Marín, F. \& Monserrat, V. J., 1995. Contribución al conocimiento de los neurópteros de Zaragoza (Insecta, Neuropteroidea). Zapateri, 5: 109-126.

McEwen, P., New, T. R. \& Whittington, A. E., 2001. Lacewings in the Crop Environment, Cambridge University Press, Cambridge. 546 pp.

McEwen, P. K. \& Senior, L. J., 1998. The use of common green lacewings in environmentally friendly pest control. Agriculture and Equipment International, 50(5): 132-134.

McEwen, P. K., Senior, L., Shuja, A. \& James, C., 1998. Chrysoperla carnea: a powerful tool for the biological control of insect pests. Antenna, Bulletin of the Royal Entomological Society of London, 22: 14-16.

McLachlan, R., 1887. Insecta in itinere Cl. N. Przewalskii in Asia centrali novissime lecta. XII. Neuroptera II. Perlides, Planipennes et Trichoptères. Horae Societatis Entomologicae Rossicae, 21: 448-457.

Monserrat, V. J., 1984. Contribución al conocimiento de los neurópteros de Alicante (Neur., Planipennia). Mediterranea, Serie Biología, 7: 91-116.

Monserrat, V. J., 1985a. Contribución al conocimiento de los Neurópteros (Neuroptera: Planipennia) de Murcia. Anales de Biología (Biología Animal), 1: 81-94.

Monserrat, V. J., 1985b. Lista de los tipos de Mecoptera y Neuroptera (Insecta) de la colección L. Navàs, depositados en el Museo de Zoología de Barcelona. Miscellània Zoològica, 9: 233-243.

Monserrat, V. J., 1986a. Sobre los Neurópteros ibéricos (IV) (Neur.). Boletín de la Asociación española de Entomología, 10: 95-105.

Monserrat, V. J., 1986b. Longinos Navás, his neuropterological work and collection. In: Gepp, J., Aspöck, H. \& Hölzel, H. (eds.). Recent Research in Neuropterology (Proceedings of the 2nd International Symposium on Neuropterology, Hamburg, 1984). Graz: 173-176.

Monserrat, V. J., 1987. Contribución al conocimiento de los Neurópteros de Almería (Neur., Planipennia). Graellsia, 42 (1986): 131-147.

Monserrat, V. J., 2005. Catálogo de los Neurópteros de Baleares con nuevos datos sobre su fauna (Insecta, Neuroptera). Bolleti Societat d'Història Natural de les Balears, 48: 71-85.

Monserrat, V.J., 2008. Nuevos datos sobre algunas especies de crisópidos (Insecta: Neuroptera: Chrysopidae), Heteropterus Revista de Entomología, 8(2): 171-196.

Monserrat, V. J., 2010. Nuevas o interesantes citas de neurópteros en la Península Ibérica (Insecta: Neuroptera). Heteropterus, 10, 1: 19-34.

Monserrat, V.J., 2011. Sobre algunas especies de neurópteros de la Península Ibérica y de las Islas Canarias de posición taxonómica problemática o con citas dudosas o cuestionables (Insecta, Neuroptera: Megaloptera, Planipennia), Boletín de la Sociedad Entomológica Aragonesa (S.E.A.), 49: 153-178.

Monserrat, V. J., 2013. Los Neurópteros (Neuroptera). In: Ruano, F., Tierno de Figueroa, M. y Tinaut, A (eds). Los Insectos de Sierra Nevada. 200 años de historia. Asociación española de Entomología, Vol. 1: 281-309. 
Monserrat, V.J., 2016. Los crisópidos de la Península Ibérica y Baleares (Insecta, Neuropterida, Neuroptera: Chrysopidae), Graellsia, 72(1): e037. https://doi. org/10.3989/graellsia.2016.v72.143

Monserrat, V.J., Acevedo, F. \& Pantaleoni, R. A., 2014 Nuevos datos sobre algunas especies de crisópidos de la Península Ibérica, Islas Baleares e Islas Canarias (Insecta, Neuroptera: Chrysopidae). Graellsia, 70(1): e002. https://doi.org/10.3989/graellsia.2014.v70.100

Monserrat, V. J. \& Díaz-Aranda, L. M., 1989a. Suarius walsinghami Navás, 1914 nuevo crisópido para la fauna europea (Neuroptera, Chrysopidae). Nouvelle Revue d'Entomologie, 6(4): 407-411.

Monserrat, V. J. \& Díaz-Aranda, L. M., 1989b. Nuevos datos sobre los crisópidos ibéricos (Neuroptera, Planipennia: Chrysopidae). Boletín de la Asociacion Española de Entomología, 13: 251-267.

Monserrat, V. J. \& Díaz-Aranda, L. M., 2012. Los estadios larvarios de los crisópidos ibéricos (Insecta, Neuroptera, Chrysopidae), nuevos elementos sobre la morfología larvaria aplicables a la sistemática de la familia. Graellsia, 68(1): 31-158. https://doi.org/10.3989/graellsia. 2012.v68.055

Monserrat, V. J. \& Marín, F., 1994. Plant substrate specificity of Iberian Chrysopidae (Insecta: Neuroptera). Acta Oecologica, 15(2): 119-131.

Monserrat, V. J. \& Rodrigo, F., 1992. Nuevas citas sobre los crisópidos ibéricos (Insecta, Neuroptera: Chrysopidae). Zoologica Baetica, 3: 123-138.

Monserrat, V. J., Rodríguez, F. \& Acevedo, F., 2019. Nuevos datos sobre algunas especies de crisópidos de la Península Ibérica (Insecta: Neuroptera: Chrysopidae). Heteropterus, Revista de Entomología, 19(2): 313-329.

Monserrat, V. J. \& Triviño, V., 2013. Atlas de los neurópteros de la Península Ibérica e Islas Baleares (Insecta, Neuroptera:Megaloptera, Raphidioptera, Planipennia) / Atlas of the Iberian and Balearic lacewings (Insecta, Neuroptera: Megaloptera, Raphidioptera, Planipennia). Monografías de la Sociedad Entomológica Aragonesa, 13. Zaragoza. 154 pp., 136 mapas.

Monserrat, V. J., Triviño, V. \& Acevedo, F., 2013. Contribución al conocimiento de los neurópteros de Navarra (Insecta, Neuroptera). Heteropterus, Revista de Entomología, 13(1): 41-58.

Nagler, C., 1958. Citeva date privitoare la raspindirea unor Neuroptere (Ord. Planipennia Heymos 1915) in R.P.R. Studii si cercetari stiintifice. Biologie si stiinte agricole. Academia Republicii Populare Romîne, Filiala Iasi, 9(2): 229-303.

Navás, L., 1908a. Neurópteros nuevos. Memorias de la Real Academia de Ciencias Naturales de Barcelona, 6, 25: 401-423.

Navás, L., 1908b. Neurópteros de España y Portugal. Brotéria (Zoológica), 7: 101-134.

Navás, L., 1909a. Notas entomológicas V. Neurópteros del Moncayo y Zaragoza. Actas de la Sociedad Española de Historia Natural, 29: 172-176.

Navás, L., 1909b. Neurópteros nuevos de la fauna ibérica. Memorias del Primer Congreso de Naturalistas Españoles, Zaragoza, 1908: 143-158.
Navás, L., 1910. Crisópidos (Ins. Neur.) nuevos. Brotéria (Zoológica), 9: 38-59.

Navás, L., 1915a. Crisòpids d'Europa (Ins. Neur.). Arxius de l'Institut de Ciències, 3: 1-99. https://doi.org/10.5962/ bhl.title. 8175

Navás, L., 1915b. Notas entomologicas, $2^{a}$ Serie. Excursiones por Cataluña. Julio de 1914. Boletín de la Sociedad aragonesa de Ciencias Naturales, 14: 27-32, 35-59, 66-80.

Navás, L., 1919. Excursiones entomológicas por Cataluña durante el verano de 1918. Memorias de la Real Academia de Ciencias y Artes de Barcelona, Serie 3, 15: 181-214.

Navás, L., 1924. Fauna de Catalunya. Entomologia de Catalunya. Neuròpters. Fascicle I. Neuròpters Propis. Publicacions de l'Institut d'Estudis Catalans, seccio de Ciències, Barcelona. 271 pp.

Navás, L., 1925. Sinopsis de los Neurópteros (Ins.) de la península ibérica. Memorias de la Sociedad Ibérica de Ciencias Naturales, 4: 1-149.

Navás, L., 1927. Mis excursiones científicas en 1926. Revista de la [Real] Academia de Ciencias Exactas Físico-Químicas y Naturales de Zaragoza, serie 1, 10: 81-124.

Naville, A. \& de Beaumont, J., 1933. Recherches sur les chromosomes des Névroptères [I]. Archives d'Anatomie Microscopique, 29: 199-243.

Naville, A. \& de Beaumont, J., 1936. Recherches sur les chromosomes des Névroptères. 2e partie. Archives d'Anatomie Microscopique, 32: 271-302.

Neuenschwander, P., Canard, M. \& Michelakis, S., 1981. The attractivity of protein hydrolysate baited McPhail traps to different chrysopid and hemerobiid species [Neuroptera] in a Cretan olive orchard. Annales de la Société entomologique de France (N.S.), 17: 213-220.

New, T. R., 1975a. Lacewings (Neuroptera) as biological control agents. Victorian Entomologist, 5: 102-103.

New, T. R., 1975b. The biology of Chrysopidae and Hemerobiidae (Neuroptera), with reference to their usage as biocontrol agents: a review. Transactions of the [Royal] Entomological Society of London, 127: 115-140. https:// doi.org/10.1111/j.1365-2311.1975.tb00561.x

New, T. R., 1984a. Chrysopidae: ecology on field crops. In: Canard, M., Séméria, Y. \& New, T. R. (eds.). Biology of Chrysopidae. Dr. W. Junk Publishers, The Hague: 160-167.

New, T. R., 1984b. The need for taxonomic revision in Chrysopidae. In: Canard, M., Séméria, Y. \& New, T. R. (eds.). Biology of Chrysopidae. Dr. W. Junk Publishers, The Hague: $37-42$.

New, T. R., 1988. Neuroptera. In: Harrewijn, P. \& Minks, A. K. (eds.). Aphids, their biology, natural enemies and control, Vol. 2B. Elsevier, Amsterdam: 249-258.

New, T. R., 1989. Planipennia, Lacewings. Handbuch der Zoologie, vol. 4(30). Walter de Gruyter. Berlin. 132 pp.

New, T. R., 1999. Neuroptera and biological control (Neuropterida). Stapfia, 60: 147-166.

New, T. R., 2001. Introduction to the systematics and distribution of Coniopterygidae, Hemerobiidae, and 
Chrysopidae used in pest management. In: McEwen, P. K., New, T. R. \& Whittington, A. E. (eds.). Lacewings in the Crop Environment. Cambridge University Press, Cambridge: 6-28.

New, T.R., 2002. Prospects for extending the use of australian lacewings in biological control. Acta Zoologica Academiae Scientiarum Hungaricae, 48(Suppl. 2): 209-216.

Nicoli Aldini, R., 2002. Insetti predatori di interesse agrario. Notiziario sulla Protezione delle Piante, 14: 81-106.

Ohm, P., 1965. Zusammensetzung und Entstehungsgeschichte der Neuropterenfauna der Nordfriesischen Insel Amrum. Verhandlung Vereinigung naturwissenchafliche Heimatforschung, 36: 81-101.

Ohm, P. \& Remane, R., 1968. Die Neuropterenfauna Hessens und einiger angrenzender Gabiete (zur Verbreitung der Neuropteren in Mitteleuropa). Faunistisch-Ökologische Mitteilungen, 3(6): 209-228.

Pantaleoni, R. A., 1982. Neuroptera Planipennia del comprensorio della Valli di Comacchio: indagine ecologica. Bollettino dell'Istituto di Entomologia della Università degli Studi di Bologna, 37: 1-73.

Pantaleoni, R. A., 1983. Riconoscimento in campo delle larve di Crisopidi. Informatore Fitopatologico, 33: $31-36$.

Pantaleoni, R. A. \& Sechi, P., 2014. ¿Existe realmente Chrysoperla carnea? Historia de la investigación sobre el complejo carnea. In: González Hernández H., Rodríguez Leyva E. \& Lomelí Flores J. R. (eds). Memorias XXV Curso Nacional de Control Biológico, Mérida, Yucatán, 2014: 223-236.

Pariser, K., 1919. Beiträge zur Biologie und Morphologie der einheimischen Chrysopiden. Archiv für Naturgeschichte (A), 83(11): 1-57.

Pappas, M. L., Broufas, G. D. \& Koveos, D. S., 2011. Chrysopid predators and their role in biological control. Journal of Entomology, Faisalabad, 8: 301-326.

Passos de Carvalho, M. U. M. M., 1997. Contribuição para o conhecimento dos crisopídeos em Portugal (Neuroptera, Chrysopidae). Agronomia Lusitana, 45(Supp. 1): 1-41.

Philippe, R., 1970. Biologie de la reproduction de Chrysopa perla (L.) (Neuroptera, Chrysopidae). Thèse de DocteurIngéneur. Université Paul-Sabatier. Toulouse. 133 pp.

Plant, C. W., 1994. Provisional atlas of the lacewings and allied insects (Neuroptera, Megaloptera, Raphidioptera \& Mecoptera) of Britain \& Ireland. Institute of Terrestrial Ecology, Huntingdon. 203 pp. 73 maps.

Popov, A., 1990. Zur Verbreitung der Chrysopiden (Neuroptera) in Bulgarien. Acta Zoologica Bulgarica, 39: 47-52.

Popov, A., 2002. Neuropterida of northern Europe. In: Sziráki, G. (ed.). Neuropterology 2000 (Proceedings of the Seventh International Symposium on Neuropterology, Budapest, 2000). Acta Zoologica Academiae Scientiarum Hungaricae, 48(Suppl. 2): 281-291.

Porcel, M., Cotes, B., Castro, J. \& Campos, M., 2016. The effect of resident vegetation cover on abundance and diversity of green lacewings (Neuroptera: Chrysopidae) on olive trees. Journal of Pest Science, 90: 195-206, https://doi.org/10.1007/s10340-016-0748-5
Principi, M. M., 1940. Contributi allo studio dei Neurotteri Italiani. I. Chrysopa septempunctata Wesm. e Chrysopa flavifrons Brauer. Bollettino dell'Istituto di Entomologia della R. Università degli Studi di Bologna, 12: 63-144.

Principi, M. M., 1947. Contributi allo studio dei Neurotteri Italiani. V. Ricerche su Chrysopa formosa Brauer e su alcuni suoi parassiti. Bollettino dell'Istituto di Entomologia della Università degli Studi di Bologna, 16: 134-175.

Principi, M. M., 1954. Contributi allo studio dei Neurotteri Italiani. XI. Chrysopa viridana Schn. Bollettino dell'Istituto di Entomologia della Università degli Studi di Bologna, 20: 359-376.

Principi, M. M., 1977. Contributi allo studio dei Neurotteri Italiani. XXI. La morfologia addominale ed il suo valore per la discriminazione generica nell'ambito delle Chrysopinae. Bollettino dell'Istituto di Entomologia della Università degli Studi di Bologna, 31: 325-360.

Principi, M. M., 1984. I Neurotteri Crisopidi e le possibilità della loro utilizzazione in lotta biologica e in lotta integrata. Bollettino dell'Istituto di Entomologia della Università degli Studi di Bologna, 38: 231-262.

Schneider, W. G., 1851. Symbolae ad monographiam generis Chrysopae, Leach. Sexaginta picturarum tabulis, in lapide acu delineatis illustratae, quarum quinquaginta quatuor coloribus impressae sunt, illustratae. Ferdinandum Hirt. Vratislaviae. 175 pp. https://doi. org/10.5962/bhl.title. 8500

Séméria, Y., 1978. Observations sur l'autoécologie et la synécologie des principales espéces de Chrysopinae (Neuroptera, Planipennia) du sud-est de la France, des genres Italochrysa Principi et Chrysopa Leach. Bulletin of Ecology, 9: 231-251.

Séméria, Y., 1984. Some caryotypes in Chrysopidae. In: M. Canard, Y. Séméria \& T. R. New (eds.). Biology of Chrysopidae. W. Junk. The Hague: 42-48.

Şengonca, Ç., 1980. Türkiye Chrysopidae (Neuroptera) faunasi üzerine sistematik ve taksonomik arastirmalar. Zirai Mücadele ve Zirai Karantina Genel Müdürlügü Matbaa Subesi Müdürlügü, Yayinlari, Ankara. $138 \mathrm{pp}$.

Şengonca, Ç., 1981. Die Neuropteren Anatoliens. 1. Chrysopidae. Mitteilungen der Münchener Entomologischen Gesellschaft, 71: 121-137.

Smith, R. C., 1922. The biology of the Chrysopidae. Memoirs of the Cornell University Agricultural Experiment Station, 58: 1287-1372.

Stitz, H., 1928. Die Neuropteren des arktischen Gebietes. Fauna Arctica, 2(5): 634-638, 955.

Thierry, D. \& Adams, P. A., 1992. Round table discussion on the Chrysoperla carnea complex (Insecta: Neuroptera: Chrysopidae). In: Canard, M., Aspöck, H. \& Mansell, M. W. (eds.). Current Research in Neuropterology (Proceedings of the Fourth International Symposium on Neuropterology, Bagnères-de-Luchon, 1991). Toulouse: 367-377.

Thierry, D., Canard, M., Ventura, M., Lourenço, P. \& Lodé, T., 2013. Is Chrysoperla agilis Henry et al., 2003 (Neuroptera: Chrysopidae) a shadow species as an outcome 
of common green lacewings' character displacement in Europe? Açoreana, 9: 73-82.

Thierry, D., Cloupeau, R. \& Jarry, M., 1992. La chrysope commune Chrysoperla carnea (Stephens) sensu lato dans le centre de la France: mise en évidence d'un complexe d'espèces (Insecta: Neuroptera: Chrysopidae). In: Canard, M., Aspöck, H. \& Mansell, M. W. (eds.). Current Research in Neuropterology (Proceedings of the Fourth International Symposium on Neuropterology, Bagnères-de-Luchon, 1991). Toulouse: 379-392.

Thierry, D., Cloupeau, R. \& Jarry, M., 1996. Distribution of the sibling species of the common green lacewing Chrysoperla carnea (Stephens) in Europe (Insecta: Neuroptera: Chrysopidae). In: Canard, M., Aspöck, H. \& Mansell, M.W. (eds.). Pure and Applied Research in Neuropterology (Proceedings of the $5^{\text {th }}$ International Symposium on Neuropterology, Toulouse): 233-240.

Thierry, D., Cloupeau, R., Jarry, M. \& Canard, M., 1998. Discrimination of the West-Palaearctic Chrysoperla Steinmann species of the carnea Stephens group by means of claw morphology (Neuroptera, Chrysopidae). Acta Zoologica Fennica, 209: 255-262.

Thierry, D., Ribodeau, M., Foussard, F. \& Jarry, M., 1997. Allozyme polymorphism in a natural population of Chrysoperla carnea sensu lato (Neuroptera: Chrysopidae): A contribution to the status of the constitutive taxons in Western Europe. European Journal of Entomology, 94: 311-316.

Tillier, P., Thierry, D., Dobosz, R. \& Canard, M., 2014. Chrysopa gibeauxi (Leraut, 1989): reinstatement as valid species and remarks on its distribution (Neuropterida, Chrysopidae). Bulletin de la Société entomologique de France, 119(4): 521-528.

Tjeder, B., 1937. Schwedisch-chinesische wissenschaftliche expedition nach den nordwestlichen provinzen Chinas, unter leitung von Dr. Sven Hedin und Prof. Sü Ping-chang. Insekten gesammelt vom schwedischen arzt der expedition Dr. David Hummel 1927-1930. 62. Neuroptera. Arkiv för Zoologi, 29A(8): 1-36.

Tsukaguchi, S., 1978. Descriptions of the larvae of Chrysopa Leach (Neuroptera, Chrysopidae). Kontyû, 46: 99-122.
Tsukaguchi, S., 1995. Chrysopidae of Japan (Insecta, Neuroptera). Edición privada, Osaka, Japan. [ii] + [224] pp.

Vidal y López, M., 1943. Catálogo provisional de Neurópteros de la región levantina. Graellsia, 1(6): 13-24.

Wells, M. M. \& Henry, C. S., 1992a. Behavioural responses of green lacewings (Neuroptera: Chrysopidae: Chrysoperla) to synthetic mating songs. Animal Behaviour, 44: 641-652. https://doi.org/10.1016/ S0003-3472(05)80292-1

Wells, M. M. \& Henry, C. S., 1992b. The role of courtship songs in reproductive isolation among populations of green lacewings of the genus Chrysoperla (Neuroptera: Chrysopidae). Evolution, 46: 31-42. https://oi. org/10.1111/j.1558-5646.1992.tb01982.x

Withycombe, C. L., 1923. Notes on the biology of some British Neuroptera (Planipennia). Transactions of the Royal Entomological Society of London, 70: 501-594. https://doi.org/10.1111/j.1365-2311.1923.tb02844.x

Withycombe, C. L., 1924. Further notes on the biology of some British Neuroptera. The Entomologist, 57: $145-152$

Whittington, A. E., 2002. Resources in Scottish Neuropterology, Acta Zoologica Academiae Scientiarum Hungaricae, 48(2): 371-387.

Winterton, S. L. \&. Brooks, S. J., 2002. Phylogeny of the Apochrysine Green Lacewings (Neuroptera: Chrysopidae: Apochrysinae). Annals of the Entomological Society of America, 95(1): 16-28. https://doi. org/10.1603/0013-8746(2002)095[0016:POTAGL]2.0 $\mathrm{CO} ; 2$

Zelený, J., 1965. Lace-wings (Neuroptera) in cultural steppe and the population dynamics in the species Chrysopa carnea Steph. and Chrysopa phyllochroma Wesm. Acta Entomologica Bohemoslovaca, 62: 177-194.

Zelený, J., 1969. Chrysopa phyllochroma Wesm. and Chrysopa commata Kis \& Ujh. (Neuroptera) in the cultivated steppe in Czechoslovakia. Acta Entomologica Bohemoslovaca, 66: 237-239.

Zelený, J., 1971. Green lace-wings of Czechoslovakia (Neuroptera, Chrysopidae). Acta Entomologica Bohemoslovaca, 68: 167-184. 